Illinois State University

ISU ReD: Research and eData

Theses and Dissertations

$12-3-2018$

\title{
An Evaluative Study of a Health Information Management Program Following a Significant Curricular Change
}

Jennifer Lynn Peterson

Illinois State University, Ipete2@ilstu.edu

Follow this and additional works at: https://ir.library.illinoisstate.edu/etd

Part of the Educational Assessment, Evaluation, and Research Commons, Higher Education

Administration Commons, and the Medicine and Health Sciences Commons

\section{Recommended Citation}

Peterson, Jennifer Lynn, "An Evaluative Study of a Health Information Management Program Following a Significant Curricular Change" (2018). Theses and Dissertations. 1035.

https://ir.library.illinoisstate.edu/etd/1035

This Dissertation is brought to you for free and open access by ISU ReD: Research and eData. It has been accepted for inclusion in Theses and Dissertations by an authorized administrator of ISU ReD: Research and eData. For more information, please contact ISUReD@ilstu.edu. 


\section{AN EVALUATIVE STUDY OF A HEALTH INFORMATION MANAGEMENT PROGRAM FOLLOWING A SIGNIFICANT CURRICULAR CHANGE}

\section{JENNIFER LYNN PETERSON}

\section{Pages}

The advent of electronic health records (EHRs) has led to significant changes in the role of those who managing patient health information, Health Information Management (HIM) professionals. These changes have further led to significant changes in the educational training required for HIM professionals, leading to new curriculum requirements. Based on the need for well-prepared professionals in the changing HIM environment, it is essential to insure that educational programs are effectively preparing students for the new roles they will be expected to fill. This study is an in-depth case study of the HIM academic program at Illinois State University. The purpose of this evaluative study is to complete an in-depth case study that contributes to a program review and evaluation to determine the impact of the recent required curriculum change on the program at Illinois State University. This study used a utilizationfocused evaluation framework that included evaluation capacity building. The study specifically assessed the ability of the recent curriculum changes to adequately prepared students for the current HIM field as well as the effects of the changes on the program as a whole. This evaluative study was designed to go beyond just the use of metrics, such as enrollment, retention, and RHIA exam pass rates but to also delve deeper into the issue through surveys, interviews, and focus groups to collect data on the perceptions of students, graduates, and employers. Through the study major themes were identified related to the perceptions of the curriculum 
changes on the ISU HIM Program and student preparedness. These included perceptions of student satisfaction and student preparedness, perceptions of the new curriculum, concern about loss of parts of the old curriculum, and future needs for the ISU HIM program and for HIM in general. While many of the findings were expected, there were some surprising or unexpected findings, such as concern about loss of parts of the old curriculum, and close alignment between area of interest or career path and perceptions of the new versus old curriculum. This study provides a model for future evaluation of the ISU HIM program as well as HIM academic programs in general.

KEYWORDS: academic program evaluation, health information management, CAHIIM curriculum competencies, curriculum changes 
JENNIFER LYNN PETERSON

A Dissertation Submitted in Partial

Fulfillment of the Requirements

for the Degree of

DOCTOR OF PHILOSOPHY

Department of Educational Administration and Foundations

ILLINOIS STATE UNIVERSITY 
Copyright 2019 Jennifer Lynn Peterson 
AN EVALUATIVE STUDY OF A HEALTH INFORMATION MANAGEMENT PROGRAM

FOLLOWING A SIGNIFICANT CURRICULAR CHANGE

JENNIFER LYNN PETERSON

COMMITTEE MEMBERS:

Phyllis McCluskey-Titus, Chair

Beth Hatt

Dianne Renn

Ryan Smith 


\section{ACKNOWLEDGMENTS}

I would like to take this opportunity to thank those responsible for helping through the doctoral study and dissertation process. I owe great thanks to my dissertation committee chair, Dr. Phyllis McCluskey-Titus. She has been the calming influence who has assured me every step of the way that I will finish. I also owe thanks to my committee for their guidance, support, and mentoring. Thank you Dr. Beth Hatt, Dr. Dianne Renn, and Dr. Ryan Smith. I owe many thanks to my family and friends for their support and encouragement, especially to my children, Hailey Lanier and Matt Peterson, and to my mother, Joan Steinburg. I owe much to my father, C. Louis Steinburg, as a parent, mentor, and guide in the world of higher education. I feel you with my every day at Illinois State. Finally, I owe my husband, Tim Peterson, the highest level of appreciation. He has stood by me through every step of this process, spent many weekends alone while I was busy working, taken on far more than his share of the household duties, and done just about whatever was needed to help me out. Thank you all. My appreciation goes beyond words. I couldn’t have done it without each and every one of you.

J. L.P. 


\section{CONTENTS}

Page

ACKNOWLEDGMENTS

CONTENTS

TABLES vii

CHAPTER I: INTRODUCTION TO THE STUDY 1

$\begin{array}{ll}\text { Introduction } & 1\end{array}$

$\begin{array}{ll}\text { Context } & 6\end{array}$

$\begin{array}{ll}\text { Purpose of Study } & 11\end{array}$

$\begin{array}{ll}\text { Key Terms and Concepts } & 12\end{array}$

$\begin{array}{ll}\text { Research Questions to be Answered } & 14\end{array}$

$\begin{array}{ll}\text { Theoretical Framework } & 15\end{array}$

$\begin{array}{ll}\text { Limitations } & 17\end{array}$

$\begin{array}{ll}\text { Researcher Positionality } & 18\end{array}$

$\begin{array}{ll}\text { Delimitations } & 19\end{array}$

CHAPTER II: INTRODUCTION TO PROGRAM REVIEW, EVALUATION, AND

$\begin{array}{ll}\text { ASSESSMENT } & 20\end{array}$

General Purpose of Evaluation and Assessment 22

$\begin{array}{ll}\text { Components of Evaluation and Assessment } & 23\end{array}$

$\begin{array}{ll}\text { Types of Evaluation and Assessment } & 24\end{array}$

Utilization-Focused and Formative Evaluation $\quad 26$

Use of Evaluation and Assessment in Program Improvement 27

$\begin{array}{ll}\text { Critiques of Evaluation and Assessment } & 28\end{array}$ 
Neoliberal Bias Effects on Higher Education Evaluation and Assessment

Equity in higher education evaluation and assessment.

History and Purpose of Program Assessment, Evaluation, and Review

Colonial and Early United States Education

Rise of Professionalism and Education Reform

Accreditation

Government Assessment of Higher Education

Internally-Driven Evaluation and Assessment Efforts

Purpose of Program Evaluation, Assessment, and Review 46

$\begin{array}{ll}\text { Program Evaluation Methods in General } & 48\end{array}$

Program Review in Health Information Management 49

CHAPTER III: METHODOLOGY

Purpose of the Study and Questions to be Answered 52

$\begin{array}{ll}\text { Research Paradigm } & 53\end{array}$

$\begin{array}{ll}\text { Type of Study } & 54\end{array}$

$\begin{array}{ll}\text { Data Collection } & 56\end{array}$

$\begin{array}{ll}\text { Participants } & 58\end{array}$

$\begin{array}{ll}\text { Data Analysis } & 60\end{array}$

$\begin{array}{ll}\text { Validity/Trustworthiness } & 61\end{array}$

Consideration of Ethical Issues $\quad 63$

$\begin{array}{ll}\text { Implications/Significance/Contributions } & 64\end{array}$

$\begin{array}{ll}\text { Conclusion } & 65\end{array}$

$\begin{array}{ll}\text { CHAPTER IV: DATA ANALYSIS AND FINDINGS } & 67\end{array}$ 
Relationship Between Curriculum Under Completion, Career Goals, and Satisfaction 70

$\begin{array}{ll}\text { New IT-focused curriculum students. } & 71\end{array}$

$\begin{array}{ll}\text { Old Management-focused curriculum students. } & 72\end{array}$

$\begin{array}{ll}\text { Concern About the Rigor of the IT Sequence } & 74\end{array}$

Concern About the Elimination of Management Classes $\quad 76$

Satisfaction with Small Class Size and Individualized Attention $\quad 77$

$\begin{array}{ll}\text { Conclusion } & 78\end{array}$

$\begin{array}{ll}\text { Graduates } & 78\end{array}$

Graduate Satisfaction and Perceptions of Preparedness 79

Support for the New Curriculum $\quad 82$

Concern About the Loss of Parts of the Old Curriculum 85

$\begin{array}{ll}\text { Conclusion } & 86\end{array}$

$\begin{array}{ll}\text { Employers } & 86\end{array}$

New Curricular Requirements and Current Skill Needs in the Health Information

$\begin{array}{lr}\text { Management Field } & 89\end{array}$

Employer Expectations and Student Preparedness 93

Future Needs in Health Information Management Education 94

$\begin{array}{ll}\text { Conclusion } & 96\end{array}$

Health Information Management Program Metrics and Other Data 96

$\begin{array}{ll}\text { Background } & 97\end{array}$

Subgroup Completion Metrics $\quad 99$

$\begin{array}{ll}\text { Retention Rates } & 100\end{array}$ 
Enrollment Rates

RHIA Exam Pass Rates

Internal Program Review Report

CAHIIM Accreditation

Conclusion

Student, Graduate, and Employer Experiences and Perceptions

Shifts in Entry-Level Skills and Knowledge of ISU Health Information Management

Graduates

Future Needs in Health Information Management

Conclusions

Illinois State University Health Information Management Program

Information Technology Issues

Inclusion of Old Curriculum Content in New Curriculum

Student Recruitment

On-going Evaluation of the Health Information Management Program

Health Information Management Educational Community

Evaluative Program Guide

Use of Evaluation Results

National Implications 
$\begin{array}{lr}\text { Background } & 129\end{array}$

Methods and Theoretical Framework $\quad 132$

Findings and Data Analysis 134

$\begin{array}{ll}\text { Implications } & 136\end{array}$

$\begin{array}{ll}\text { Conclusion } & 139\end{array}$

$\begin{array}{ll}\text { REFERENCES } & 141\end{array}$

APPENDIX A: AHIMA ENTRY LEVEL COMPETENCIES FOR HEALTH

INFORMATION MANAGEMENT (HIM) AT THE BACCALAUREATE

$\begin{array}{ll}\text { DEGREE LEVEL } & 148\end{array}$

$\begin{array}{ll}\text { APPENDIX B: CONSENT FORMS } & 160\end{array}$

APPENDIX C: INTERVIEW QUESTIONS, FOCUS GROUP GUIDE, AND SURVEYS 168 


\section{TABLES}

Table

Page

1. Bloom's Taxonomy Levels

2. 2018 Cohort Curricular Track Enrollment and Completion

3. 2019 Cohort Curricular Track Enrollment and Completion

4. Retention Rates Based on Starting Subgroup

5. Junior Year HIM Major Enrollment

101

6. Total Enrollment

101

7. RHIA Exam Pass Rates

102 


\section{CHAPTER I: INTRODUCTION TO THE STUDY}

\section{Introduction}

In 2009, the United States government enacted the Health Information Technology for Economic and Clinical Health (HITECH) Act to encourage the use of technology in healthcare. This act led to significant changes in one of the key components of healthcare, the patient health record. This act focused on the use of "technology to improve the quality of care and to decrease healthcare costs” (Palkie, 2013, para. 1). To this end, this act led to the widespread adoption and use of electronic health records (EHRs) throughout the healthcare field. This change led to significant revisions in the role of those responsible for managing patient health records, health information professionals. These revisions have significantly changed the type of educational training necessary for health information professionals, leading to new curricular requirements. In this time of educational programming transition in this area, it is important to insure that educational programs are effective in preparing students for the new roles they will be expected to fill.

Since the advent of the HITECH act, health information professionals have been called upon to serve in roles not dreamt of even 20 years ago. No longer are health information professionals buried in paper working to get physicians to complete their charts. These professionals now need to have a much higher level of information technology knowledge as well as more data and information governance and analytic skills. “'Big data’, electronic-record keeping, and a shifting regulatory environment have reshaped it (the health information field) and now these positions often involve sophisticated, judgment-based work” (Burning Glass, 2014, p. 01). Health information professionals now need the skills to work with the technology as well as to analyze the vast quantities of data provided by the technology. 
The transition to the use of electronic health records (EHRs) has dramatically changed the health information field. Many health information management (HIM) professionals are now intimately involved with the information technology (IT) behind the electronic health records. New skills in IT, including information and data security, IT project management and implementation, and even programming and trouble-shooting, are required in many HIM professional settings. The transition to EHRs has also resulted in great quantities of data that are available to health care entities. HIM professionals are now being called upon to analyze these data for business, clinical, and planning purposes. This requires skills in information governance, data analytics, statistics, and data presentation.

In order to meet these changing needs in the profession, health information academic programs have been called upon to focus their curriculum more closely on these areas as well. With the vast changes in the professional field, there has been an obvious need for change in the education of future health information professionals. In 2014, the Health Information educational accrediting body, Commission on Accreditation for Health Informatics and Information Management Education (CAHIIM), published new curriculum competencies requiring this additional focus in all health information education curricula starting in 2017. These curriculum changes were significant in that new topic areas were required and many curricular competencies must be covered much more extensively. The curricular change implementation has challenged health information educators due to the extent of the changes as well as due to the addition of new topical areas. As these changes have been implemented, however, the question arises as to whether or not the required changes have resulted in improvements in the educational programs and in better preparation of graduates to meet the current professional needs. 
Health information management (HIM) academic programs are one educational component in the health information arena. These are four year, baccalaureate programs designed to prepare students for mid- to upper-level roles in the health information field. There are also two-year, associate degree programs as well as master's degree programs in health information. Students who graduate from HIM programs are eligible to sit for the Registered Health Information Administrator (RHIA) examination and to become credentialed in the profession. In order to prepare students for this field and the RHIA credential, academic programs must be accredited by the Commission on Accreditation for Health Informatics and Information Management Education (CAHIIM). CAHIIM publishes the requirements for curriculum taught in HIM programs and accredits HIM programs based on compliance with these requirements. The new curriculum competencies published in 2014 and required in 2017 included significant changes based on the above-noted professional field changes. These changes included a much greater emphasis on information technology, data analytics, and information governance. The health information management professional organization, American Health Information Management Association (AHIMA) defines data analytics as "a crucial operation for healthcare organizations. Practitioners are required to acquire, manage, analyze, interpret, and transform data into accurate and consistent information in a timely manner” (AHIMA Data Analytics, 2017, para. 1). AHIMA defines information governance as "an organization wide framework for managing information throughout its lifecycle and for supporting the organization's strategy, operations, regulatory, legal, risk and environmental requirements” (AHIMA Information Governance Basics, 2017, para.1). Each curriculum competency is associated with a Bloom's Taxonomy Level. Bloom's Taxonomy is a 
“framework for categorizing educational goals” (Armstrong, 2018, para. 2). This framework consists of six categories of learning ranging from remembering to creating (Table 1).

Table 1

Bloom's Taxonomy Levels

\begin{tabular}{|l|l|}
\hline \multicolumn{1}{|c|}{ Bloom's Level } & \multicolumn{1}{|c|}{ Description } \\
\hline Remember & $\begin{array}{l}\text { Student can perform basic recollection of } \\
\text { facts and concepts; memorization }\end{array}$ \\
\hline Understand & $\begin{array}{l}\text { Student can provide basic explanations or } \\
\text { descriptions of concepts; explanation }\end{array}$ \\
\hline Apply & $\begin{array}{l}\text { Student can use information and concepts; } \\
\text { demonstration }\end{array}$ \\
\hline Analyze & $\begin{array}{l}\text { Student can compare and contrast or question } \\
\text { data; experimentation }\end{array}$ \\
\hline Evaluate & Student can justify or defend a position; \\
& critique \\
\hline Create & Student can create work using the concept or \\
information; design
\end{tabular}

Note. Adapted from “Bloom's Taxonomy,” by P. Armstrong, 2018, Vanderbilt University Center for Teaching. Retrieved from https://cft.vanderbilt.edu/guides-sub-pages/blooms-taxonomy/

This framework is used frequently in education as a guide for objectives and learning goals and has been adopted by CAHIIM as a part of the curriculum requirements. Not only did the latest curriculum changes include new competencies but they also included more complex levels of required Bloom's Taxonomy Levels for some existing competencies. For example, with an increased focus on data analytics, some related CAHIIM competencies may now require 
a Bloom's level 6 (creating) instead of the previously required level 4 (analyzing) or 5 (evaluating) (e.g., performing a data analysis instead of analyzing an existing data analysis). While these curricular changes were obviously needed to prepare students for the health information field, they have provided significant challenges for HIM educators. For example, educators may not be as well versed in information technology (IT) skills as they would need to be to adequately teach the required IT competencies. Also, programs may not have adequate "extra” time in their curricula to add additional courses and/or topics and still maintain 4 year graduation rates for their students. Therefore, adding courses from IT departments and rearranging and removing courses and topics has been required in many cases. Such changes may have included a decrease in the number of medical coding classes or classes involving nontraditional healthcare due to the decreased focus on medical coding at the baccalaureate level and the integration of multiple healthcare settings into most classes. Courses in data analytics may have been revised to include higher level analytics, such as the use of Statistical Package for the Social Sciences (SPSS); skills that are now required in the professional field. Significant discussion, planning, and analysis has had to go into the HIM curricular changes in the HIM educational programs.

As these changes have been implemented, it is time to move to the next step, that of evaluating the revised curricula and educational programs. Based on the obvious need for HIM professionals with knowledge and skills beyond that provided by educational programs in the past, it is essential that these curricular changes have resulted in appropriately trained graduates. Burning Glass, a job market analysis company, recently completed a study that found that while "health care reform depends on the better management of medical information....the labor market is not keeping up with the demand for workers with these skills” (2014, p. 01). Burning 
Glass even goes so far as to say "a shortage of talent qualified to undertake these jobs can impede key improvements to America's health care system” (2014, p. 05). Obviously, the provision of appropriately trained HIM professionals is integral to the success of the health care system in America. Evaluation of the HIM curricular and program changes is of utmost importance. As these changes have been in the implementation stage up until the last year, to date, there have been no published evaluation research studies on the effects of the changes on HIM academic programs. This evaluative study was designed to fill that gap and to focus on the evaluation of the changes in the HIM curriculum and program in one HIM academic program, specifically an evaluation of the ability of the changes to adequately prepare students for the current HIM field. The goal of this evaluation was utilization-focused so that the results of the evaluation could be used by stakeholders for continuous program improvement. It is hoped that the findings not only benefit the program under review but also provided insight for other HIM programs.

\section{Context}

This evaluation was completed using an in-depth case study of the HIM academic program at Illinois State University (ISU), a large Midwestern public university. The evaluation was focused on the Health Information Management Program at ISU and specifically assessed the effects of a CAHIIM curriculum change. The HIM program is one of five programs in the Department of Health Sciences, which is a member of the College of Applied Science and Technology at ISU. These five programs include Medical Laboratory Science, Health Promotion and Education, Environmental Health, and Safety in addition to Health Information Management. The HIM program has maintained accreditation for 45 years and was preparing 
for re-accreditation at the time of the study. There are three full time faculty who teach in the oncampus sequence, and a part time faculty member who teaches in the online sequence.

ISU has had an accredited HIM program since 1972 and prides itself on having maintained that accreditation. The required CAHIIM curricular changes were potentially made more quickly at ISU than at other institutions due to the fact that ISU was to undergo their CAHIIM re-accreditation assessment and visit during the 2017-2018 academic year. The reaccreditation was to be based on the new curriculum, so the HIM faculty wanted to insure that this curriculum was in place and being taught prior to the 2017-2018 academic year. Therefore, ISU was an ideal site to use for an early evaluative study of the effects of newly implemented CAHIIM competencies on HIM academic programs.

The HIM program at ISU offers two baccalaureate sequences: a traditional, 4-year, oncampus sequence and a 6-course, online sequence for individuals with an Associates' Degree in Health Information and the Registered Health Information Technician credential (RHIT-RHIA program). Both sequences are accredited by CAHIIM and both are required to comply with the curriculum competencies as well as the other CAHIIM standards for accreditation. The curricular changes affected the on-campus sequence curriculum and program much more than the online sequence since students have completed a portion of their HIM education in their associate's degree program, therefore, this study focused on the on-campus sequence only. The on-campus sequence in HIM is relatively small, with only about 25-30 students per graduating class and students move through the sequence of courses in a cohort model based on their graduation year. Students may select the HIM major upon admission to Illinois State, however they may only start their major courses after successful completion of all prerequisite courses as well as maintenance of a GPA of 2.25 or above. All HIM majors must take Medical 
Terminology and two courses in Human Anatomy and Physiology as well as two IT programming classes as prerequisites. Within the major courses, there are 14 HIM classes that each student must take and six IT classes. Students also must take a statistics course at ISU or at a community college prior to their senior year in the major. Students must pass all prerequisite and major courses with a grade of a $\mathrm{C}$ or above and may only retake a course once. There is a set sequence of courses within the major and there are no HIM electives offered. The sequence of courses or plan of study consists of 14-15 credit hours each semester so students do not have time available to take non-HIM electives unless they take a course overload or stay in school for additional semesters. Each HIM course is only offered once a year and all 25-30 students in a given cohort move through the HIM course sequence together.

Upon graduation from an HIM program, students are eligible to sit for the Registered Health Information Administrator (RHIA) examination. This is a national exam administered by the American Health Information Management Association Commission on Certification for Health Informatics and Information Management (CCHIIM) that graduates of CAHIIM accredited HIM programs can take to obtain the RHIA certification. Many jobs in the HIM field require RHIA certification, however, some students who follow non-traditional careers, such as those in the insurance industry, IT industry, or fields unrelated to HIM choose not to take the examination. Passage of the RHIA exam or certification are not required for graduation or successful completion of the HIM baccalaureate program. However, the ISU HIM program does track exam pass rates as an outcome measure. It should be noted that the RHIA exam content is not directly tied to the CAHIIM Curriculum Competencies but is instead based on content areas identified as being important for entry level professionals through HIM professional surveys. 
In 2014, the CEE and CAHIIM released the 2014 Curriculum Competencies, which were required to be implemented by 2017. These changes were based on the significant changes that had occurred in the HIM field, including an increased emphasis on information technology (IT), data analytics and governance, and information governance. As outlined previously, these changes provided a challenge to HIM educators in the implementation of new curriculum and more complex Bloom's taxonomy levels in existing areas.

At Illinois State University, the first step in implementing the new 2014 competencies was completion of a gap analysis. This gap analysis compared the existing curriculum to the newly required curriculum and identified areas in which changes were needed in order to comply with the new curriculum. The gap analysis identified a number of areas in which curriculum needed to be added in order to meet the new requirements. These areas were focused primarily in the area of information technology and included the following competencies: IT security issues such as collaboration in the design and implementation of risk assessment, contingency planning, and data recovery procedures; IT regulatory compliance issues such as assess systems capabilities to meet regulatory requirements; IT development issues such as take part in the development of networks, including intranet and internet applications; and IT database issues such as database design and data warehousing. There were also further areas that were not covered in the existing curriculum in the areas of data governance and analysis and information governance. This analysis led to the identification of the need for curriculum for new competencies as well as an increase in the Bloom's levels taught in some areas. This included competencies such as: discover threats to data integrity and validity (increase from Bloom's level understanding to application); and facilitate the use of enterprise-wide information assets, such as warehoused data, to support organizational strategies and objectives (new competency). 
Based on the data found during the gap analysis, a number of areas were identified for change. Between 2014 and 2016, the newly required curricula and programmatic changes were developed by the HIM faculty. ISU started implementing the required revisions to the curriculum during the Fall of 2016 and were fully transitioned to teaching only the new curriculum with students entering their junior year of the program in the Fall of 2018. These curricular changes include the following:

- $\quad$ The addition of six information technology classes selected to cover the IT competencies of information assurance and security, systems development, and project management; these classes include: IT 168 - Structured Problem Solving Using the Computer, IT 178 - Computer Application Programming, IT 250 Fundamentals of Information Assurance and Security, IT 254 - Hardware and Software Concepts, IT 261 - Systems Development, and IT 262 - Information Technology Project Management.

- $\quad$ The removal of three economics and management classes that were felt to overlap with HSC 346 - Healthcare Finance, and HSC 320 - Organization and Management of Health Information Services. The classes that were removed include ECO 105 - Principles of Economics, MQM 220 - Business Organization and Management, and MQM 323 - Human Resources Management.

- $\quad$ Extensive revisions to the Health Information Data Analysis and Introduction to Health Information Management classes to include further information regarding data analysis and data governance, as well as a much greater focus on the use of electronic health record systems. 
- $\quad$ The integration of the Health Information Technology and Trends in Health Information Management classes into other existing HIM classes. Basic health information technology skills as well as non-traditional healthcare settings, the main topics of these two classes, are now integrated throughout the HIM curriculum.

Based on University policies regarding curriculum changes, these changes were implemented with the 2016 University Course Catalog, meaning that all incoming freshmen in the fall of 2016 as well as some transfer students who started at ISU in the fall of 2016 were required to complete the new curriculum. This resulted in a transition process in which two cohorts, the graduating classes of 2018 and 2019, had dual sequences. These cohorts had a mix of students completing the old curriculum and students completing the new curriculum, based on which sequence they were required to complete as assigned at the time of enrollment. The graduating class of 2018 had 4 students in the new "IT" curriculum and 17 students in the old curriculum; the class of 2019 had 6 students in the new "IT" curriculum and 11 students in the old curriculum. The graduating class of 2020 will be the first cohort in which all students will be required to complete the new "IT" curriculum.

\section{Purpose of Study}

During any transition, there are problems encountered and questions that arise as to whether or not the change is positive and effective. Typically, there may be informal reviews or changes made during the transition process. However, in order to fully assess the impact of a program curricular change, a more formal process is needed. Therefore, the purpose of this evaluative study was to complete an in-depth case study that contributed to a program review and evaluation to determine the impact of the recent CAHIIM curriculum change at Illinois State 
University. This included not only the impact of this change on student learning outcomes, but also on the program as a whole, including enrollment and retention, as well as time to graduation and RHIA examination pass rates. This evaluation process was designed to be quality improvement focused as well as utilization-focused. The goal was to determine the effectiveness of the curricular change as well as the effect of this change on the program and to use those findings to improve the curriculum and program.

For the purposes of this study, the term evaluation will be used to mean the "process of observing and measuring a thing for the purpose of judging it and of determining its 'value', either by comparison to similar things, or to a standard” (Institute for Teaching, Learning, and Academic Leadership, n.d., para. 3). While the terms evaluation and assessment may be used interchangeably, this study is considered an evaluative study based on the above definition. In addition, evaluation can be formative or summative. Formative evaluation refers to evaluation "for the purpose of improving” (Institute for Teaching, Learning, and Academic Leadership, n.d., para.2). Much of this study falls into the realm of formative evaluation.

To that end a variety of methods were used to gather data and evaluate the program and the curricular change. This included the review of various program metrics, such as enrollment rate, retention rate, new curriculum transfer rate, and certification exam passing rate; surveys, interviews, and focus groups of students, graduates, and employers; and review of documents from internal program review. Utilization of this combination of data sources provided a full picture of the effects, positive and negative, of the curriculum change on the HIM program at ISU. A full description of the methodology that was used is included in Chapter 3.

\section{Key Terms and Concepts}

The following are key terms and concepts used throughout this dissertation proposal: 
American Health Information Management Association (AHIMA) - the professional organization for Health Information professionals (AHIMA, 2017)

Commission on Accreditation for Health Informatics and Information Management Education (CAHIIM) - "independent accrediting organization whose Mission is to serve the public interest by establishing and enforcing quality Accreditation Standards for Health Informatics and Information Management (HIM) educational programs” (CAHIIM, 2017, para. 1)

Council for Excellence in Education (CEE) - body created by AHIMA to oversee the educational needs for health information students and professionals (AHIMA, 2017)

Data Analytics - use of qualitative and quantitative processes to evaluate information; in health care can be used for clinical and business purposes

Data Governance - management of data including availability, use, integrity, security

Electronic Health Record (EHR) - electronic version of individuals' health information including both administration and clinical data such as demographics, physician and other provider documentation, medications, laboratory results, radiology results, and immunizations

Health information - data related to an individual's health and interactions with the healthcare continuum, including health, family, and social histories; diagnoses; procedures; and outcomes

Health information management (HIM) - process of acquiring, analyzing, and protecting individuals' health information

Health Information Technology for Economic and Clinical Health Act (HITECH act) - "part of the American Recovery and Reinvestment Act of 2009, was signed into law on February 
17,2009 , to promote the adoption and meaningful use of health information technology" (U. S. Department of Health \& Human Services, 2017, para. 1)

Information Governance (IG) - management of information within an organization including all policies, procedures, processes, and controls related to this management Information Technology - encompasses computer applications and electronic data and the storage, use, retrieval, transmission, and manipulation of data using such applications Registered Health Information Administrator (RHIA) - certification for health information professionals who have completed a baccalaureate level of study and successfully passed the certification exam

\section{Research Questions to be Answered}

The questions to be answered by this study are:

1. What is the nature of current students, graduates, and employer experiences related to Health Information Management (HIM) curriculum shifts from the 2012 Commission of Accreditation for Health Informatics and Information Management Education (CAHIIM) curriculum standards to the 2014 revision?

a. What are student perceptions regarding the curriculum changes and preparedness for the HIM field?

b. What are graduate perceptions regarding the curriculum changes and preparedness for the HIM field?

c. What are employer perceptions regarding student preparedness for the HIM field for those students who have completed the new curriculum?

2. In what ways have the 2014 Commission of Accreditation for Health Informatics and Information Management Education (CAHIIM) curricular requirements shifted the entry- 
level skills and knowledge of Health Information Management graduates in comparison to the 2012 curriculum standards?

3. Considering the on-going changes in the CAHIIM curriculum requirements, what are the implications for the Health Information Management field and for individual programs moving forward?

\section{Theoretical Framework}

In order to insure that HIM educational programs are teaching the skills and knowledge needed in entry-level HIM positions, the American Health Information Management Association Foundation Council for Excellence in Education (CEE) and the Commission on Accreditation for Health Informatics and Information Management Education (CAHIIM) work together to set appropriate curriculum competencies for accredited educational programs. Every 3-5 years, curriculum competencies are updated for the associate, baccalaureate, and master's levels. Educational programs are not only called upon to insure they are meeting these curriculum competencies but also insuring that changes made to meet these competencies are adequately preparing students for the HIM field. Evaluation of the changes made, the curriculum after the changes, and the program as a whole is needed to insure both that the competencies are met and that the program is preparing students appropriately.

One of the main foci of this study was to use the findings for improvement of the HIM program under review as well as HIM education in general. Therefore, the use of a utilizationfocused evaluation framework was appropriate. Patton (2012), one of the leading proponents of utilization-focused evaluation states that "the focus in utilization-focused evaluation is on intended use by intended users" (p. 4). One of the key tenets of utilization-focused evaluation, therefore, is, the close involvement of stakeholders in the evaluative process. By involving 
stakeholders in the evaluative process, the intended users are "learning from and about evaluation through their participation” (Preskill \& Boyle, 2008, p. 1). As the intended users, or stakeholders, learn about evaluation, they better understand the evaluative process and develop support for continuous, sustainable quality evaluative practices. This, in turn, leads to ongoing evaluation and collection of data that provides evaluation findings that can be used to improve systems and processes in the educational setting (Preskill \& Boyle, 2008, p. 2). Such involvement and stakeholder awareness and learning is referred to as evaluation capacity building or ECB, which is an important concept of quality utilization-focused evaluations.

ECB can also carry over into the institutional or program culture, leadership and organizational learning capacity. An organization or program that desires evaluative processes that will be used by the intended users must have a culture and leaders that support quality, meaningful evaluation, value the results of evaluative processes, and use those results to enact meaningful change (Preskill \& Boyle, 2008, Labin, Duffy, Meyers, Wandersman, \& Lesesne, 2012, p. 5). True ECB results in ongoing quality evaluation and use of the evaluative results through systems and programs that enable users to analyze their programs on a regular basis, and "interpret the results, in order to understand and strengthen program implementation, to improve program outcomes, and to meet the accountability requirements of funders and accrediting bodies” (Suarez-Balcazar \& Taylor-Ritzler, 2014, p. 96).

The concepts of UFE and ECB were appropriate for this study since the study findings were meant to be used to determine the impact of the recent curriculum changes on the HIM program at ISU. The small number of faculty members and close involvement and support of the department chair lent itself to true development of ECB. Since the release of the CAHIIM curriculum changes in 2014, the faculty had worked together to complete a gap analysis of the 
existing curriculum related to the new requirements, collaborated to develop new courses and make curricular changes as needed to meet the new requirements, and have had ongoing discussions about the effectiveness of the curriculum changes. Through these activities, the faculty and department chair had been building evaluation capacity and desired a quality evaluation of the program and curricular changes that could be used to improve the program and meet the students' needs. In addition, due to the on-going nature of CAHIIM curricular changes, the stakeholders wanted a process in place that would allow for on-going evaluation of the program and curricular changes (Volkov \& King, 2007, p. 1).

\section{Limitations}

One limitation of this study was the fact that this is an evaluative study of an HIM program in which I am a faculty member. I have been closely involved with the curriculum change and have personally dealt with many of the challenges in the transition to the new curriculum. This presents positives as well as negatives. I am well versed in the CAHIIM competencies and standards and have been highly involved in the re-accreditation self-study process. Therefore, I was in an excellent position to conduct a program review and evaluation. However, as a member of the faculty, I have some inherent bias, even if I am unaware of such bias. This is further addressed under Researcher Positionality.

Another limitation of this study was that there were a limited number of graduates who had completed or students who were completing the new curriculum. There were four such students in the 2018 cohort and 6 in the 2019 cohort. However, there were approximately five additional students in the 2018 cohort who started the new curriculum and changed their plan of study to the old curriculum. This provided additional information of interest for the evaluation. This evaluative study provided useful information to inform the HIM program of the status, at 
the time of the study, of the curriculum change in the preparation of students. Since this was the entire population of current students, it was felt that the small number of students was acceptable in order to complete the study in a timely manner. While the small number allowed for an evaluation of the program, to truly assess student learning outcomes, evaluation over a longer period of time and involving more students would be required.

\section{Researcher Positionality}

As stated above, I am a member of the faculty in the program that was evaluated in this study. This means that I was intimately involved with the curricula and program under review. Due to this involvement, there may be findings that reflect directly on curricula I had developed or taught. All attempts were made to manage my subjectivity throughout the course of this evaluative study. This was done through a variety of methods including pilot testing and review of interview protocols and surveys by the other HIM faculty members. In addition, triangulation, prolonged engagement and persistent observation were used to increase the research validity. Triangulation is the use of multiple data sources to enable confirmation of findings and adds to the "trustworthiness of our analysis” (Miles, Huberman, Saldana, 2014, p. 299). Through the use of program metrics and multiple groups of surveyed individuals, triangulation could be used in this study. An advantage of my role as faculty in the program under review was the fact that the results were more likely to be seriously considered by the other faculty members, the department chair, and administration, and to be used for continuous improvement of the HIM program.

As stated earlier, the other faculty members and the department chair had been involved in the curriculum change process to date. A gap analysis was completed by and analyzed by all program faculty. Also, all faculty members were actively involved in the curriculum change process, including development of new courses and changes in courses. Finally, all faculty 
members and the department chair had been involved in informal discussions regarding the curriculum and programmatic changes through bi-weekly program meetings. Based on these stakeholders' involvement, evaluation capacity had been built and the stakeholders were invested in the results of this utilization-focused evaluative study.

\section{Delimitations}

This in-depth evaluative study focused on the HIM program in which I teach. Such a study would not be possible in a program where I had no relationship. While the findings may be limited in their generalizability it was felt that aspects of this study would contribute to general knowledge in the HIM educational arena. The evaluative process outlined in this study provides a guide for other health information programs in the areas of evaluation and assessment. The overall findings related to CAHIIM competencies and their alignment with the needed knowledge and skills of new graduates is generalizable and may provide information that is useful for CAHIIM in their development of future competencies. Also, the findings from this study and the curriculum revisions that have been made may be useful to other HIM programs.

This study therefore evaluated a revised curriculum in a baccalaureate health information management program in a large university setting. Further, the setting was an on-campus setting which included no HIM major on-line courses. While there are many types of on-line health information programs, this study did not evaluate such a program. 


\section{CHAPTER II: INTRODUCTION TO PROGRAM REVIEW, EVALUATION, AND}

\section{ASSESSMENT}

In order to fully understand and appreciate the role of evaluation and assessment in the changing HIM programs, it is helpful to have a good grasp of program review, evaluation, and assessment in general. It can be seen that one of the many goals of higher education is to adequately prepare students for careers in their field of study and for society at large (Gallagher, 2016). In order to prepare students for future jobs, educational programs must provide them with certain knowledge or competencies as well as with the skills needed to function in the work world; students should be prepared with the ability to continue to learn in a changing world. Programs design their curriculum and other programmatic elements to provide students with this knowledge and these skills in order to meet this goal. Programs that optimally prepare students in this way may be considered to be effective.

However, how is it decided what constitutes "optimal preparation”? How is it determined when a program effectively meets their goal of student preparation for their students? What is needed for students to be adequately prepared? One way of assessing a program's effectiveness in adequately preparing students for their careers and for society at large is the use of program evaluation. Done correctly, and in a meaningful way, program evaluation and assessment can provide a program with data or feedback that can be the basis of decision-making for programmatic improvement (Preskill \& Boyle, 2008, p. 2). Program evaluation and assessment can be used to identify what a program is doing well as well as areas in which the program needs to improve. Issues such as equity, access, and student, graduate, and employer satisfaction can be examined to ensure that all students are receiving the educational experience 
and career preparedness they desire (Rickards, 2018). When shortcomings are found, areas of improvement can be identified and changes can be made to the program.

A caveat exists, though. There are also many uses of program evaluation and assessment that provide many different representations of various aspects of academic programs. Some of these may not result in meaningful data or feedback and may just be paper exercises with no real value for programmatic improvement (Rickards, 2018). Educational programs may encounter such evaluation and assessment requirements, both from internal and external sources. For example, there has been an increased emphasis in recent years on evaluation and accountability of programs and schools based on certain metrics, such as retention rate or graduation rate. Such focus exists both internally in colleges and universities as well as externally among government and accreditation bodies. There has been much debate as to the usefulness of such metrics in truly assessing schools’ and academic programs’ success (Judd \& Keith, 2018), however, many feel this is an appropriate representation of school or program success. Whether or not such measures can be used to evaluate a program, requirements to collect such metrics and meet related standards exist at many levels. This, combined with other external influences and factors, can complicate the ability of educators to complete meaningful evaluation of their programs and to implement meaningful change in their programs. External forces that further complicate this situation may include rapid changes in entry-level competencies that students must acquire or specific accreditation body curriculum and program requirements. These can require hurried changes in the program's planned curriculum and other programmatic elements. All of these requirements can affect a program's ability to successfully meet their goals on an ongoing basis. Educators must work hard to juggle all these requirements while still trying to meet their goals and provide meaningful student learning outcomes. 
There are many methods that programs may use to judge their adequacy in preparing students; these can range from review of basic metrics such as graduate job attainment and informal graduate feedback to more formal methods of evaluation and assessment. While keeping track of metrics such as time to graduation, graduate job attainment and word-of-mouth graduate preparedness may be a simple way of judging program achievement, in order to truly evaluate and assess a program, a more formal mechanism must be used (Rickards, 2018).

Program evaluation and assessment can be an integral part of an effective higher education program. A program may provide courses and assume student attainment of required knowledge and preparedness for careers in the field, yet without some type of formal evaluation, the educators will not be able to truly assess whether they are adequately meeting their goals. Tyler (1949) states

many variables make it impossible to guarantee that the actual learning experiences provided are precisely those that are outlined in the learning units. Hence it is important to make a more inclusive check as to whether these plans for learning experience actually function to guide the teaching in producing the sort of outcomes desired (p. 105). While some may feel that formal evaluation and assessment is merely a series of meaningless hoops that must be jumped through, program evaluation and assessment can be completed in a meaningful way that can be used for ongoing program improvement (Rickards, 2018, p. 100-101).

\section{General Purpose of Evaluation and Assessment}

Palomba and Banta (1999) state "the overriding purpose of assessment is to understand how educational programs are working and to determine whether they are contributing to student growth and development” (p. 5). The authors, therefore, emphasize that evaluation and 
assessment must focus on programs, not on individuals. The ultimate goal, as they state, is to determine "whether students, as a result of all their experiences, have the knowledge, skills, and values that graduates should possess” (Palomba \& Banta, 1999, p. 5). The role of evaluation then becomes an assessment as to whether or not the program has provided experiences that have contributed to students' growth and the knowledge needed to be competent in the field. By completing a formal evaluation and assessment process, a program can ensure that they are meeting the goal of adequately preparing students and can take that a step further by using evaluation information to make ongoing programmatic improvements (Patton, 2012).

\section{Components of Evaluation and Assessment}

Patton (2012) defines evaluations by stating that they "typically describe and assess what was intended (goals and objectives), what happened that was unintended, what was actually implemented, and what outcomes and results were achieved” (p. 3). This view of evaluations makes clear that the evaluative process includes the components of existing goals and objectives (e.g., adequately prepared students, alignment with accreditation requirements), current implementations (e.g., program methodology and curriculum), and outcomes, either intended or unintended (e.g., students who may or may not be prepared, alignment or lack of alignment with accreditation requirements). Use of these components in the evaluation process provides results and findings, either positive or negative, which can be used in a variety of ways. Uses of Evaluation and Assessment

According to Stufflebeam and Coryn (2014) evaluations can be used for improvement, accountability, information dissemination, and enlightenment. Stufflebeam and Coryn (2014) further state that formative evaluation and assessment can be used to ensure and improve the quality of a program while summative evaluations, or "retrospective assessments" (p. 22), can be 
used to provide feedback on a program and are "useful in ascertaining accountability for successes and failures” (p. 22). Evaluation results can be disseminated to the public and consumers to demonstrate success or provide comparisons with competitors. Finally, the results of evaluations can lead to "new understandings .... . [and] "to focused, applied research efforts and sometimes to development of institutional or social policies” (Stufflebeam \& Coryn, 2014, p. 25).

\section{Types of Evaluation and Assessment}

In his 2001 monograph Stufflebeam outlines 22 evaluation models. He groups these in four broad categories: pseudoevaluations, questions- and methods-oriented evaluation approaches, improvement/accountability-oriented evaluation approaches, and social agenda/advocacy approaches. He states that "the study of alternative evaluation approaches is important for professionalizing program evaluation . . . [and to] help evaluators discredit approaches that violate sound principles of evaluation and legitimize and strengthen those that follow the principles” (Stufflebeam, 2001, p. 9). He also includes tables regarding evaluation purposes, strengths, and weaknesses to aid in the selection of evaluation methods. (Stufflebeam, 2001, p. 11).

Grayson (2018) focuses his review of evaluation models on three main categories: formative, summative, and developmental. He further states the purpose of formative evaluation as program evaluation designed to "provide constructive feedback," summative evaluation as “measuring program performance in terms of outcomes and impacts,” and developmental evaluation as “informing social program innovators who intend to bring about major change through development of new program models” (p. 458). Erlandson (2018) is a proponent of naturalistic evaluation, a method of delving deep into the program under study to determine 
“'What’s happening here?’” (p. 474). Godfrey and Finkelstein (2018) discuss the value of responsive evaluation, a method that evaluates the process of a program's implementation in a way that provides feedback on the actions taken in relation to the values of the stakeholders (p. 491). These various categorizations and descriptions of types of evaluations show that evaluation and assessment types are varied with overlapping components or purposes. Selection and use of an evaluation type is best determined by the goal of the evaluation process.

One of the most common types of evaluation and assessment in higher education is that used for accreditation, a process required by a large number of higher education programs. In fact, Buchan, et. al. (2004) states that "the emphasis on assessment in higher education belongs in large part to various levels of accreditation” (p. 242). This evaluative process usually involves a self-study, an external review, a site visit, and a formal report of the external accreditation agency's findings. These findings may lead to required improvements or changes that must be made prior to full accreditation, recommended improvements or changes for quality improvement for the program, or insight into changes or improvements needed in the future. Such evaluations and assessments "are grounded in clear accreditation criteria and guidelines for self-assessment” (Stufflebeam \& Coryn, 2014, p. 27).

Stufflebeam includes accreditation under the improvement/accountability-oriented evaluation approaches (Stufflebeam, 2001, p. 61). Other evaluation and assessment processes used for accountability, such as decision/accountability and consumer oriented approaches, are frequently very closely aligned with accreditation and regulatory processes (Stufflebeam, 2001). Accountability evaluation and assessment focuses on "oversight and compliance, which typically includes assessing the extent to which a program uses funds appropriately, follows mandated processes and regulations, and meets contract obligations” (Patton, 2012, p. 119). 
Participatory evaluation and assessment is a type of evaluation designed to form "a partnership between someone who is trained in evaluation and those who are not” (Stufflebeam \& Coryn, 2014, p. 153). This allows the evaluator to provide support for the program participants yet allows the participants to conduct their own evaluation. The advantage to this type of evaluation is that the "process of engaging in evaluation can have as much or more impact than the findings generated” (Patton, 2012, p. 154). Frequently educators and staff involved at this level in the evaluative process are more likely to view the results as valid and useful as well as to actually use the results in program improvement.

\section{Utilization-Focused and Formative Evaluation}

One key component to evaluation and assessment is for the results to be used for continued improvement. Formative evaluations are one type of evaluative process that "focuses on ways of improving and enhancing programs rather than rendering definitive judgment” (Patton, 2012, p. 118). Improvement-oriented evaluations also aim to "foster improvement and accountability through informing and assessing program decisions” (Stufflebean \& Coryn, 2014, p. 174). One example of this is seen in Widrick, Mergen, and Grant (2002) who provide an overview of the use of a Total Quality Management model in evaluation in higher education. Their model focuses on "three dimensions: quality of design (QD), quality of conformance (QC) and quality of performance (QP)” (p. 123). Evaluation in these three areas can provide a measurement of current status that can be used as the basis for identification of areas that can be improved upon and as “an integral part of continuous improvement” (Widrick, Mergen, \& Grant, 2002, p. 130).

Use of results is obviously an important component in evaluation and assessment processes. Patton (2012) is a strong proponent of utilization-focused evaluation and states that 
such evaluation "begins with the premise that evaluations should be judged by their utility and actual use” (p. 4). Patton also focuses on identifying and involving key stakeholders, all individuals or groups that may have a vested interest, throughout the evaluation process. The focus of such evaluation, therefore, is on "intended use by intended users" (Patton, 2012, p. 4). Stufflebeam (2001) states that "all evaluation methods are fair game in a utilization-focused program evaluation. The evaluator will creatively employ whatever methods are relevant” (p. 78). By designing evaluation and assessment processes for which the results are intended to be used by the involved groups, there is a much higher likelihood that the results will not only be valued but will also be used to make improvements and changes in the educational program.

Selection of an evaluation and assessment method is based on a number of factors. These include the relative fit of the method to the assessment question to be answered, reliability and validity of the method and measures, available time and budget, and motivation for use of a particular method (Palomba \& Banta, 1999, chapter 4). Patton (2012) ties the method selected to the purpose of the evaluation and states "one purpose is likely to become the dominant motif and prevail as the primary purpose informing design decisions” (p. 136). Stufflebeam (2001) states that his review of evaluation methods shows that "the (best) approaches are showing a strong orientation to stakeholder involvement and the use of multiple methods” (p. 89).

\section{Use of Evaluation and Assessment in Program Improvement}

In reviewing the types of evaluation and assessment processes it is clear that use of the results to improve educational programs is an underlying key (Grayson, 2018, p. 458). While certain evaluation types may have a quality improvement focus, many types of evaluation can be used for such purposes. Reviewing evaluation and assessment results and providing those results to key stakeholders is the first step (Patton, 2012). Using the results to determine areas of 
needed improvement and change, implementing those changes, and monitoring the results of those changes are further steps needed to ensure true program improvement (Widrick, Mergen, \& Grant, 2002). Evaluation and assessment reports placed on a shelf and never reviewed or used do not do anything to improve the educational program or to ensure effectiveness of a program. True review and use of the results will provide insight into areas that need improvement and the means to truly achieve programmatic goals. However, the key to use of such data is the design of a meaningful evaluation and assessment program that will provide findings that can be used for true program improvement.

\section{Critiques of Evaluation and Assessment}

\section{Neoliberal Bias Effects on Higher Education Evaluation and Assessment}

There are a large number of approaches to higher education program evaluation and assessment. As mentioned earlier, some are more effective or meaningful than others in producing useful data and findings as well as in use for program improvement. Many of the approaches and theories surrounding program evaluation and assessment relate directly to beliefs about the purpose of higher education. Even within one belief system, it is important to recognize "how assessments might be more or less fitting in different contexts" (Rickards, 2018, p. 103).

Much of the concern about recent evaluation and assessment attempts are related to the neoliberal focus on creating a policy-laden environment. As the emphasis on the purpose of higher education has moved toward fulfilling the needs of the job market, higher education has become a more highly controlled and accountable entity and an economic factor in United States society. With that comes a business model with higher education playing a role in the free market as well with the placement of much tighter control on higher education institutions 
(Apple, 2005, p. 11). There is a demand for higher education institutions to be competitive and efficient (Lorenz, 2012, p. 601). To that end, government and accreditation agencies have started demanding evaluation and assessment activities to justify expenditures and federal support. Frequently these activities involve the collection and dissemination of defined metrics that may or may not truly demonstrate quality. However, in an attempt at transparency, these metrics are also frequently used in the public arena to demonstrate school quality so that the higher education consumer can make educated choices. Often such metrics are considered to be outcome measures as they include retention rates, graduation rates, and time to graduation.

Many in higher education do not agree with these required measures of quality and the "notion of national accountability through standard outcomes assessment at the college level" (Judd \& Keith, 2018, p. 70). Most educators feel that such accountability measures are merely data collection exercises that result in data that is not meaningful and does not in any way demonstrate quality of an institution. In addition, such data is most often never used for any type of school or program improvement (Rickards, 2018, p. 100). In fact, many of these metrics focus on efficiency, not on effectiveness, and efficiency measures most often focus on cost (Lorenz, 2012, p. 604). Such measures, therefore, are not going to be meaningful to educators aiming to improve the quality of education provided to students, they are only meaningful to the bottom line of the institution. "It is no longer the quality of student attainment as assessed by the faculty that really matters but quantitative output criteria and ranking objectives as decreed by management” (Lorenz, 2012, p. 613).

Accreditation as an evaluation and assessment process is also frequently felt to be a data collection exercise that results in no useful data or meaningful results. A recent article in The Chronicle of Higher Education by Flores (2017) was entitled “Accreditation is broken”. The 
author goes on to state, “America’s system for safeguarding the billions of dollars spent on federal student aid [accreditation] is not up to the task" (para. 1). Her premise is based on the low budgets of most accreditation agencies which has resulted in meaningless accreditation decisions and even situations in which "accreditors have signed off on colleges that are hurting students” (Flores, 2017, para. 3). Many also feel that accreditors are functioning on the premise of competition and the free market and that accreditation decisions are frequently based on perceived market needs, not the true quality of a program (Lorenz, 2012, p. 607).

This change in focus to higher education as a business has resulted in many demanding that higher education be run as a business, with competition for consumers, business efficiencies, and predetermined standards of performance. This results in more regulations and evaluations as well as less autonomy (Apple, 2005). There have even been attempts to tie higher education funding to performance. While not widely successful, such attempts have been noted to deprofessionalize and demoralize faculty and staff (Lorenz, 2012, p. 613; Apple, 2005, p. 20). The entire concept of quality assurance (QA) in higher education is questioned as it is felt that "the complexity and quality of real education has been fatally reduced by the QA models to the quantitative pass rate” (Lorenz, 2012, p. 619). Such activities have resulted in many in academia feeling as if evaluation and assessment and quality improvement activities are just meaningless exercises. Lorenz (2012) notes that these activities have resulted in "widespread cynicism and hypocrisy among faculty regarding the application of QA procedures” (p. 620). This is unfortunate because this has created a culture in which even meaningful program evaluation and assessment may be scorned or frowned upon by many in academia.

Interestingly enough, United States higher education is just one entity that has become enmeshed in this the currently "fashionable" culture (Apple, 2005, p. 11). Similar changes have 
been seen in the U.S. in other industries such as healthcare, and the current business focus in higher education is seen around the world. Neoliberalism has led to an overreliance on set standards which has result in "an audit culture” (Apple, 2005, p. 14). This takes us back full circle to the debate over what the true purpose of higher education should be. Should it be to prepare students to be good citizens or should it be a business, with customers, efficiencies, and profits? While we, again, have no answer to this debate, it is clear that this question has a strong impact on higher education and the role of evaluation and assessment in higher education in the current environment.

\section{Equity in higher education evaluation and assessment.}

The focus on neoliberalism in higher education has also led to many concerns regarding equity issues in the current arena of evaluation and assessment. While there are more concerns focused on issues surrounding individual student assessment, the area of program evaluation and assessment still raises equity issues. Leathwood (2005) states

assessment is used to provide a rationale and legitimacy for the social structures and power relations of modern day societies, and for one's place within these. It is concerned directly with what is taught and what is valued within our education systems. It can influence not only how we see ourselves, but also our social relations with others and how we see them (p. 307-308).

Assessment is often associated with a program or university's value as well as with ranking of institutions or programs. Any programmatic value resulting from an assessment in turn results in the ability "to legitimize and rationalize the unequal distribution of power and resources in society” (Leathwood, 2005, p. 310). The neoliberal forces discussed previously play into the equity issues surrounding assessment and evaluation. As the distribution of 
resources is frequently tied to the ranking of programs or universities, higher ranked programs may receive more resources, which leads to the vicious cycle that causes higher education to mirror social stratification. Those with more resources continue to get more resources, while those with less, continue to get less. This can clearly be seen in the ongoing lower public funding of historically black colleges and universities (Harper, Patton, \& Wooden, 2009) as well as of tribally controlled colleges and universities (McClellan, Fox, \& Lowe, 2005, p. 12). In many cases, this cycle also results in more assessment in order to obtain more resources and to be more competitive in the marketplace (Leathwood, 2005).

This competitive focus leads to efforts to avoid "dumbing down" the curriculum and to ensuring enrollment of top students. These efforts highlight "social class differentials in the student populations of different universities” (Leathwood, 2005, p. 314). Reeves (2017) states that such concerns are legitimate "because the best 'customers' for colleges are often those who are already at an advantage” (para. 15), again, mirroring the existing social stratification.

These issues also raise questions as to who determines what should be taught, and, again, what the purpose of higher education should be. Many feel that the neoliberal state has resulted in the commodification of higher education and state that the focus has shifted to competition and profit. (Apple, 2005). Leathwood further points out how evaluation and assessment academic standards set under this model frequently relate to the "values of the dominant classes" (2005, p. 315). This has been seen since the colonial era of education. Since that time, the education of oppressed groups has frequently been provided only for the purpose of transforming these groups into acting and thinking like Euro-Americans (McClellan, Fox, \& Lowe, 2005, p. 9). Standards set under the dominant class mindset, therefore, penalizes females and minority students. Apple (2005) echoes this sentiment by stating that "markets provide these things 
[education] in radically unequal ways" (p. 18). He goes on to state that this model "function[s] to increase the chances for mobility by middle-class children.... [but does not have this effect on] students of oppressed minorities” (p. 21). Further, most programmatic evaluation and assessment does not include any type of equity assessment. In a study they completed, Harper and Hurtado (2007) noted that "in every focus group on each of the five campuses, student participants (Whites and racial/ethnic minorities alike) indicated that it was the first time any institutional effort was made to inquire about the qualitative realities of their racialized experiences” (p. 19).

The current focus of assessment use for resources and competition raises concerns that there will be increasing calls for assessment, benchmarking, and standardization in higher education (Leathwood, 2005). Critiques of evaluation and assessment point to the use of quality improvement methods as a method of control and of the use of outcomes measures as prescriptive, focusing only on performance and not on learning. Leathwood (2005) states that such evaluation and assessment "add [to] an increasingly hierararchized society” (p. 320).

However, Apple (2005) provides a glimmer of hope in stating that evaluation and assessment can provide some positive results regarding equity if they require "public accountability - to ask universities to provide evidence that they are taking seriously their social responsibilities concerning hiring practices for example” (p. 23). Skrla, Scheurick, Garcia, \& Nolly (2004) further state that while the topic of evaluation and assessment and equity is extremely polarizing, it must be recognized that the relationships are "extremely complex, dynamic, ... and confusingly interactive with other policy initiatives” (p. 136). Skrla, Scheurick, Garcia, \& Nolly go on to state that methodologies including systemic equity and equity audits can make assessment and evaluation more meaningful and can help address equity concerns in 
this area. Maldonado, Rhoads, and Buenavista (2005) completed case studies demonstrating that student groups can play a role in assessment of programs and universities and can have positive effects on student retention, especially of underrepresented student populations, a metric that is frequently used in some evaluation and assessment models. Laden noted similar results among Hispanic students in Hispanic-serving institutions (2004, p. 192-193). In addition, Harper and Hurtado (2007) recommend “greater transparency regarding racial realities in learning environments at PWIs [Predominantly White Institutions]” (p. 19) as well as “attention to diversity in the curriculum and cocurriculum” (p. 20) for greater equity in programmatic evaluation and assessment.

It can be seen that there are obvious potential problems and biases in program evaluation and assessment. Therefore, any evaluation and assessment methodology and procedures must take these concerns into account. Awareness of these issues, as well as careful selection of evaluation assessment method and procedures can aid in the avoidance of such biases and in the completion of a meaningful evaluation and assessment process.

\section{History and Purpose of Program Assessment, Evaluation, and Review}

Historically, higher education has not been a regulated entity (Cohen \& Kisker, 2010, p. 64). Institutions have acted independently without government or other oversight. Government attempts to enter into the higher education arena have been quickly shut down (Cohen \& Kisker, 2010, p. 311-312). This historical background has led many in higher education to bristle at the concepts of assessment, evaluation, and review. While higher education is a much more evaluated and assessed entity than in the past, many still feel that such evaluations and assessments are meaningless and a threat to academic freedom (Judd and Keith, 2018). A review 
of the history and evolution of program evaluation in higher education can point to what is needed for meaningful and useful evaluation and assessment today.

\section{Colonial and Early United States Education}

Higher education in the United States was developed during the colonial era predominantly to produce learned people who could serve society. Universities provided prestige to their communities, enabled young men to be prepared as better citizens, and provided basic training in areas such as law, medicine, and commerce. Most of the early universities were founded by religious institutions and much of the focus was on teaching “discipline, morals, and character” (Cohen \& Kisker, 2010, p. 27). The universities operated independently without any national guidelines on admission, curriculum, or graduation requirements. This trend continued after the Revolutionary War and through the early growth of the nation. By the mid nineteenth century there were several hundred colleges and universities, however, there was still no oversight body for higher education. This lack of oversight encouraged the rapid growth in the number of colleges and universities. Attempts were made to develop a national university or national standards but these fell short. “Absent a national ministry of education, the principle of anything goes guided their development [new colleges and universities]” (Cohen \& Kisker, 2010, p. 27). This resulted in a large number of schools that were "exceedingly weak underfunded, too small to support a broad curriculum, too poor to pay their staff more than a subsistence wage, and in many cases, too marginal even to survive” (Cohen \& Kisker, 2010, p. 68-69).

\section{Rise of Professionalism and Education Reform}

During the mid-1800s an increased emphasis on professionalism combined with the poor standing of many colleges and universities led to early attempts at educational reform that 
included inserting some level of evaluation and standardization into schools. During the 1840s, Francis Wayland “introduced written examinations as a progressive method of evaluating merit" (Bledstein, 1976, p. 225) as well as an early grading system. Printed tests were also started in grade schools and high schools. "Horace Mann championed this approach and advised Boston to base school policies on factual results from testing the eldest class in each of the city's nineteen schools” (Stufflebeam \& Coryn, 2014, p. 31). These reforms, however, were not widely accepted at that time. It was not until after the Civil War that such reforms started to take root. Bledstein (1976) points to the further development of professions as the impetus for such reforms. As the level of professionalism increased and professional associations were founded, licensing, school standardization, and accreditation grew. Professionals such as librarians, social workers, dentists, architects, pharmacists, teachers, veterinarians, and accountants started founding schools with set standards. "By 1894, twenty-one states had established an examination system for medical doctors, and fourteen others permitted only graduates from accredited medical schools to practice” (Bledstein, 1976, p. 84). The development of professional schools and school standards carried over into other areas of higher education as well. By the end of the 1800s, a national accreditation movement was established with the goal of minimally required standards for schools and "The Association of American Universities was founded in 1900 for the avowed purpose of establishing a similar uniformity of standards at the level of the graduate school” (Veysey, 1965, p. 313).

Such movements, however, did not guarantee quality education. Throughout the late 1800s and early 1900s, there were continuous efforts at reviewing, improving and standardizing education. Barry (2004) provides an overview of the efforts to improve the poor quality of medical education in the early 1900s. He outlines the work of Simon Flexner and Rufus Cole, 
two strong proponents of improvements in medical education. Historically, "no medical school in American allowed medical students to routinely either perform autopsies or see patients, and medical education often consisted of nothing more than two four-month terms of lectures” (Barry, 2004, p. 32). Based on the poor quality of medical education, these proponents, and others like them, enacted significant changes in medical schools, including setting standards, evaluating medical schools based on those standards, developing a school ranking system, and requiring patient research.

Other education reformers also contributed to increased emphasis on standards, evaluation, and accreditation. Pugh (1995) outlines William Rainey Harper's role in the early 1900s in the development of the "Association of American Universities, which promoted higher standards for the PhD. . . . [as well as] the North Central Association of Colleges and Secondary Schools, which promoted higher standards of college education” (p. 261).

\section{Accreditation}

The late 1800s and early 1900s saw the beginnings of concerted accreditation efforts and the development of accreditation associations. "The Northeast Association of Colleges and Secondary Schools dates from 1885. By 1909 the North Central Association had adopted explicit standards for the institutions in its region, and by 1924 associations were functioning in the other regions” (Cohen \& Kisker, 2010, p. 167). These associations set standards and evaluated schools' educational quality based on these standards. Schools who met the standards received accreditation. These accreditation associations were predominantly developed in order to provide value to the degree received by an individual (El-Khawas, 2001, p. 28). Based on the outcomes of accreditation evaluations, lists of accredited programs that met the association's standards were published, thus providing documentation of the quality of schools' educational 
programs. Specialty accreditation grew from the general accreditation movement. Professional associations "worked continually to establish standards for curriculum and for entrance and graduation requirements, as well as to persuade states that graduation from an accredited program should be a prerequisite for licensure in an occupation” (Cohen \& Kisker, 2010, p. 168). Specific program accreditation grew from the "concern with how well the colleges and universities were preparing their graduates” (El-Khawas, 2001, p. 32). Medical schools and law schools, as well as programs for nursing, teaching, architecture, and business started seeking accreditation to demonstrate the quality of education they provided (El-Khawas, 2001, p. 34).

Cohen and Kisker (2010) point out that it is important to note that this growth of independent accrediting associations demonstrates how higher education found ways to selfregulate as opposed to accepting attempts from the government for federal oversight. Higher educational institutions produced strong backlash to government attempts to enter the accreditation arena. "The U.S. Bureau of Education attempted to produce its own list of accredited institutions but withdrew from the process in 1911 because of reaction against what the institutions perceived as government interference” (Cohen \& Kisker, 2010, p. 168).

However, when federal monies entered the picture after World War II in the form of the G.I. Bill, questions again arose as to the government's role in assuring the quality of education at an institution. At that point "the federal government really did not want to get into the business of certifying colleges and schools... . [thus] the federal government agreed to accept as a proxy the institutional evaluations that colleges and universities themselves rendered as part of voluntary accreditation associations” (Thelin, 2004, p. 265). This decision created the on-going regional accreditation association model in which colleges and universities are required to be accredited every ten years if they accept federal funds. In 1952 the "U.S. Secretary of Education 
(then Commissioner of Education) publish[ed] a list of recognized accreditation associations” (ACICS, 2010). The number of accreditation associations thus continued to grow and by the late 1990s,

the process of accreditation has evolved so that it rests now on complex relationships between federal and state governments and the voluntary members of the various accrediting groups. This involved system includes six regional accrediting associations with eight higher education commissions within them, eight national associations, and around seventy-five specialized and programmatic accreditors. ... The regional associations accredit each institution as a whole. The national associations also accredit institutions but are more specialized, such as associations accrediting Bible colleges. Programmatic accrediting bodies have been established for numerous fields of study (Cohen \& Kisker, 2010, p. 386).

Currently, accreditation has become significantly more important in higher education. "The U.S. Department of Education reviews and determines which accrediting associations are acceptable and insists they employ specific criteria in their assessment of institutions” (Cohen \& Kisker, 2010, p. 521). Accrediting bodies set standards and evaluate institutions' or programs' compliance with those standards through self-studies and site visits. Accrediting bodies provide feedback reports to the program or institution, including positive as well as negative findings. The goal of accreditation is to provide a designation for an institution or program that indicates that a quality education is being provided (El-Khawas, 2001). While accreditation is required for higher education institutions receiving federal funds, specialty accreditation for individual academic programs is more closely aligned with specific occupations or professions for which 
licensure or credentialing is required. Frequently, graduation from an accredited program is required for such licensure or credentialing.

Accreditation provides an assurance of the quality of accredited higher education institutions. It aids in the transfer process as well since the receiving institution can accept accreditation as evidence of the quality of the transferring institution (Commission on Accreditation for Health Informatics and Information Management Education, 2017). In recent years accreditation associations have also made changes to keep up with educational evaluation reform and now purport to focus on student outcomes more than the physical and environmental factors that they assessed in the past. However, there are many opponents of the use of accreditation as an evaluation and assessment tool. Criticisms include "the tendency for uniform criteria to limit creativity and instead effect homogeneity” (Cohen \& Kisker, 2010, p. 387) as well as the forced comparison of dissimilar institutions. In addition, many feel that accreditation still focuses more on structure and process factors such as financial stability, environment, facilities, and leadership, as opposed to outcome measures such as student mastery of competencies or demonstrations of student learning. Godfrey and Finkelstein (2018) state that "in order for an educational program to be fully understood, its evaluation must include description in addition to judgment” (p. 491).

\section{Government Assessment of Higher Education}

While higher education institutions have managed to limit government involvement in accreditation, they have been unable to do so in the area of government assessment. In the 1980s, "pressure to justify budgets by measuring tangible contributions grew" (Cohen \& Kisker, 2010, p. 429). State budget planners began to demand reporting of measures of the quality of education they were funding. "By 1989 two-thirds of the states had programs mandating 
assessment that included incentives for compliance and penalties for failure to follow the directives” (Cohen \& Kisker, 2010, p. 430). Assessment mandates involved the reporting of a variety of metrics, including student retention rates, years to degree, graduation rates, student satisfaction, employer satisfaction, and other student outcomes. Higher education institutions were quite displeased that the government, once again, was attempting to enter the higher education arena. Cohen and Kisker (2010) summarize the complaints of opponents of assessment reporting. "Analysts insisted that a college could not be measured in terms of outcomes, impacts, or tangible benefits because of the nature of learning and the human experience” (p. 432). However, the authors point out that in order to receive state funding, most institutions had to accept such reporting and comply. Godfrey and Finkelstein (2018) agree that educational programs cannot be truly evaluated based on outcome measures alone; true program evaluation can only occur when a full picture of the program can be seen (p. 491). Judith S. Eaton, president of the Council for Higher Education Accreditation takes this thought one step further. In an interview for The Chronicle of Higher Education she states that such requirements "might be based on more consumer-friendly information, such as graduation rates, job placement, and salaries, ... but ... [do not] necessarily deal with core issues of academic quality that employers are also concerned about, such as critical-thinking skills” (Kelderman, 2013, para. 7).

In recent years, the government's desire for assessment reporting has turned to a desire for accountability. In this setting, accountability "refers to the responsibility of system administrators to provide reports of their stewardship of public funds, to show the relationship between expenditures and results” (Cohen \& Kisker, 2010, p. 544). In 2013, President Obama issued a document entitled, “The President’s Plan for a Strong Middle Class and a Strong 
America” which included a section entitled, "Holding colleges accountable for cost, value and quality” (p. 5). This section outlined additional measures to be built into the accreditation system and suggestions for alternative accreditation systems to insure that "colleges ... receive federal student aid based on performance and results” (Obama, 2013, p. 5). This desire for accountability has led to attempts at performance-based funding for higher education; providing higher funding for institutions with higher performance scores. While this concept has been tried in many states, it has yet to be successful due to difficulties in administration and lack of improvements in outcomes.

Performance indicators are also a recent development in the government's assessment of higher education. "In 1994 one-third of state legislatures or coordinating boards had mandated or strongly urged the use of performance indicators” (Cohen \& Kisker, 2010, p. 550). Such data, designed to evaluate efficiency and effectiveness, include measures such as "numbers of degrees awarded, graduates’ performance on licensure exams, and student loan default rates” (Cohen \& Kisker, 2010, p. 550). States have required the reporting of such data to, again, attempt to judge the quality of what they are funding. National associations, such as the National Center for Education Statistics publish reports containing similar data, again, to encourage efficiency and effectiveness in higher education (St. John, Daun-Barnett, \& Moronski-Chapman, 2013, p. 121).

As discussed previously, opponents of such assessment reporting argue that such data and measures do not adequately assess or demonstrate institutional quality. The measures focus on very basic metrics and do not dig deeper into student outcomes or the causes of negative student outcomes. In addition, the reported data do not lend themselves to useful analysis resulting in true educational quality improvement. The measures may even encourage dishonest reporting, passing through of students, and other negative actions. 
The historical development of evaluation and assessment discussed thus far has focused on external agencies that have enforced accreditation or other assessment methods at the higher educational level. As stated above, many feel that such methods do not adequately assess higher education, do not consider true measures of quality, and result in findings and reports that are not widely used. These are the meaningless hoops that must be jumped through and the reports that end up on shelves. Judd and Keith (2018) state "external pressures to engage in SLO (student learning outcome) assessment have produced voluminous amounts of work by faculty and staff, but have not necessarily become part of the routine work of institutions” (p. 70). They state that while compliance is frequently the driver for external evaluations, the impetus behind evaluation and assessment should be use for improvement. "In the spirit of assessment is a culture of improvement, where the evidence collected is used to improve student learning” (Judd \& Keith, 2018, p. 70) and the standards to share values and make curricula (and instruction) more coherent.

\section{Internally-Driven Evaluation and Assessment Efforts}

As accreditation started growing in the early 1900s, internal evaluation and assessment efforts started to grow as well. "Tenure and promotion reviews, student evaluations, and peer reviews of research" (Cohen \& Kisker, 2010, p. 168) were started. Recognition of the need for evaluation and assessment as well as a desire to avoid government intervention was a driving force behind the internal evaluation and assessment movement.

One of the major proponents of early educational evaluation was Ralph W. Tyler. Starting in the 1930s, he worked to develop a strategy that was different from others. "What mainly distinguished his approach was its concentration on clearly stated objectives. In fact, he defined evaluation as determining whether objectives have been achieved” (Stufflebeam \& 
Coryn, 2014, p. 33). His focus on the desired student outcomes or behaviors was designed to drive curriculum development from a focus on the content to a focus on student learning (Tyler, 1949). This focus also affected test development and encouraged testing related to the desired objectives. His approach differed significantly from other approaches in the past. "The approach concentrates on direct measures of achievement, as opposed to indirect approaches that measure such inputs as quality of teaching, number of books in the library, extent of materials, and community involvement” (Stufflebeam \& Coryn, 2014, p. 33). Tyler’s focus on objectives and aligning curriculum and testing to these objectives, while not immediately adopted, still affects evaluation and assessment techniques today.

Another leader in educational evaluation was Lee Cronbach. "In looking at the evaluation efforts of the recent past [1960s], he sharply criticized the guiding conceptualizations of evaluation for their lack of relevance and utility” (Stufflebeam \& Coryn, 2014, p. 35). He stated that the focus of evaluation should not be competition but, instead, "gathering and reporting information that could help guide curriculum development” (Stufflebeam \& Coryn, 2014, p. 35).

The 1970s saw another jump in the level of interest in evaluation and assessment and in new evaluation and assessment models. A number of new approaches were developed with a focus on "the need to evaluate goals, look at inputs, examine implementation and delivery of services, and measure intended as well as unintended program outcomes” (Stufflebeam \& Coryn, 2014, p. 37). Robert Stake was a leading proponent of evaluation that went beyond a basic review of outcome measures. He felt that a deeper picture was needed to fully understand the program. This picture should be "focused on understanding program activities and communicating results to stakeholders in ways that fit their natural understanding” (Godfrey \& Finkelstein, 2018, p. 491). In addition, he stated that educators did not use the results of formal 
evaluation "due partly to the fact that most formal evaluations did not address the questions that the educators themselves were most interested in getting answered” (Godfrey \& Finkelstein, 2018, p. 491).

Also during the 1970s the field of education evaluation began to transition into a profession, higher education offerings in the discipline were implemented, and professional organizations were developed. An oversight body, The Joint Committee on Standards for Educational Evaluation, was developed and "issued standards for judging evaluations of educational programs, projects and materials” (Stufflebeam \& Coryn, 2014, p. 38). These standards have been updated twice and are now published as The Program Evaluation Standards. Other groups have also published standards for educational evaluation including the American Evaluation Association's (AEA's) Guiding Principles for Evaluators and the International Handbook of Educational Evaluation.

In the early 2000s, a movement took place directing educational evaluation towards evidence-based methods. These methods, similar to randomized controlled trials in medicine, are now frequently required for many evaluative studies, and, in particular, for those receiving federal funding (Stufflebeam \& Coryn, 2014, p. 39). There is a fair amount of argument about the use of such evaluative methods in higher education, however, based on the difficulty of ensuring the time and funding necessary for randomized study.

Also, in recent years, a concern about equity has led to the inclusion of equity audits or climate assessments in program evaluation and assessment. As noted earlier, such activities can be valuable in the evaluation and assessment process by making the evaluation more meaningful and by addressing equity concern (Skrla, Scheurick, Garcia, \& Nolly, 2004). 


\section{Purpose of Program Evaluation, Assessment, and Review}

It can be seen that there are varying purposes for evaluation and assessment. Historically, accreditation was developed to enable the assignment of value to a degree and to indicate a level of quality held by an educational institution or program. Government assessment efforts have been put into place to require a level of accountability related to funding for educational institutions or programs. However, most importantly, it is noted that evaluation and assessment can be used to improve student learning and outcomes through curriculum design and program methodology.

As stated previously, although there is much debate regarding the purpose of higher education, one goal is to provide for student growth and to prepare students to be successful in careers and in society. In higher education's quest to meet this goal, evaluation and assessment can be an invaluable tool. Tyler, one of the first experts to tie outcomes to objectives, states "it should be clear that evaluation then becomes a process for finding out how far the learning experiences as developed and organized are actually producing the desired results and the process of evaluation will involve identifying the strengths and weakness of the plans” (Tyler, 1949, p. 105). Tyler's efforts to tie objectives to outcomes to methodology resonate in the truest purpose of evaluation and assessment, that of using the results of such tools to implement curricular and other improvements and, therefore, to improve outcomes. The results of evaluation and assessment are thus to be used to evaluate the learning methods and curriculum and to implement needed improvements in order to fully meet the goal of student learning and student preparedness. Grayson (2018) points to the use of program evaluation as an important component in this process. "Professional program evaluation is to be methodologically systematic, addressing questions that provide information about the quality of a program in order 
to assist decision-making aimed at program improvement, development, or accountability and to contribute to a recognized level of value” (Grayson, 2018, p. 457). Without evaluation and assessment, program leaders must assume a level of quality provided by their educational program. Evaluation and assessment activities provide sound data that can be used to clearly see what outcomes the program is producing. "Assessment, to be useful, needs the collection of evidence that allows judgments to be made regarding the achievement of SLOs [student learning outcomes]” (Judd \& Keith, 2018, p. 75).

A higher education institution or program is driven by their mission, goals, and objectives.

The mission defines the institution's or program's stated purpose and the anticipated results (goals or outcomes) of the experience that occur during the program. What occurs during the program is what we refer to as the curriculum.... The activities that comprise the curriculum are driven by the outcomes - one should be able to discern an alignment between these activities, and the outcomes to which they are contributing (Judd \& Keith, 2018, p. 70).

This alignment, between the mission, curriculum, and outcomes is the key to an educational program (Judd \& Keith, 2018). Evaluation and assessment fits into this equation as the measure of alignment between these three components. For example, if an educational program has a mission that graduates will be adequately prepared to start in an entry level accounting position, the curriculum must provide activities that enable student learning of entry level accounting skills. Student learning outcomes, such as passing the Certified Public Accountant exam and performing entry level skills in an accounting firm close the loop and demonstrate that the curriculum allowed the program to meet their goals and mission. Evaluation and assessment of 
this process and of student outcomes allows for the discovery of areas in which the program is not meeting anticipated goals and objectives, or is not meeting them at the desired level. The program can then use these areas as the focus for changes and improvements. Curricular and programmatic changes can be made based on the identified, now known, areas needing improvement. Future evaluation and re-assessment can determine if the changes result in closer alignment with the desired outcomes. With the collection of data and information, evaluation and assessment provides evidence that mere supposition cannot provide. "When the evidence points to a weakness in the achievement of an outcome, it . . inform[s] the stakeholders where action can be taken to strengthen the outcome” (Judd and Keith, 2018, p. 75).

\section{Program Evaluation Methods in General}

Formal evaluation and assessment is key in improving educational programs.

“Traditionally, university functions are comprehensively assessed in informal ways. ... Informal ways are fallible” (Stake, Contreras, \& Arbesu, 2018, p. 44). In order to meaningfully evaluate and assess a program formal evaluation and assessment techniques are needed. Formal evaluation and assessment "reveals ... not only the quality of operations but their complexity" (Stake, Contreras, \& Arbesu, 2018, p 44). A formal evaluation and assessment can reveal findings from multiple sources that can be used to analyze that complexity. Results from evaluation and assessment can provide the opportunity for triangulation, which can "strengthen our confidence in our conclusions and recommendations” (Judd \& Keith, 2018, p. 77). Triangulation is the use of multiple data sources to enable confirmation of findings and adds to the "trustworthiness of our analysis” (Miles, Huberman, Saldana, 2014, p. 299). Evaluation and assessment can also use tools such as benchmarking to examine comparisons or trends over time, providing valuable data that can be used for improvement (Guthrie \& Seybert, 2018, p. 115). 
Formal evaluation and assessment provides the basis for true review of the alignment of a program's mission, goals, and outcomes, with resultant findings pointing to areas of misalignment that can be improved upon.

\section{Program Review in Health Information Management}

As outlined previously, program review, evaluation, and assessment are integral parts in insuring that an educational program meets their mission, goals, and outcomes, and adequately prepares students for their careers. As discussed, accreditation is one form of educational program evaluation and assessment. To this end, accreditation is a key component in education and credentialing in the Health Information Management profession. In fact, educational program accreditation is directly tied to their professional credentialing criteria. In order to be eligible to take the credentialing exams for the HIM profession (Registered Health Information Technologist (RHIT), Registered Health Information Administrator (RHIA)), an individual must have graduated from an accredited educational program. This accreditation is carried out by the Commission on Accreditation for Health Informatics and Information Management Education (CAHIIM). "CAHIIM is an independent accrediting organization whose Mission is to serve the public interest by establishing and enforcing quality Accreditation Standards for Health Informatics and Information Management (HIM) educational programs” (CAHIIM, 2017, para. 1).

Health Information educational program accreditation by CAHIIM is designed to insure quality of the educational program as well as to serve many of the functions discussed under accreditation previously, such as aiding in the transfer process and insuring that educational program curricula meet current professional needs. Graduates of such programs can also point to this accreditation in assuring employers or graduate schools that they received a quality health 
information education. The CAHIIM accreditation process is based on standards regarding the program's mission, goals, assessment, and outcomes; program director and faculty; program resources; and the educational program curriculum. In order to achieve accreditation, the educational program must meet and demonstrate compliance with the CAHIIM standards. These standards include ongoing improvement processes, a faculty development plan, up-to-date curriculum, entry level student learning outcomes, qualified faculty, and appropriate student resources. Programs must address these standards through completion of a self-study as well during a site visit by CAHIIM. HIM educational programs are required to select goals related to students and graduates as a part of their self-study, however, there are no required goals that must be met and there are no penalties for not meeting the selected goals. For example, a program may set a goal of an $85 \%$ passage rate on the RHIA exam, however, if only $75 \%$ of the students who take the exam pass, there is no penalty related to CAHIIM accreditation for the lower passage rate. CAHIIM's focus is on the general standards, not necessarily the individual program goals. Following the accreditation review, a program may be granted full accreditation (either initial or continuing), probationary accreditation, or have their accreditation withheld or withdrawn (CAHIIM, 2012).

While accreditation and ongoing review and improvement is required by CAHIIM and the American Health Information Management Association (AHIMA) for graduate eligibility for certification, there are no other required evaluation and assessment activities. HIM educational programs may undergo department or university specific evaluations and assessments or individual programs may take further steps in self-program review, evaluation, or assessment. A program, may, for example, use metrics such as RHIA exam pass rates as outcome measures and set their own goals and action plans related to these. However, there is no national requirement 
for specific evaluation and improvement activities. In addition, there is debate as to how effective metrics such as the RHIA exam pass rate are in an evaluation of a HIM educational program. As stated earlier, the RHIA exam content is not tied to the CAHIIM Curriculum Competencies and some graduates do not take the exam if it is not required by their job. Therefore, use of such metrics may or may not be valuable in the evaluation and assessment process. In addition, there is a dearth of literature on HIM program review and evaluation beyond the accreditation process. This evaluation is designed to help fill that gap in the literature and provide a guide for HIM educational program review, evaluation, and assessment. 


\section{CHAPTER III: METHODOLOGY}

\section{Purpose of the Study and Questions to be Answered}

Recent changes in the Health Information Management (HIM) environment have led to a significant change in the Commission on Accreditation for Health Informatics and Information Management Education (CAHIIM) required curriculum for HIM academic programs. The need for appropriately trained HIM professionals in the new electronic health care environment is necessary and HIM academic programs are adapting curricula to meet these changing needs. As these changes are implemented, evaluation of the success of the academic programs' changes will be required. To date, there have been no published evaluation studies on the effects of the changes on HIM academic programs. This study was designed to fill that gap by focusing on the evaluation of the changes in the HIM curriculum and program in one HIM 4 year baccalaureate academic program as well as to provide a methodology for program evaluation for the field as a whole. This evaluative study specifically assessed the ability of the changes to adequately prepare students for the current HIM field as well as the effects of the changes on the program as a whole. This study was evaluative yet also utilization-focused so that the results of this study could be used by stakeholders for ongoing improvement of the academic program. The questions that were answered by this study are as follows:

1. What is the nature of current students, graduates, and employer experiences related to Health Information Management (HIM) curriculum shifts from the 2012 Commission of Accreditation for Health Informatics and Information Management Education (CAHIIM) curriculum standards to the 2014 revision?

a. What are student perceptions regarding the curriculum changes and preparedness for the HIM field? 
b. What are graduate perceptions regarding the curriculum changes and preparedness for the HIM field?

c. What are employer perceptions regarding student preparedness for the HIM field for those students who have completed the new curriculum?

2. In what ways have the 2014 Commission of Accreditation for Health Informatics and Information Management Education (CAHIIM) curricular requirements shifted the entrylevel skills and knowledge of Health Information Management graduates in comparison to the 2012 curriculum standards?

3. Considering the on-going changes in the CAHIIM curriculum requirements, what are the implications for the Health Information Management field and for individual programs moving forward?

\section{Research Paradigm}

This was an evaluative study and involved an in-depth case study that contributed to a program review and assessment of a recently revised curriculum and the effectiveness of this revision in preparing students for the professional world. While there are a few objective measures of effectiveness that are used as program goals including student grades, student completion rates, and graduate RHIA examination pass rates, measures of effectiveness are primarily subjective. Student preparedness may mean one thing for one student, something different for a second student, and something else entirely for an employer. This study focused on measuring outcomes through the student, graduate, and employer perceptions of mastery of competencies and preparedness for the HIM field.

This study used the Utilization-Focused Evaluation (UFE) theoretical framework, and, thus, focused on use of the findings to make positive changes in the program. In conjunction with 
this, the study used the concept of Evaluation Capacity Building (ECB) to insure that the HIM faculty, department chair, and other stakeholders understood the evaluative process and were ready to use the results for positive change.

\section{Type of Study}

This was an evaluative study that focused on a program review and assessment of the recently revised curriculum in the HIM program at Illinois State University. This study was modeled after Patton's Utilization-Focused framework (Patton, 2012). Patton developed a theoretical framework that focuses on the use of evaluation information. Evaluation and assessment completed under his theoretical frame uses a "targeted group of stakeholders whom it empowers to determine the evaluation questions and information needs” (Stufflebeam \& Coryn, 2014, p. 215). In such evaluations, "the primary intended users of the evaluation” (Patton, 2012, p. 66) determine the evaluative criteria. The theory behind this high level of stakeholder involvement is that, by including the stakeholders in the design of the evaluation, the results will be more useful and more likely to be used. The purpose is to "give them [the stakeholders] the information they need to fulfill their objectives” (Stufflebeam \& Coryn, 2014, p. 215). This theoretical framework can be quite valuable in educational program improvement since "this approach is geared toward maximizing evaluation impacts [and] fits well with the key principle of change” (Stufflebeam \& Coryn, 2014, p. 218). The weaknesses of this theoretical frame include the possibility of stakeholder turnover, and the potential for stakeholders to "look for evidence to confirm [their] preconceptions and biases” (Patton, 2012, p. 25).

The personalized nature of utilization-focused evaluation can result in faster and more accepted changes and improvements. The "crucial point is that evaluators must determine and focus their studies on intended evaluation uses and produce and report findings that an identified 
group of intended users can and probably will value and apply to program improvement" (Stufflebeam \& Coryn, 2014, p. 404). The goal of this theoretical frame is to use the evaluation findings to improve educational programs, thus resulting in improved programmatic outcomes and student learning. It was felt that this was an appropriate framework for this evaluative study as this program review and assessment was meant to not only evaluate the student, graduate, and employer perceptions of the new curriculum but also aid in the identification of potential improvements that ISU's HIM program could take to best prepare students for the HIM field.

This evaluative study was designed to go beyond the mere collection of metrics to truly evaluate the effectiveness of the revised curriculum in meeting the program's goals and desired student learning outcomes. While HIM programs undergo accreditation and, possibly, other types of internal program review, those program evaluations frequently focus on structure and process and do not focus on outcomes, such as student learning and preparedness for the field. This study provided an in-depth evaluation that included perceptions of the students, recent graduates, and employers on the effectiveness of the revised curriculum in adequately preparing students for the HIM field. While quantitative measures were also used, such as enrollment, retention, new curriculum transfer rates, and RHIA exam pass rates, this study focused on evaluating the effectiveness of the curricular changes based on the perceptions of students, graduates, and employers. Effectiveness in adequately preparing students cannot be measured by grades alone. While a particular student may receive good grades on assignments in classes, they may not be adequately prepared to function in the workforce. Therefore, this study delved into the review of the HIM program through a utilization-focused evaluative methodology designed to determine the students' readiness for the professional world based on their education in the program as a whole. 
The program was well-prepared for an evaluative study. The faculty and department chair had been involved in the planning process since the revised CAHIIM Curriculum requirements were released. The faculty undertook a gap analysis of the existing curriculum to determine the need for changes in the curriculum. The faculty collaboratively worked to implement the changes in the curriculum, including changes in courses, addition of new courses, and deletion of other courses. Finally, the faculty, department chair, and students had been involved in on-going informal discussions of the curriculum change and the status of the HIM program.

\section{Data Collection}

This evaluative research used an in-depth case study of one HIM academic program, a method proposed by Patton. Patton outlines the advantages of in-depth case studies as a method that enables a "holistic understanding" (2012, p. 250) of the program under review. In addition, an in-depth case study can be seen to be a "rigorous alternative to randomized experiments" (Patton, 2012, p. 301). Thus, an in-depth case study was felt to be appropriate for this evaluative study. A variety of methods were used to collect data for this study including surveys and interviews, as well as review of a variety of documents and metrics, including enrollment rates, retention rates, new curriculum transfer rates, and RHIA exam pass rates. Also, through use of these multiple methods of data collection, evaluation capacity could be built as stakeholders became involved and aware of the data collection process and data collected.

In order to assess students', recent graduates', and employers' perceptions of the success of the revised HIM program in preparing students for the HIM workforce, surveys were administered to each of these groups. These surveys were developed by the researcher and were administered electronically to each group through the use of Qualtrics. The surveys were pilot tested by the HIM faculty for validity and reliability. Following the pilot-test, modifications 
were made. These surveys were used to enable the collection of basic data regarding the students', graduates', and employers’ perceptions of the HIM program (Appendix C).

In addition, in order to gather more in-depth data, interviews were held with targeted employers who hosted the most professional practice students or who hired the most new graduates from ISU's HIM program. These interviews were developed by the researcher as well and the interview protocols were reviewed by the HIM faculty for validity and reliability. Again, modifications were made following this review. The interviews were held at a time convenient to each employer and were conducted face-to-face or by phone. The interviews were conducted by the researcher and were recorded and transcribed by the researcher. The interviews were approximately 45-60 minutes in length. The employer interviews allowed for the collection of more in-depth data regarding the employers' experiences with ISU HIM students and graduates and their perceptions of the ISU HIM program (Appendix C).

Focus groups of students were also held in order to obtain more in-depth data from the ISU HIM students regarding their perceptions of the HIM program. These two focus groups included a group of students following the new IT curriculum, and a group of students following the traditional curriculum. There were 5 students in each group. The ISU Department of Health Sciences academic advisor facilitated these focus groups. It was felt that using an outside facilitator enabled a more open discussion among the students, especially based on the researcher's positionality as faculty in the HIM program. The focus groups were guided by basic questions designed to start discussion. These questions were developed by the researcher and reviewed by the HIM faculty (Appendix C). Again, following the review, appropriate changes were made. The focus groups were held in a location that was convenient to the HIM students, a conference room in the building in which their classes were held. 
Documents displaying program metrics, such as enrollment trends, retention rates, time to graduation, and new curriculum transfers, were also used for review of student and potential student actions related to the specific changes. Exam pass rates for the RHIA were analyzed as a measure of student preparedness. The internal program review report was also reviewed for findings and recommendations related to the curricular changes and student preparedness. Through the review of multiple types of data, including these documents as well as the surveys, interviews, and focus groups, triangulation could be used to determine answers to the evaluative

study questions and to assess the effect of the curricular and programmatic changes in adequately preparing HIM program graduates. Triangulation is the use of multiple data sources to enable confirmation of findings and adds to the "trustworthiness of our analysis" (Miles, Huberman, Saldana, 2014, p. 299).

\section{Participants}

All participants in this evaluative research were affiliated with Illinois State University. All final year HIM seniors (17) were surveyed during their fall semester. This survey was implemented electronically using Qualtrics. Students who electronically consented to participate in the study were given access to the survey questions. The first question on this senior survey was a question designed to determine which sequence the student completed. This allowed for identification of those students on the new versus old curriculum. Other questions were aimed at gathering information regarding the students' perceptions of the HIM curriculum, program, and student preparedness.

All final year HIM senior students (17) were invited to participate in the appropriate focus group, either IT sequence students, or traditional sequence students. The focus groups were held at a location convenient to the students and were facilitated by the Department of 
Health Sciences academic advisor. Discussion in the focus groups was aimed to gather more indepth data about the students’ perceptions of the ISU HIM program.

All graduates (21 from the 2018 cohort and 25 from the 2017 cohort) were sent a survey, six months (2018 cohort) or one year (2017 cohort) after graduation, again electronically using Qualtrics. Graduates who consented to participate in the study were given access to the survey questions. These included questions regarding the perceptions graduates had of their preparedness for the HIM workforce at the time of graduation as well as the question related to which curriculum sequence the graduate completed. It was expected that the perceptions of graduates might differ from the students' perceptions since the graduates had the potential of six months to one year of work experience and were able to reflect on this issue with that experience in mind.

All employers who hosted a junior or senior professional practice student (37) were surveyed as well. This included hospitals and other healthcare related employers throughout Illinois. This survey was sent electronically to the HIM director or individual who oversaw the professional practice. Employers who consented to participate in the study were given access to the survey questions which included inquiries about the employers' perceptions of student and new graduate preparedness for the workforce based on the newly revised curriculum. Targeted employers (5) were selected for interviews. These employers were selected based on the number of professional practice students they had hosted and/or the number of new graduates they had hired from the HIM program at ISU. The five employers who hosted the most professional practice students were selected for interviews. The interviews included more in-depth questions regarding the employers' perceptions. These employers provided valuable information in this 
regard since most of these employers not only provided professional practice opportunities for ISU students, but they also hired many ISU graduates.

\section{Data Analysis}

The constant comparative method outlined by Glaser (1965) was used for analysis of the data collected in this study. As each interview was audio recorded, the first step in data analysis was a word-for-word transcript of the interview. The interview transcripts, focus group summaries, and survey open ended question responses were then coded to identify themes. General categories were identified through this coding. Initially broad categories were identified, followed by identification of specific details within the broad categories. As further data were analyzed and coded they were "compare(d) ... with the previous incidents coded in the same category" (Glaser, 1965, p. 439). Strauss and Corbin (1998) note that "categories have conceptual power because they are able to pull together around them other groups of concepts or subcategories” (p. 65). Categorizing provides the ability to organize large amounts of data into manageable pieces that can be analyzed (Coffey \& Atkinson, 1996). Eventually, this results in themes that can be identified and analyzed. Glaser (1965) outlines analysis of the categories and themes as follows: After all data were analyzed, categories and themes were integrated to provide a more in-depth understanding of the inter-relationships between categories and themes. The integration of categories and themes allowed for the delimitation of categories and the development of a more fine-tuned and cohesive group of categories and themes. At this point, no new categories were developed and, in fact, categories might have been combined or eliminated based on similarities or consistent themes. This allowed for a greater analysis and understanding of the remaining, focused, categories and themes. Finally, the coded data and themes were used to summarize the data and the over-arching themes found in the data. The 
constant comparative model allowed for a thorough, organized approach to understanding the data collected through the various methodologies used in this evaluative study.

Program metrics, exam pass rates, and closed-ended survey questions were analyzed using basic descriptive statistics, such as means, modes, standard deviations, and frequencies, to determine trends and variations related to the implementation of the new curriculum. These data were tied into the constant comparative analysis through triangulation to gain a deeper picture of the effectiveness of the new curriculum in meeting the program's goals and desired outcomes. These metrics were used to evaluate basic program outcomes and trends over time as well as compared with and combined with qualitative data to further evaluate relationships between the groups’ perceptions and quantitative outcomes.

\section{Validity/Trustworthiness}

In order to increase validity and trustworthiness of this evaluative study several strategies were used. The first of these is triangulation. Glesne (2006), defines triangulation as the "use of multiple data-collection methods, multiple sources, multiple investigators, and/or multiple theoretical perspectives” (p. 37). This study used multiple data-collection methods, such as interviews and surveys from multiple sources, such as students, graduates, and employers. By interviewing and surveying students in the HIM program as well as graduates and employers, the data collected were able to be compared and contrasted through triangulation for data verification and for identification of all pertinent themes.

Another strategy that was used to insure validity and trustworthiness was prolonged engagement and persistent observation. Lincoln and Guba (1985) define prolonged engagement as “the investment of sufficient time to achieve certain purposes: learning the 'culture', testing for misinformation introduced by distortions either of the self or of the respondents, and building 
trust” (p. 301). They further define persistent observation as "maintaining long-term, in-depth contact in relation to salient features” (Lincoln \& Guba, 1985, p. 109). As I had been involved with the curriculum change process since its inception I had spent a great deal of time working with the CAHIIM requirements, implementing curriculum change, and hearing initial feedback. Also, by working in the involved program I had "develop(ed) trust, (and) learne(ed) the culture" (Glesne, 2006, p. 37). As a professional in the HIM field, I had a great understanding of the professional needs of graduates within the HIM realm. These experiences provided me with a deep understanding of the culture of the HIM academic program as well as the HIM field and aided in my understanding and analysis of the data collected.

In order to improve validity and reliability, all surveys and interview protocols were pilot tested or reviewed by HIM faculty. In addition, my familiarity with the HIM field and the ISU HIM program improved the validity and reliability of the qualitative data collection. Miles, Huberman, \& Saldana (2014) state that “issues of instrument validity and reliability ride largely on the skills of the researcher. . (and) some markers of a good qualitative researcher-asinstrument are good familiarity with the phenomenon and the setting under study” (p. 42).

However, my close involvement with the program as well as the HIM field could raise concerns regarding researcher bias. I am well aware of the potential role that my subjectivity could have played in this study. By exploring others' perceptions through multiple data collection methods and multiple data sources I was able to use triangulation (Glesne, 2006) and the constant comparative method (Glaser, 1965) to limit my subjectivity and increase trustworthiness of the review of the data collected. Not only did I use pilot testing for all surveys and interviews to reduce any implicit bias in these instruments as outlined above, I further enlisted the input of the other HIM program faculty in the review and development of themes 
and theories to increase the trustworthiness of the analysis of my findings. Also, the Department of Health Sciences academic advisor conducted the focus groups which increased trustworthiness at this level. As stated previously, the advantage to my close involvement in this program is that the results are more likely to be used for quality improvement in the program.

Many of these methods to increase trustworthiness also fed into the ECB focus as well. With the involvement of stakeholders there were others involved in the evaluation and analysis of the evaluative findings. This increased trustworthiness and increased the ECB in the program and the potential use of the data findings.

\section{Consideration of Ethical Issues}

All participants were asked to consent to participate in this study. Interviewees were asked to sign a consent form and participants who were surveyed indicated consent by clicking "next” before starting the additional portion of the survey. (Appendix B)

Participants who were interviewed were able to choose a private, comfortable area for the interview. Participants who participated in focus groups met in a convenient and familiar location, a conference room in the building in which their major classes are held. Pseudonyms were used for all interviews and focus groups and no identifying information was included in the dissertation or any written publications or oral presentations.

All surveys were completed anonymously and no attempts were made to discover identification of respondents' servers or computers. Students were assured that there was no extra credit or penalty for completing or not completing the survey.

While participants were told that this study would not benefit them directly, it is expected that all participants will receive some benefit at some point in the future. By using the study results to make improvements in ISU's HIM program, employers, including future employers 
(students and new graduates) will benefit through the provision of better prepared ISU graduates and new professionals. The HIM community in Illinois is very close-knit so all will benefit from improvements in the ISU program. Many ISU graduates become managers and directors in health care facilities in the area, so students and graduates will benefit from ongoing improvement in the HIM program at ISU and in the assurance that ISU students will graduate with the most up-to-date knowledge and skills needed in the HIM environment.

Institutional Review Board (IRB) approval was obtained through the Illinois State University IRB. An IRB protocol was submitted following approval of the study proposal and no study activities took place until IRB approval was received.

\section{Implications/Significance/Contributions}

This study provided knowledge regarding the effectiveness of the curricular change in the ISU HIM program in preparing students as HIM professionals. As the curricular changes were based on the national required CAHIIM competencies, HIM academic programs across the country may benefit from this new-found knowledge. By sharing the results of this evaluation, other programs will have further information about the effectiveness of these CAHIIM competencies in preparing students for the workplace, as well as knowledge as to how their own HIM curricula can be evaluated and improved through the use UFE and ECB. As the CAHIIM curricular changes are recent, there has been no evaluative research in this area so this study was one of the first to provide such information. This study also provides a guide for other studies for appropriate methodology for HIM program review and evaluation.

In addition to providing information to HIM academic programs, the results of this study can be used to inform CAHIIM of the effectiveness or lack of effectiveness of the curricular changes. This information can be used by CAHIIM to influence future curricular changes or for 
fine-tuning existing curriculum. Finally, as these curricular changes tie directly to changes in the HIM field, the results of this study can also be used by professionals in the field and employers to determine the skills and knowledge set they should expect to see in new HIM graduates. Ongoing ECB and UFE in this program as well as others will help to inform programs, CAHIIM, and the profession of student learning outcomes, appropriate preparedness of students, and need for improvement.

\section{Conclusion}

This evaluative research study reviewed the HIM program at ISU and evaluated the effectiveness, or lack thereof, of the recent significant curriculum change. This evaluative study was designed to gather student, graduate, and employer perceptions regarding student preparedness for the workforce based on these curricular changes. Interviews and surveys were used to collect data from current students, recent graduates, and employers affiliated with ISU. Documents were used to provide further data related to the curriculum change and its effect on the HIM program. Data from these sources was coded and analyzed using the constant comparative method outlined by Glaser (1965). This enabled the identification of all pertinent themes. The variety of data collection methods and sources enabled the use of triangulation as well as statistical data analysis which provided research validity. While I am a member of the faculty of the program under study and am aware of the concerns for researcher bias, I provided reflection as to the potential role that my subjectivity could have played in this study. However, I have also stated that an advantage of my close association with the program under review is that the study results are more likely to be used for true quality improvement in the ISU HIM program. 
The results of this study are important in the current HIM academic environment. As the curricular changes were only recently implemented, a formal evaluation of the success of these changes was both merited and necessary for the ongoing improvement in HIM academic programs nation-wide. 


\section{CHAPTER IV: DATA ANALYSIS AND FINDINGS}

The recent changes in the Health Information Management (HIM) field related to the adoption of Electronic Health Records (EHRs) have led to a significant change in the Commission on Accreditation for Health Informatics and Information Management Education (CAHIIM) required curriculum for HIM academic programs. New HIM professionals need skills in managing the electronic health record systems as well as the data available through such systems. This has led HIM academic programs to adapt their curricula to meet these changing needs and the CAHIIM requirements. As these changes are implemented, evaluation of the success of the academic programs' success in preparing students appropriately is required. This study was designed to focus on the evaluation of the changes in the HIM curriculum and program in one HIM 4 year baccalaureate academic program as well as to provide a methodology for program evaluation for the field as a whole. This evaluative study specifically assessed the ability of the changes to adequately prepare students for the current HIM field as well as the effects of the changes on the program as a whole. Data were gathered from ISU HIM students, graduates, and employers in order to obtain in depth information about the perceptions of each of these groups on the recent curriculum change, the ISU HIM program in general, and the preparedness of graduates for the HIM field. In addition, HIM program metrics were reviewed for additional data regarding trends in the HIM program related to the curriculum change. These data were analyzed for each group and then summarized into overarching themes that could be used for improvement and other activities in the HIM program.

\section{Students}

Current senior ISU HIM students were surveyed and student focus groups were held with select students to obtain information about their perceptions of the curriculum change and their 
feelings of preparedness for the HIM field. The survey was developed by the researcher and was pilot tested by the HIM faculty for validity and reliability. The pilot test included review of the survey questions by the HIM faculty followed by discussion of the questions and the ability of the questions to elicit information of use to the program assessment. The survey was administered electronically to 17 students. The response rate for the survey was 14/17 (82\%). The students who responded to the survey were representative of the student cohort with 4/6 (67\%) of the students in the new curriculum responding and 10/11 (91\%) of the students in the old curriculum responding. It should be noted that all students were aware of basic aspects of both curriculum sequences as these concepts were discussed in classes as well as between peers.

In addition to the student survey, two student focus groups were held. These two groups were based on the curriculum the students were completing, either the old or new curriculum. All senior students were invited to participate in the appropriate student focus group. These groups were designed to delve deeper into the perceptions the students had regarding their experiences with the ISU HIM program. These focus groups were led by the ISU Health Sciences Department academic advisor and were completed using a semi-structured focus group process. The focus group protocol was developed by the researcher and reviewed by ISU HIM faculty for validity and reliability. Prior to the focus groups, the researcher reviewed the focus group protocol as well as the study research questions with the advisor. The focus groups were 30-45 minutes in length, were tape recorded, and allowed for more specific discussions of the students' perceptions of the changes in the ISU HIM curriculum, their experiences in the HIM program, and the feelings of preparedness for the HIM field. Five students voluntarily participated in each of the two focus groups. A word-for-word transcript of each focus group was prepared following the completion of each group meeting. 
The constant comparative method (Glaser, 1965) was used to analyze both the survey results and the interviews. The survey results were first reviewed and broad general categories were identified. These included: HIM careers students were planning to pursue, satisfaction with the specific curriculum sequence under completion, areas of the curriculum that would be helpful to student career goals, and student perceptions of preparedness for the HIM field. Subsequently, the results were further analyzed and details were identified within each broad category. Within each of these categories responses were summarized into 5-6 specific areas. At this point it was clear that themes were emerging. The focus group transcripts were also analyzed using the constant comparative method. At first broad categories were identified: why students chose the curriculum sequence they selected (if they were given the option), challenges with their curriculum, career goals, curriculum satisfaction related to career goals, areas in which the curriculum was lacking, and overall perceptions of ISU's HIM program. Again, the results were further analyzed and 5-6 specific areas were identified within each of the broad categories. Similar themes were identified as those seen in the survey analysis. Therefore, after these initial steps, the survey results and the focus group transcripts were further analyzed and coded together so that broad themes and categories were identified based on the results of both the surveys and the interviews. Further analysis resulted in fine-tuning of these themes and categories until no new categories were identified. Categories were then combined or eliminated based on consistent themes and similarities. This allowed for a final group of four focused categories and themes that could be used to summarize the data and the over-arching themes found in the data. These four main themes included the relationship between curriculum under completion, career goals, and satisfaction with curriculum under completion; concern about the rigor of the IT sequence, especially related to programming classes; concern about the elimination of some of the old 
curriculum classes in management; and satisfaction with the fact that the major is a small major with significant personal attention.

\section{Relationship Between Curriculum Under Completion, Career Goals, and Satisfaction}

The information obtained in the survey and the focus groups pointed to somewhat significant differences between the students in the two curriculum sequences. The students' interests, career goals, and satisfaction aligned closely with the curriculum sequence they were completing. This was foremost reflected in why, if given the choice, the students selected the curriculum they were completing. Most of the students who participated in the focus groups stated that they had a choice as to which curriculum they could follow. The students who chose the new IT-focused curriculum made statements such as, "I chose [IT] because I knew it was the future" or "I would say all the IT security stuff is going to be big.” It should also be noted that all 5 new curriculum students who participated in the focus group were pursuing a minor in IT as well as a major in HIM. Many of the students who chose the old management-focused curriculum stated that they chose that curriculum because they were "not tech savvy" or they felt, “I’m not really good with computers so I think the management track would help me more than the IT track.” One old curriculum student stated, “I couldn’t see me doing something more IT, I'd rather have a management position so I thought that was a better choice for me.” It should, however, be noted that students who did not have a choice in the curriculum they were completing also had similar comments reflecting positive perceptions of the curriculum they were following.

The students' career goals fell in line in a similar vein. While some of the students in the new IT-focused curriculum were interested in traditional HIM jobs such as coding, they expressed more interest in IT and data analytics focused positions, such as health informatics, 
quality management, and compliance. The students in the old management-focused curriculum were interested in the more traditional HIM career paths such as coding and management. These thought processes were clearly reflected in student satisfaction with the program as well as the curriculum. With this in mind, the two groups were further analyzed in greater detail.

\section{New IT-focused curriculum students.}

Of the IT students responding to the survey, $4 / 4$ (100\%) stated that they were satisfied with the curriculum they were completing. When asked which courses they felt would be most helpful to their careers, most of the new curriculum students mentioned IT classes such as IT security, systems development, and project management. A number of the students also mentioned the medical coding courses and the Introduction to Health Information Management course. When asked which courses would be the least helpful to their careers, all of the new curriculum survey respondents stated that the IT programming classes were the least helpful. These students also stated that they had gained other skills through the curriculum such as time management, communication, and professionalism.

The new curriculum students did see some areas in which their curriculum was lacking. Students stated that they felt a disconnect between the HIM and IT classes. "I’m doing my IT

classes and I'm doing my HIM classes, they're not really overlapping and showing where they interconnect.” The students also stated that they felt they were missing some content that was taught in the old curriculum but not in the new curriculum, such as flow charting or basic management concepts. Students also mentioned that they felt the teachers spoke more to the management side of the profession as opposed to the "new" IT side in terms of jobs and opportunities. "They talk about the new curriculum bridging the gap between IT and HIM but we haven’t really seen what those jobs are for the skills that we have moving forward.” The 
students also stated that they felt that the since the IT curriculum was new, HIM classes were still taught from more of a management angle than an IT angle. One student provided an example of a concept that was covered extensively in one of the IT courses and then was repeated very simplistically in an HIM class.

When asked about the challenges the students faced in this curriculum, the overwhelming response was time management. The students also stated that they felt that the time required for some of the IT courses pulled them away from work on the HIM courses. Another challenge cited by the new curriculum students was a feeling of unacceptance in the IT courses. One student stated, “I have also found in my IT classes that the faculty don't know that we are HIM students and they expect that we already know certain things or have taken stuff.” This feeling was expressed about entry level courses as well as the senior level IT courses. The students stated that in the senior level courses, other students "have already had IT internships. That gives them a little bit more hands on knowledge and sometimes I feel a little bit more behind on what they're teaching.” Female students also commented on the gender divide that exists in the IT classes and how this differs from the HIM classes. "We're pretty much the only girls in our classes. It's different from HIM where there’s only 3 guys.” The new curriculum students stated that they felt the curriculum was beneficial. The new curriculum students all also stated that they felt that they were prepared or highly prepared for a career in HIM. "If you can get through it [IT courses] that shows you have skills for HIM.”

\section{Old Management-focused curriculum students.}

The old curriculum students who responded to the student survey all expressed that they were satisfied or highly satisfied with their curriculum. The old curriculum students stated that they felt the curriculum they were following was providing them with the skills they would need 
in the HIM field. They also mentioned that they appreciated the applied aspect of the curriculum. "It's a lot more preparation for the types of jobs that we can get than I feel like a lot of other majors are.” Many focus group participants commented on the fact that their curriculum is business based which is what they wanted or expected. When asked which courses they felt would be the most helpful to their careers, the students most commonly mentioned medical coding, pathophysiology, law, trends in healthcare, and healthcare quality. When asked which courses would be the least helpful to their careers, many stated that all courses were helpful while others mentioned trends in healthcare or medical coding.

When asked if they felt that there were any areas that were lacking in their curriculum, some old curriculum students stated that they felt nothing was lacking. There was a discussion in the old curriculum focus group involving the lack of IT knowledge but none of the students stated that they felt that the lack of these skills would affect their job prospects. One student stated, "I definitely believe that this program will prepare us for when we leave and graduate and get into the job market. 100\% believe that I will be prepared.” Another student stated, "I feel like if I still want to do IT I could still do that because I still have some of that.” Another stated, "The only IT part I ever saw [on professional practice] was my manager/boss making graphs, like typing things into Excel.” They also stated that they felt that they had business and management skills that the new curriculum students would not have. The students also tied this into their career goals and their areas of interest, which focused on management and business.

When asked about the challenges the students faced in the old curriculum, most focus group participants stated that medical coding was one of the biggest challenges. They stated that much of the challenge of this part of the curriculum was the amount of time that these classes required. This resulted in time management also being a significant challenge. In conjunction 
with this, the students stated that there were high expectations and a significant amount of work that was assigned at any given time. The students, however, did state that they had gained good time management skills due to these issues. "I feel like we all have really good time management skills but just trying to find the time to do everything in a week, like social life, exams coming up, coding cases we have to do - it's a lot.” The old curriculum students did state that they found their curriculum beneficial and all of the old curriculum survey respondents stated that they felt prepared or highly prepared for their career in HIM.

Overall, both groups of students expressed satisfaction with the ISU HIM program and their experience with the program and curriculum. One student stated, "I would say, in general, in the major, you can learn a lot of really good skills and knowledge that can take you in many different paths.... It's a really great major if you want to work in healthcare without working as

a nurse or doctor." Another agreed, "Without having to do hands on with health, but [if you are] interested in the field, this is a really good program for that."

\section{Concern About the Rigor of the IT Sequence}

Concerns and issues regarding the IT sequence arose from both curriculum groups. The new curriculum group expressed concern over the rigor of the IT sequence with one student summing it up, “I think it’s a little bit harder with the IT classes, having no background in IT is difficult.” At the point in the curriculum transition that the focus groups were held, the students in the new curriculum were all transfer students and, thus, had taken the pre-requisite IT courses at the same time as their first HIM courses. Many expressed that this made their course workload heavier than that of the old curriculum students. "We feel like we have more work on our plate than the other students especially the first two semesters. We were all struggling more than the other students.” The students in the new curriculum focus group stated overwhelmingly 
that the time required for the pre-requisite IT courses, IT 168 and IT 178, required great time management skills and pulled them away from time spent on HIM classes. However, they stated that this was more of an issue with those two early classes and that the situation resolved somewhat after IT 168 and 178 were completed.

Discussion in the new curriculum focus group included some concerns about the IT programming course requirements, IT 168 and IT 178. While student respondents stated in the survey that they felt that these classes were the least helpful to their career and some students in the focus group questioned their value, most students in the focus group stated that they felt these classes were beneficial and helped in subsequent IT courses. One student stated these classes are beneficial, "when you have to build the programs from the ground level up to actually know how the computer works and why it works the way it does.” Another student stated that the "IT coding [programming] helps too as it makes you more valuable; it helps with problem solving." Students did express a feeling of accomplishment after completing these two courses, "When you're done with those two classes, it's really rewarding.”

The new curriculum students stated that the first two IT courses, IT 168 and 178, were not what they expected and expressed concern that, "they may scare a few people away." Students recommended that the program require a pre-requisite class before IT 168 that would aid in preparing students for the harder work in IT 168. Students also encouraged the recommendation that incoming students take IT 168 and 178 earlier in their course sequence so those classes are completed before the student starts in the HIM major courses. Finally, students expressed appreciation for the fact that the HIM program had hired an IT tutor to work with the HIM students who were taking IT 168 or IT 178, “Having an IT tutor was very helpful.” 
Students in the old curriculum also expressed some concerns about the new IT-focused curriculum. As stated previously, many of these students stated they did not want to work in an IT focused job or felt that they were not "good with computers." The old curriculum students expressed a fair amount of concern regarding the change to the new curriculum and the effect this would have on ISU's HIM program. One student stated, “I feel like it [the new curriculum] will make our major smaller because a lot of people don’t want IT.” Another stated, “I hope that this major doesn’t become integrated into the IT program. Like is it going to one day become IT based and not healthcare based? We'll see. I hope it becomes more healthcare.” To this end, the old curriculum students questioned whether there was a way to integrate 1-2 IT courses into the curriculum and meet the accreditation requirements without having such a strong focus on IT.

\section{Concern About the Elimination of Management Classes}

The old curriculum students expressed a fair amount of concern about the elimination of the management classes. One student stated, “It make me kind of sad that they're not having the management anymore.” The students stated that ideally it would be nice if the program was able to offer two sequences, an IT sequence and a management sequence. One student stated, "I just feel like with the IT, I wouldn't benefit like looking at a computer because I'm more interested in business and what the old curriculum has to offer.” Another stated, “A lot of people don't want IT so having that option for IT or the management would be really beneficial.” One student summed it up stating, "I really think it depends on what you want to do.” Students also expressed concerns that even with IT skills, graduates would still need some of the skills in the management curriculum, "if any IT person wanted a management role.” 


\section{Satisfaction with Small Class Size and Individualized Attention}

Many students in both curriculum sequences commented on their satisfaction regarding the fact that ISU's HIM program is a small program which enables them to develop close working relationships with their professors and peers. One student stated, "I also appreciate how we have smaller classes and teachers we get to know on a deeper level.” The students pointed out that this is one thing that really sets ISU's HIM program apart from other programs on campus. The new curriculum students pointed out that this is significantly different from their IT classes. Other students pointed out that their roommates and friends have commented on the differences in the HIM students' experience. One student stated, "One of my roommates is a marketing major and she’s like, ‘you’re so lucky your professors help you pick out your internships, we have to find ours on our own. That's really nice.”' Students stated that they appreciated the fact that their professors provided support, "I think all of our professors all want us to be successful so that's a really good feeling too and they're really helpful about helping us with finding jobs and opportunities. I really, really like that because our major is so small we get to form close relationships with them so I feel like that's really beneficial.” This carried over into student advice to future students. One student stated, "I would just honestly say go see ... [your teachers] because they're willing to help and they just want to see you be successful.”

In addition to developing close working relationships with professors, students also commented on the fact that they appreciated the close relationships they have developed with their peers. One new curriculum student stated, "We have a bond over grinding through the IT classes.” Another student stated, "You also have your classmates to back you up and help you with whatever problem you have.” 


\section{Conclusion}

The student data provided great insight into the students’ perceptions of the HIM program, providing input into both what the program is doing well and what the program could improve upon. It was noted that while all students were satisfied with their curriculum, there was clear alignment among the students between the curriculum they were completing, their career goals, and their level of satisfaction with the curriculum. Students did raise concerns about the rigor of the IT sequence and questioned the need for the computer programming courses. In addition, students were concerned about the elimination of some of the old curriculum and expressed the feeling that management knowledge was still needed. Finally, students expressed satisfaction with the fact the ISU's HIM program is a small major and therefore, students receive significant personal attention.

\section{Graduates}

Recent graduates were surveyed to obtain information about their perceptions of the curriculum changes and student preparedness for the HIM field. An open-ended survey was used to gather this data from both 2017 and 2018 ISU HIM graduates. The survey was developed by the researcher and was pilot tested by the HIM faculty for validity and reliability. The pilot test included review of the survey questions by the HIM faculty followed by discussion of the questions and the ability of the questions to elicit information of use to the program evaluation. The survey was administered electronically to twenty-four 2017 graduates and eighteen 2018 graduates. All individuals graduating in 2017 and 2018 were included in the survey. The response rate for the survey was 46\% for 2017 graduates and 61\% for 2018 graduates; the overall response rate was 52\%. Of the respondents, 4/22 (18\%) had completed the “new” IT-focused curriculum, and 18/22 (82\%) had completed the “old” management focused 
curriculum. The respondents worked in a variety of jobs with the most common being in billing and revenue cycle, medical coding, or HIM director/manager positions.

The constant comparative method (Glaser, 1965) was used to analyze the survey results. The results were first reviewed and broad categories were identified. These included areas in which graduates felt well prepared, areas in which they felt they were not well prepared, strengths and weaknesses of the new curriculum, and advice for incoming students. Subsequently, the results were further analyzed and details were identified within each broad category. Five to six specific areas were found summarizing each broad category. At this point, themes started to emerge. Further analysis resulted in fine-tuning of these themes and categories until no new categories were identified. This was followed by combining similar categories to allow for the identification of focused categories and themes that could be used to summarize the data. Three main themes were identified from the graduate survey responses. These included graduate satisfaction and the perception of preparedness, support for the new curriculum, and concern about the loss of parts of the old curriculum.

\section{Graduate Satisfaction and Perceptions of Preparedness}

When asked questions about how the graduates felt the HIM curriculum prepared them for their career in HIM, 82\% of the respondents stated that they felt they were prepared or highly prepared. When asked if they felt the HIM curriculum at ISU had prepared them for their current job, $65 \%$ of the respondents stated that they felt they were well prepared. Areas in which the graduates felt they were well prepared were data analysis, Health Insurance Portability and Accountability Act (HIPAA) and other legal functions, Electronic Health Records (EHRs), management, coding, and problem solving. One respondent stated, “I feel confident that I can perform all of my job functions and more with a high level of satisfaction as a result of having 
gone through the HIM curriculum at ISU.” Another stated, “I feel that the curriculum along with those that taught it allowed me to advance as fast as I have been within my current company as usually it takes two years to reach what I have done in 8 months."

In addition, respondents stated that course activities such as projects and presentations as well as the higher grading scale helped prepare them for their careers. The grading scale in the HIM program is $93-100 \%$ - A, 85-92\% - B, 77-84\% - C, 70-76\%- D, below 70\%-F, and students must receive a C or higher in all major courses. One graduate stated, "As funny as it sounds, presentations no matter which it was in, prepped me for my career. Being comfortable in your own skin and talking with colleagues was the most difficult part of the transition.” Another stated, "I also think having a structured grade scale of 77\% made me work my butt off and I am better because of it.” Still another stated, "The projects will give you a good idea as to potential careers you could have and will make choosing professional practice sites much easier.”

While graduates stated that a variety of classes were the most or the least helpful in their career, a number of graduates pointed to all classes as being of use in HIM career preparation. One graduate stated, "I use aspects of each course and assignment in everyday work life.” Another stated, "I think all of the classes together provides a good foundation." One graduate also referenced preparation for the RHIA certification exam, "I felt strongly prepared to take the RHIA upon graduation, having passed on my first attempt.” Finally, a graduate referenced the rigor of the course work but also the reward at the end, "It's going to be really hard and really frustrating but your degree will be more valuable than your peers.” One graduate summed up their feelings about the value of the program and their preparedness by stating, "From my interactions with other HIM professionals, the training I received at ISU is far beyond any other program.” 
While most graduates felt that they were well prepared for the HIM field and their current jobs, there were some graduates who felt they were not well prepared overall or were not well prepared in certain areas. One area in which graduates felt they were not as well prepared was revenue cycle and billing. This aligned with the percentage of graduates whose current job was in billing or revenue cycle (18\%). " $5 / 10$ [preparedness]. My current job is more revenue based and we only had one revenue class and I work a lot with billing. Now my past job in the records department I felt extremely prepared for 9/10.” Other graduates pointed to the fact that there was a large amount of on-the-job learning required, "It prepared me with the basics of coding. However, there were still many things that I had to learn on the job.” Along these same lines, one graduate pointed to the wide range of careers for which the HIM program prepares students, "This major is very diverse. It incorporates healthcare, management, and information technology." Another respondent followed in this same vein by stating, "I feel as though it (HIM curriculum) gave me a slight insight of what the HIM profession actually consists of. This is not ISU's fault; the HIM profession is so large that there is no exact way of prepping a student for it."

Graduate perceptions of preparedness by curriculum completed was also analyzed. Of the graduates who completed the new curriculum 3/4 (75\%) felt they were prepared or highly prepared and 1/4 (25\%) were unsure of their preparedness for the HIM field or their current job. Graduates who stated they felt prepared or highly prepared stated that the HIM curriculum "prepared me with great problem-solving skills" and "I do not see any weakness [in the curriculum].” One graduate (25\%) who stated they were unsure of their preparedness was not yet working in the HIM profession at the time of the survey. 
Of the graduates who completed the old curriculum, 17/18 (94\%) felt they were prepared or highly prepared and 1/18 (6\%) was unsure of their preparedness for the HIM field or their current job. The graduates who felt they were prepared stated that the HIM curriculum, "prepared me very well” and "prepared me very well in my current job.” One graduate who stated that they felt prepared for their job stated, however, "In terms of the old curriculum, I don't feel that it prepared me very much for my current career." The one graduate who stated they were unsure of their preparedness made no comments to indicate why they felt unsure.

\section{Support for the New Curriculum}

Overall the graduates expressed strong support for the new IT-focused curriculum. Most respondents pointed to the growing IT emphasis in the HIM field as well as the fact that the new curriculum broadens HIM graduates' job opportunities. Regardless of the curriculum the graduates completed, they were all well aware of the changes in the field due to the fact that they were exposed to the curriculum transition and were conscious of the reasons for the change.

When asked about the strengths of the new curriculum, many respondents focused on the changes in the HIM profession and the new curriculum's alignment with these professional changes. One respondent stated, "The HIM profession is largely leaning towards IT and fully electronic.” Another pointed out, "I think the new curriculum is great because, it is more on information technology which is vital for health information exchange.” One graduate spoke directly to graduate preparedness by stating, "The new curriculum prepares students for the next step of the HIM profession as a whole.” Still another graduate focused on their professional practice experience and how they saw the need for HIM professionals with IT training, stating, "I finished an HL7 conference at [a large health insurance company] and that field needs HIM ITs, not ITs going into HIM." One graduate who completed the old curriculum stated, "I did not take 
the IT portion of the program, but I wish that I would have. Much of what I do involves IT services, and I am expected to be knowledgeable and able to merge IT services with HIM functions on a daily basis.”

Other respondents focused on specific IT skills that they had learned through the new curriculum and how these were helpful to them in starting their careers. They mentioned skills such as understanding computers, hardware and software concepts, building macros, working with databases, and data analysis. One respondent stated, "You get to see how technology is going to affect the workplace and the workflow.” Another student tied the entire curriculum together stating, "I feel as if the core HIM classes give the students a great understanding of management.... However, the IT/IS courses give the students a good understanding of system processes. Together it is a well blended curriculum!” One student who completed the new curriculum stated they felt the curriculum was important in preparing them for the IT focus of HIM, "I feel the HIM program helped in preparing me for the use and growth towards an electronic healthcare world.” Some graduates who did not complete the new curriculum expressed the desire to have that knowledge base. One stated, "I wish we had learned more of the IT stuff. Now I'm trying to figure that into my continuing education.” Another graduate stated of the old curriculum, “It didn’t prepare me for the health information technology portion of the RHIA, I felt like there was this whole missing piece from the program about technology and data stewardship.”

Respondents also focused on the perception that the new IT-focused curriculum would broaden job opportunities for HIM graduates. As IT becomes a greater focus of the HIM profession and of healthcare in general this can be valuable as new graduates start their job searches. New graduates are no longer limited to health information department positions. With 
the HIM and IT education, they can work in many more areas of hospitals or other healthcare settings. One respondent stated, "I feel the strengths of this new curriculum will help students broaden there (sic) career searches to not just Medical records or management but also the analytical side as well." Another stated "I see more HIM students having a wider variety of IT jobs opening up.” Another advantage that graduates mentioned regarding the new curriculum was the ability to obtain a minor in IT, which required only one additional class. One graduate stated that the advice they would give to students considering HIM at ISU is, "do get the IT minor with one extra class.”

While most respondents were quite supportive of the new curriculum, some did express areas of concern. These graduates focused on their perceptions that IT was not a good fit for all students, the IT courses were not healthcare focused, and computer programming was not needed in the HIM field. The graduates that focused on their feeling that IT was not a good fit for all individuals stated that this was a concern for both students who might not want to focus on learning IT concepts and graduates who might not want to work in an IT focused area. When speaking to IT as a fit for graduates, one graduate stated, "Not everyone wants to do IT, and if you work in a strictly records setting you won't use it much. And there are so many jobs where you won't need that concentration that you can apply for after graduation.” Several graduates expressed concern regarding IT as a fit for students. One stated, "The only weakness I could see [in the new curriculum] would be for those who aren't as tech savvy and that may struggle in those types of courses” while another stated it, "can be hard to follow some IT classes." Other graduates expressed concern about the heavy workload of the IT courses on top of rigorous HIM courses such as pathophysiology. 
Some graduates expressed the concern that the IT classes were not healthcare focused. Since these classes are taken in the IT department they are not specific to healthcare but involve a variety of business and industry applications. Graduate concern regarding this was noted in comments such as, "There are no classes focused on healthcare IT processes/build" and "It [the new curriculum] hasn't focused directly on health information systems.”

Finally, some graduates stated that they perceived that the computer programming classes such as IT 168 and IT 178 were not needed in the HIM curriculum. These classes are required by the school of IT as pre-requisite classes for the HIM-major required IT classes. IT coding (programming) was mentioned as a part of the curriculum that was felt to be the least helpful in the graduates' careers. One graduate was adamant about the fact that they felt programming was not needed, stating, "You take classes that do literally nothing for your career like IT 168."

\section{Concern About the Loss of Parts of the Old Curriculum}

While many graduates expressed support for the new IT focused curriculum, some did express concern for the loss of parts of the old management-focused curriculum. One graduate stated, "I still see a lot of benefit in the management side of the curriculum, especially working as a new manager. Understanding basic management functions in a health care facility (or nonHC) and how to work with your staff would be beneficial.” Another stated, "Some people [would] rather take management courses instead of IT courses.” As stated previously, regardless of curriculum completed by the graduates, they were all aware of the reasons for the changes in the curriculum. The business department management classes that were required in the old curriculum were deleted from the curriculum in order to allow room for the new IT classes. The pertinent management content was added to remaining HIM courses. One graduate found a way to maintain the business management focus by recommending that incoming students, "minor in 
business.” Other graduates recommended the addition of finance, business, and accounting classes to the HIM curriculum, especially for those interested in working for insurance companies.

By and large, the graduates in the new curriculum felt more positive about the value of the IT curriculum and the students in the old were more concerned about the loss of some of the management-focused classes. This did not seem to be tied to the graduates' current job as there were no substantial differences in the types of jobs the graduates had relative to their completed curriculum.

\section{Conclusion}

There were three main themes identified in the data gathered from the HIM graduates. Overall the graduates felt "prepared” or "highly prepared” for their careers or first jobs. The graduates expressed support for the new curriculum and saw the need for the changes in the curriculum based on changes in the field. They also saw the new curriculum as a path to broader job opportunities for graduates. However, they were concerned about the fact that they felt that IT was not a fit for all individuals, the IT classes were not healthcare focused, and computer programming was not needed in the HIM field. Finally, graduates expressed concern about loss of parts of the old curriculum, stating that there is a benefit to the management curriculum, some individuals would prefer management to IT, and some career paths require more business knowledge and skills.

\section{Employers}

Perceptions of employers about the curriculum changes and student preparedness for the HIM field were gathered using both open-ended surveys and interviews of HIM professionals who hosted HIM program professional practice students or who employed program graduates. 
The survey was developed by the researcher and was pilot tested by the HIM faculty for validity and reliability. The pilot test included review of the survey questions by the HIM faculty followed by discussion of the questions and ability of the questions to elicit information of use to the program assessment. The survey was administered electronically to 37 individuals at 25 different health care organizations. Professionals at these organizations were selected to receive the survey because they had hosted ISU HIM students for professional practice within the last year or had hired an ISU HIM graduate within the last year. Some organizations had more than one area or department that hosted professional practice students or hired new graduates from ISU's HIM program, therefore multiple professionals from those organizations were contacted. The response rate for the survey was 17/37 (46\%) of the professionals representing 12/25 (48\%) of the organizations.

In addition to the employer survey, five HIM professionals were invited to participate in an interview that allowed the researcher to delve deeper into the perceptions these employers had regarding their experiences with the ISU HIM curriculum change. These five professionals were selected as their organization and/or they personally had hosted or hired the greatest number of ISU HIM students or graduates. These professionals were interviewed using a semi-structured interview process in which the interview protocol was developed by the researcher and reviewed by ISU HIM faculty for validity and reliability. Three of the interviews were conducted via phone calls and two via face-to-face based on convenience for the professional. The interviews were 30-90 minutes in length, were tape recorded, and allowed for more specific discussion of the professionals' perceptions of the changes in the ISU HIM curriculum and how this affected student preparedness for the HIM field. A word-for-word transcript of each interview was prepared following each interview. 
Almost all professionals surveyed or interviewed had personally hosted an ISU HIM professional practice student, either as a junior or senior. Most organizations selected had hired at least one ISU HIM graduate to be employed in their facility or company. All professionals surveyed or interviewed had supervisory experience with either an ISU HIM professional practice student or an ISU HIM graduate.

The constant comparative method (Glaser, 1965) was used to analyze both the survey results and the interviews. The survey results were first reviewed and broad general categories were identified. These included: essential skills for new employees to possess when starting a job, essential skills for employees to learn on the job, the importance of IT skills, specific IT skills of importance, the importance of data analysis skills, specific data analysis skills of importance, ISU HIM students'/new graduates' preparation, effect of new curriculum on student/new graduate preparation, and overall impression of ISU HIM curriculum. Subsequently, the results were further analyzed and details were identified within each broad category. Within each broad category responses were summarized into 2-6 specific areas. At this point it was clear that some themes were emerging. Initially, the interview transcripts were analyzed in a similar manner. At first broad categories were identified: the need for IT skills, specific IT skills needed, the need for data analysis skills, specific data analysis skills needed, areas in which ISU HIM students were well prepared, areas in which ISU HIM students were not well prepared, the effect of the curriculum changes on student preparedness, and overall perceptions of ISU's HIM curriculum.

Again, the results were further analyzed and 2-6 specific areas were identified within each of the broad categories. Similar themes were identified as those seen in the survey analysis. Therefore, after these initial steps, the survey results and the interview transcripts were further analyzed and 
coded together so that broad themes and categories were identified based on the results of both the surveys and the interviews. Further analysis resulted in fine-tuning of these themes and categories until no new categories were identified. At that point, some categories were combined or eliminated based on similarities or consistent themes. This allowed for a final group of three focused categories and themes that could be used to summarize the data and the over-arching themes found in the data. These included the relationship between new curricular requirements and current skill needs in the HIM field, employer expectations and student preparedness, and future needs in HIM education. As the new curriculum competencies focused more on information technology (IT) skills and data analysis skills, these were the foci of the survey and interview questions regarding the new curriculum.

\section{New Curricular Requirements and Current Skill Needs in the Health Information Management Field}

While only two professionals who responded to the survey or were interviewed had experience with students who had completed the new curriculum, most of the surveyed or interviewed professionals were familiar with the recent curricular changes and their focus on IT and data analysis. When asked about information technology (IT) skills, most employer respondents stated that they use IT skills frequently. One interviewee stated that they use IT skills, “every day, all day.” Another interviewee stated, “I’m dependent on using my HIM skills in combination with my IT skills on a daily basis.” Respondents most often cited their need to know how to use Microsoft Excel and Office as well as the specific electronic health record (EHR) used by their facility. They also noted the need for knowledge of work flows and chart functions, project management, and “technology as a solution”, as well as an understanding of what to request from IT for their specific needs. Some stated that it was important for them to be 
comfortable with IT and with working with IT personnel. One interviewee stated of working with IT personnel, “There’s a lot of disconnect there if they’re talking about slow processing and switches and these servers, etc. Understanding the language, speaking the same language, and being able to articulate what the problem actually is and what you're trying to solve” is invaluable.

Most professionals learned some of their IT skills in college and some on the job. This was also directly affected by the timeframe the professional was educated as some stated technology had changed significantly since they took classes. Many cited Electronic Health Record (EHR) training and other application-specific training provided by their employer as other sources of IT education. Their expectation for new staff was that employees would come into the workforce with fundamental technology skills, such as basic computer knowledge and use of Microsoft Office, and would learn specific software on the job. They overwhelmingly stated that the most important IT skills for employees are knowledge of Microsoft Office and the knowledge of the specific EHR or software application used by the healthcare facility.

When asked about data analysis skills, it was noted that most HIM professionals at the employers that were surveyed or interviewed stated that they used data analysis skills slightly less than their use of IT skills, and mainly for work flow/productivity purposes, analysis of documentation, financial purposes, and marketing and other services. One interviewee stated, “Every email I get, there’s some type of data analysis in it.” Many of the employers stated that they used reports that were prepared automatically by the EHR system or by the IT department. One interviewee stated, “so our analysis is more like the data is presented to us and we're ... deciding if this looks right, why is this the way it is, etc.... I feel that's more the data analysis that I do; like it's presented to me and I'm interpreting it.” There was a significant focus among 
most respondents on the use of Microsoft Excel for data analysis although a few stated that Tableau is used at times. One interviewee stated, "Excel is pretty much your best friend.” Another shared that knowing Excel was a great asset to her personally both from her ability to use the software as well as the ability to help others use it. Tableau, a business intelligence and analytics software package, was recommended by one interviewee who focused on the need for students to learn advanced capabilities in Excel first and then some basics in Tableau second. Another interviewee stated that in spite of the use of various business intelligence software in the field such as Tableau and Qlikview, HIM students should be taught Excel as the foundation for analyzing and manipulating data. "Their skills should be more in Excel in terms of how to show it [data] in a way that makes sense.” Again, most professionals learned their data analysis skills through a combination of formal education and on the job training. They stated that data analysis skills are very important for new employees and new incoming HIM professionals are expected to have data analysis skills when they enter the workforce. The respondents stated that the most important data analysis skills for employees to possess include the ability to create reports and present data, use data for quality improvement purposes, understand clinical data, and understand the data entry process and the data access points. One interviewee stated, “A lot of data comes to us that we have to interpret, like patient experience scores or quality engagement scores.” HIM professionals, therefore, need to not only be able to analyze the data but understand the data sources in order to make sense of the data.

Respondents stated that they felt that the changes in the ISU HIM curriculum will better prepare students in needed areas such as data governance, data analytics and critical thinking, data presentation, understanding IT (speaking the IT language), and working with insurance algorithms. They also emphasized that students need a good background in Microsoft Excel and 
Microsoft Access, both of which are taught in the new curriculum. Many respondents stated that new graduates now need an additional focus on IT so the change to a more IT focused curriculum will serve students well. One survey respondent stated "technology is going to be very disruptive to the HIM workplace over the next 5-7 years. The program needs to continue working with IT in order to produce the competent HIM professionals [needed] in the next decade.” Another stated, “I wish I could go back to take the IT courses! They are integral!” One interviewee stated the IT focus is needed "so an HIM graduate who comes out can interact with IT professionals and can understand the concepts of operating systems and those things.... I think getting it to a level where an HIM professional has enough exposure that they can act in a leadership role, or a project manager, or that they can attain and be in a contributor role. I thought that was a good move.” It was noted, however, that in spite of the support for additional IT courses, some respondents noted that they did not feel that HIM students needed computer programming, courses that have been added to the HIM curriculum as they are prerequisites for required IT courses. Respondents also stated that they felt that additional focus on data analytics is essential for HIM students. One respondent noted that this focus can help students both in data analysis as well as other areas. He stated, "the data analytics side definitely helps with those critical thinking skills.”

HIM professionals surveyed or interviewed were also asked about their perceptions of the effect the new curriculum will have on ISU HIM students' future careers. Some respondents stated that they didn’t feel the new IT focus would help ISU HIM graduates who seek traditional HIM careers in hospital HIM departments. Others, however, noted that it would broaden job opportunities and open new doors for ISU HIM graduates in the healthcare employment arena. Overall, it was noted that the curricular changes are in line with changes in the profession and in 
the job skills needed for new HIM graduates, therefore these curriculum changes are needed to adequately prepare HIM students and new graduates.

\section{Employer Expectations and Student Preparedness}

When the respondents were asked what skills new employees needed to know before entering the field, the responses were almost unanimous in citing skills such as communication, problem solving, critical thinking, adaptability, and attention to detail. They stated that basic technology skills and knowledge of the composition of the patient record were expected as well. One respondent stated new graduates should possess, “critical thinking skills, coding (medical), overall knowledge of body systems, A\&P (anatomy and physiology), how to maneuver through IT systems, databases.” Another stated new graduates should have, “foundational knowledge of medical records functions." When asked what skills new employees would be expected to learn on the job within the first few months, similar skills again were highlighted: teamwork, attention to detail, and communication. However, employers also focused on other skills that should be learned on the job, such as specific software or technology as well as other job specific skills. One respondent summed it up by stating skills employees should learn on the job include, “specific computer program skills, specific processes of organization, how to function within organizational team [sic], specific job responsibilities.”

When asked about the preparedness of ISU HIM students for professional practice or employment the responses were overwhelmingly positive. Of the survey respondents, 100\% stated that ISU HIM students were “prepared” or “highly prepared”. Interview respondents stated that ISU students and new graduates were highly prepared, very prepared, or extremely prepared. Respondents noted that ISU HIM students were better prepared for employment than community college students. One interviewee stated, "ISU is always our go to for trying to get 
students” based on how well prepared they are. Two interviewees did note that preparation varied by individual student but overall the ISU HIM students were very prepared.

When asked in which areas ISU HIM students were well-prepared, the most common response was medical coding. One respondent stated, "we have many coders employed with us who went to ISU and their foundations in coding are very strong.” This was followed by overall preparation, professionalism, computer applications, business operations and processes, and traditional HIM functions. A survey respondent stated, “I’ve had students from other school intern for me and I've hired students who have an RHIA/RHIT from a different school and their skills don’t compare to ISU students. ISU students are more highly skilled in most areas, specifically coding and overall professionalism.” It was also stated that ISU HIM students demonstrate a desire to learn, learn quickly, and are able to apply what they have learned.

When asked in which areas ISU HIM students were not well-prepared, respondents stated business communication or oral communication, ability to work in an office environment, regulatory requirements, and HIM fundamentals. One interview respondent stated, “they don’t know how to write for business. They put all kinds of adjectives in there, they don't write directly and succinctly.” Another stated, “they’ve got the knowledge to do the job, they're just not used to working in an office so they may not have that office discipline yet." Some respondents stated that there were no areas in which ISU HIM students were not well-prepared.

\section{Future Needs in Health Information Management Education}

HIM professionals surveyed or interviewed were also asked to comment on the academic program overall and what educational needs should be considered in the future. Overall, the respondents stated that ISU has a strong HIM program and that they liked the direction in which the program was heading. They commented on the need for IT and data analytic skills in the 
current HIM arena and added that they felt the addition of these concepts to the curriculum was positive. One survey respondent stated, “we feel the ISU HIM program is a 5 Star program!!!!”

Recommendations for future changes in the ISU HIM curriculum by employers included the continued focus on data governance and the addition of business intelligence. One interviewee stated, "I think the data governance and being familiar with the data governance model is a critical class and I'm glad to see that in the curriculum.” These topics were felt to be reflective of the direction HIM is heading. Professionals, however, expressed concern that too many curricular changes might mean that ISU's HIM program would lose a focus on the fundamentals. This could lead to fewer new graduates prepared for traditional HIM roles, which concerned them. One interviewee stated that they depend on ISU for inpatient and outpatient coders. "The good coders come out of ISU, that's the bottom line.” She expressed concern over ISU’s HIM program cutting any coding classes, “This makes me really nervous,....So if you guys don’t do it, who is going to do it?”

Many professionals interviewed expressed concern over future proposed changes in the CAHIIM Curriculum Competencies. They felt that CAHIIM might be taking too much out of the baccalaureate level curriculum and transferring it to the master's level curriculum. One interviewee voiced his concern over cuts to the baccalaureate curriculum by stating, "You're going to simplify or dumbify it to a certain level and then it's not going to be the quality that it has been in the past.” Respondents recommended that ISU’s HIM program maintain the curriculum at the current level and not "water down the recent changes" by reducing the rigor of the new curriculum, despite any changes CAHIIM might make in the future. Respondents also recommended that ISU's HIM program focus on the local and regional healthcare employers' needs in order to insure that ISU HIM graduates are prepared to fill local and regional jobs and to 
meet the work force needs of the Illinois HIM community. One interviewee stated, "Nothing against the Midwest, I love it here, but it's not the same as what you're going to have on the two coasts. I don’t know, I’d say it's even (the same in) the Chicago area because it's still the Midwest. It goes to the two coasts and gets proven or disproven out there and then falls to the center and that's where it really becomes reality, by the time it gets to the Midwest.”

\section{Conclusion}

There were three main themes identified in the employer data. Employers stated that they felt that overall the new curriculum aligns with the skills needed in the HIM workforce today and that the new curriculum will better prepare students. However, they did express concern about the need for computer programming, stating that this is not a skill that is needed in HIM. Employers were quite pleased with ISU HIM student preparedness, with $100 \%$ of the employers stating that ISU HIM students are “prepared” or "highly prepared” for the field. Employers specifically pointed to the fact that ISU students and graduates are very well prepared in medical coding. Employer respondents also stated that they felt ISU's HIM program was heading in the right direction, however, they were concerned about the loss of fundamental knowledge, including medical coding, that could occur with the new curriculum. They also expressed that the HIM program should not “water down” the curriculum based on potential changes to curriculum requirements in the future.

\section{Health Information Management Program Metrics and Other Data}

Select HIM program metrics were evaluated to provide additional information for analysis of the effect of the curriculum changes on student preparedness of students in the HIM program as well as the effect on the HIM program itself. While CAHIIM required that the curriculum changes were made by the fall of 2017, the change to the new curriculum was made 
effective in the ISU HIM program with the 2016 University Course Catalog. In the fall of 2016, incoming freshmen had to follow the new curriculum (including IT courses) and most transfer students could choose between the old course catalog (and old curriculum) and new course catalog (IT courses). The transfer students were encouraged to choose to follow the new course catalog and, thus, the new curriculum.

\section{Background}

Students were initially very dissatisfied with the IT courses. They openly shared their frustrations with HIM faculty. There were stories of IT faculty stating that the IT 168 course was only for IT students and that non-IT students shouldn't be in the course. There were suggestions that non-IT students should be in IT 164 instead, even though this was not a required prerequisite.

In the fall of 2016, 21 HIM students were in IT 168 courses. Of those, 8 were incoming freshmen and 13 were junior transfer students. One (12.5\%) of the freshmen left the university in the first week of classes. Three (13\%) of the junior transfer students chose to change back to the old catalog prior to the drop date at the end of two weeks of classes. These changes were all based, at least in part, on the students' desire to avoid taking the IT courses.

It was noted that many HIM students selected the HIM major because they were not admitted to the nursing program and saw HIM as an attractive alternative. It was also noted that many of these students did not have the data/IT focus or interest that would be needed for the new curriculum. Therefore, it was decided that student recruitment efforts would need to change and students that could not get into nursing and instead chose HIM might need to be counseled regarding the level of IT requirement. 
It was also suggested that IT 164 might need to be added as a recommended prerequisite for students with limited IT/math backgrounds. In addition, the Health Sciences advisor noted that the students who had only the Math 104 prerequisite were struggling in IT 168. The suggestion was also made to add MAT 119 as an HIM prerequisite.

In September 2016, another HIM sophomore transferred out of the major due to struggles with the IT 168 course. Also during that month, other students continued to struggle and some juniors transferred out of the new catalog and back to the old catalog. It was eventually decided to make IT 164 and MAT 119 recommended prerequisites for students who did not have a strong IT or Math background. Moving forward this seemed to help some students experience greater success in IT 168.

In October 2016, problems associated with the Community College transfer students’ schedules were discovered. First, they had limited time to take the IT courses, so they had to take more than one a semester and could not miss any or their graduation would be delayed. In addition, there was a scheduling issue between offerings of required IT courses and required HIM classes. In order to resolve this, HIM classes were rearranged and the students who wanted to remain in the IT sequence all decided to stay longer and pursue an IT minor.

In further discussions with 2018 cohort students during the spring 2017 semester, it was noted that many students felt that a tutor specific for HIM students in IT 168 or IT 178 would be helpful. Students noted that it was hard to find open times for the tutoring in the IT department. In the fall 2017, tutoring for HIM students in IT 168 or 178 was started. This tutoring was supported by the Health Sciences department and was held in the HIM laboratory. Students noted that this was helpful both from a learning standpoint as well as from a peer networking standpoint. Tutoring for these students through health sciences has continued. 


\section{Subgroup Completion Metrics}

Based on the above background, faculty and staff were aware that there would be some negative program metrics during the transition between the old and new curricula. Based on early student reaction, it was known that many students changed the curricular track they started and that this could increase time to degree. Table 2 summarizes student curricular track enrollment and completion for the first (2018) transition cohort. It can be seen that 14 of 29 (48\%) students started in the IT track in the fall of 2016; 4 of those finished in the IT cohort and graduated in either May or December of 2018.

Table 2

2018 Cohort Curricular Track Enrollment and Completion

\begin{tabular}{|l|l|l|}
\hline Student Subgroup & Number & $\begin{array}{l}\text { Percentage of } \\
\text { Subgroup }\end{array}$ \\
\hline IT Group & $\mathbf{1 4}$ & $\mathbf{1 0 0 \%}$ \\
\hline $\begin{array}{l}\text { Completed IT track with an IT minor and graduated on } \\
\text { schedule }\end{array}$ & 1 & $7 \%$ \\
\hline $\begin{array}{l}\text { Completed IT track with an IT minor and graduated after } \\
\text { one additional semester }\end{array}$ & 3 & $21 \%$ \\
\hline Switched to non-IT track and graduated on schedule & 5 & $36 \%$ \\
\hline Changed major & 5 & $36 \%$ \\
\hline Non-IT Group & $\mathbf{1 5}$ & $\mathbf{1 0 0 \%}$ \\
\hline Completed non-IT track and graduated on schedule & 12 & $80 \%$ \\
\hline Plan to complete non-IT track with 2019 Cohort & 3 & $20 \%$ \\
\hline $\begin{array}{l}\text { Total students completed 2018 Cohort in starting } \\
\text { curriculum track and on schedule } \\
\mathbf{1} / \mathbf{1 4} \text { IT (7\%), 12/15 Non-IT (80\%) }\end{array}$ & $\mathbf{1 3}$ & $\mathbf{4 4 \%}$ \\
\hline
\end{tabular}

Table 3 summarizes student curricular track enrollment and completion for the second (2019) transition cohort. It can be seen that 10 of 23 (43\%) students started in the IT track in the fall of 2017; at the time of this evaluation, 6 of those are still in the IT cohort and planning to complete the IT cohort and graduate in May 2019. It should be noted that the percentage of IT group students who continued on the IT track increased significantly between the 2018 (28\%) 
and 2019 (70\%) cohorts. Also, the students on the IT track who plan to complete on schedule with the 2019 cohort is $60 \%$ compared to the percentage of IT track students who completed the 2018 cohort on schedule (7\%).

Table 3

2019 Cohort Curricular Track Enrollment and Completion

\begin{tabular}{|l|l|l|}
\hline Student Subgroup & Number & $\begin{array}{l}\text { Percentage } \\
\text { of Subgroup }\end{array}$ \\
\hline IT Group & $\mathbf{1 0}$ & $\mathbf{1 0 0 \%}$ \\
\hline Plan to complete IT track and graduate on schedule & 6 & $60 \%$ \\
\hline Changed major & 3 & $30 \%$ \\
\hline $\begin{array}{l}\text { Changed to part time status; plans to complete IT track } \\
\text { with 2020 Cohort }\end{array}$ & 1 & $10 \%$ \\
\hline Non-IT Group & $\mathbf{1 3}$ & $\mathbf{1 0 0 \%}$ \\
\hline Plan to complete non-IT track with 2019 Cohort & 11 & $86 \%$ \\
\hline Plan to complete non-IT track with 2020 Cohort & 1 & $7 \%$ \\
\hline Changed major & 1 & $7 \%$ \\
\hline $\begin{array}{l}\text { Total students planning to complete 2019 Cohort and } \\
\text { graduate on schedule } \\
\text { 6/10 IT (60\%), 11/13 Non-IT (85\%) }\end{array}$ & $\mathbf{1 7}$ & $\mathbf{7 4 \%}$ \\
\hline
\end{tabular}

\section{Retention Rates}

Table 4 shows retention rates of ISU HIM students based on the curriculum with which they started the program. It should be noted that the retention rate for the IT subgroup students increased dramatically between 2018 cohort (28\%) and 2019 cohort (70\%).

Table 4

Retention Rates Based on Starting Subgroup

\begin{tabular}{|l|l|l|l|}
\hline Cohort & IT & Non-IT & All Students \\
\hline 2017 & n/a & n/a & $23 / 30(77 \%)$ \\
\hline 2018 & $4 / 14(28 \%)$ & $12 / 15(80 \%)$ & $21 / 29(72 \%)$ \\
\hline $2019 *$ & $7 / 10(70 \%)$ & $11 / 13(85 \%)$ & $18 / 23(78 \%)$ \\
\hline
\end{tabular}

* As of $10 / 18$ 


\section{Enrollment Rates}

Table 5 shows enrollment rates for junior year HIM majors. This metric is important due to the fact that this reflects enrollment in major classes for students who have successfully completed major prerequisite courses. Figure 4 clearly demonstrates a slight decrease in the junior year HIM enrollment in 2017 and a significant decrease in the junior year HIM enrollment in 2018. The timing of these decreases in enrollment align with the timing of the implementation of the changes in the HIM curriculum.

Table 5

Junior Year HIM Major Enrollment

\begin{tabular}{|l|l|}
\hline Junior Year HIM Major Enrollment & Number of Students \\
\hline 2015 & 30 \\
\hline 2016 & 29 \\
\hline 2017 & 23 \\
\hline 2018 & 8 \\
\hline
\end{tabular}

Table 6 summarizes total enrollment (freshmen through senior) for each year, 2013-2018.

It can be seen that while total enrollment is down for 2018, the change between 2018 and previous years is not as significant as that for junior year HIM major enrollment.

Table 6

Total Enrollment

\begin{tabular}{|l|l|}
\hline Year & Number of Students \\
\hline 2013 & 96 \\
\hline 2014 & 119 \\
\hline 2015 & 89 \\
\hline 2016 & 102 \\
\hline 2017 & 81 \\
\hline 2018 & 73 \\
\hline
\end{tabular}




\section{RHIA Exam Pass Rates}

RHIA exam pass rates were also analyzed. At the time of this analysis, none of the graduates who had completed the new curriculum had taken the exam. Therefore, there is no data specific to RHIA exam pass rates relative to curriculum completed. While this data does not speak to student preparedness related to the IT portion of the new curriculum, it does reflect other changes that were made to the curriculum starting in 2016, including a greater emphasis on data analytics. This additional focus on data analytics in the curriculum should have better prepared students for data analytics exam questions starting with the 2017 cohort. Table 7 shows RHIA Exam pass rates for the most recent ISU HIM Cohorts. It should be remembered that the RHIA exam is not required for all employment settings, therefore not all graduates chose to take the exam.

Table 7

RHIA Exam Pass Rates

\begin{tabular}{|l|l|}
\hline Cohort & Pass Rate \\
\hline 2016 & $13 / 14(93 \%)$ \\
\hline 2017 & $14 / 17(82 \%)$ \\
\hline 2018 & $6 / 7(86 \%)$ \\
\hline
\end{tabular}

\section{Internal Program Review Report}

The ISU HIM program underwent internal program review by the Academic Planning Committee during 2017. The Committee report and follow-up documentation was reviewed for findings and recommendations related to the curriculum change in the HIM program. The Committee commended the program for maintaining alignment with the "changing accreditation standards that reflect changes in the discipline” (Illinois State University, Review of the B.S. In Health Information Management Consultative Draft, 2018, p. 1). They also stated, 
"commendable is accommodation in the curriculum for students to earn a minor in information technology, which can aid graduates in their job searches and career advancement” (p. 1).

The Committee Recommendations included the following:

- cclosely monitor and evaluate the impacts of the revisions (curriculum) on student recruitment, retention, graduation, licensure, and job placement” (p. 2)

- cdevelop and implement a plan for recruiting students highly credentialed in science and mathematics" to meet the higher levels of aptitude needed in these areas due to the increased focus on IT and data analysis in the revised curriculum” (p. 2)

- "revisit the mathematics requirement for admission to and graduation from the program" based on the revised curriculum and to meet the goal of improving certification exam pass rates” (p. 2)

- Further evaluate the time to degree for HIM students. "The committee notes lower percentage of first-time-in-college students graduating from the program within four years compared to the average across all undergraduate programs at the University” (p. 2-3)

In closing, the Committee noted, "With the curricular changes made by faculty since the 20092010 program review, students completing the HIM on-Campus plan of study are better equipped to successfully compete for health information management positions having an information technology focus” (Illinois State University, Review of the B.S. in Health Information Management Overview, 2018, p. 4). 


\section{CAHIIM Accreditation}

It should be noted that at the time of this evaluation, the CAHIIM re-accreditation process was ongoing and a site visit was scheduled for 2019. Therefore, there was no pertinent CAHIIM Accreditation report to review for inclusion in this evaluation.

\section{Conclusion}

Program metrics point to the fact that there was some initial dissatisfaction among students following the addition of the IT courses and that there have been some significant changes in program metrics since the curriculum change. The percentage of students who changed back to the old curriculum from the new curriculum, and the decrease in enrollment clearly point to concerning changes that have occurred since the new curriculum was implemented. ISU's internal program review report reflects concern about these areas as well through the recommendation to monitor the impact of the curriculum change on such metrics and through the focus on student recruitment. The program metrics and program review reports clearly point to similar findings and concerns.

\section{Data Analysis Summary}

Once each individual group: students, graduates, and employers, was analyzed, the constant comparative method (Glaser, 1965) was again used to analyze the data and to identify the prevailing themes that existed between the groups. The HIM program metrics were also included in the analysis to provide further depth of information. The data from these sources were compared and contrasted through triangulation, which allowed for data verification and identification of all pertinent themes. The use of triangulation also increased trustworthiness of the analysis and enabled confirmation of findings. Once the data were analyzed in this manner several major themes emerged. These included: perceptions of student satisfaction and student 
preparedness, perceptions of the new curriculum, concerns about loss of parts of the old curriculum, and future needs for the ISU HIM program and for HIM in general. These major themes aligned closely with the research questions to be answered by this study:

1. What is the nature of current students, graduates, and employer experiences related to Health Information Management (HIM) curriculum shifts from the 2012 Commission of Accreditation for Health Informatics and Information Management Education (CAHIIM) curriculum standards to the 2014 revision?

a. What are student perceptions regarding the curriculum changes and preparedness for the HIM field?

b. What are graduate perceptions regarding the curriculum changes and preparedness for the HIM field?

c. What are employer perceptions regarding student preparedness for the HIM field for those students who have completed the new curriculum?

2. In what ways have the 2014 Commission of Accreditation for Health Informatics and Information Management Education (CAHIIM) curricular requirements shifted the entry-level skills and knowledge of Health Information Management graduates in comparison to the 2012 curriculum standards?

3. Consider the on-going changes in the CAHIIM curriculum requirements, what are the implications for the Health Information Management field and for individual programs moving forward?

The broad themes that were identified through the analysis and triangulation of data were, therefore, able to be used to answer these questions. While the themes that were identified closely aligned with the research questions to be answered, it was noted that there were some 
findings that stood out as interesting or unexpected. The concerns about the loss of parts of the old curriculum were interesting and somewhat unexpected based on the changes in the HIM field. In addition, the perceptions regarding the new and old curriculum sequences and the alignment of these perceptions with the sequences based on the individuals' areas of interest was also somewhat surprising.

\section{Student, Graduate, and Employer Experiences and Perceptions}

Overall students, graduates, and employers expressed positive experiences with and perceptions of the ISU HIM program, the new curriculum, and student preparedness. All students surveyed stated they were satisfied or highly satisfied with the HIM program. Students cited specific classes that they felt would benefit their career as well as attainment of skills, such as time management, that contributed to their satisfaction. Students also commented on the fact that the HIM program was a small program with significant individualized attention and stated that this was a positive aspect of the program; something that set HIM apart from other programs on ISU's campus. Graduates also expressed overall satisfaction with the HIM program, with statements such as it was a "great program." Graduates commented on the fact that the majority of classes were useful to them in their career and that their education had served them well in their first jobs and early career advancement. This is reflected in one graduate's statement, "I highly recommend this program.” Students and graduates also commented on the rigor of the program but expressed appreciation for the fact that the hard work required in the program helped prepare them for the field. Employers praised ISU's HIM program stating that the graduates were professional and that they were consistently pleased with the ISU graduates they hired. One employer stated that ISU was their "go-to" school when looking to hire new graduates to fill open positions. 
When focusing on the new curriculum specifically, the respondents had positive comments overall although there were some areas of concern. The groups were all aware that the HIM profession was moving toward a much greater focus on IT and data analytics and that this was the impetus behind the changes in the ISU HIM program curriculum. All groups understood that these changes were a result of the movement to Electronic Health Records (EHRs) and the additional data available through EHR systems. The students indicated a division in their perceptions of the new curriculum based on the curriculum they were completing. The students completing the new curriculum had more favorable perceptions of this curriculum than those completing the old curriculum. Students completing the new curriculum were pleased with the IT component because they felt that IT was the "future" of HIM and that it would broaden their career opportunities. Students in the new curriculum did express some concerns about a perceived disconnect between the IT and HIM classes as well as a lack of focus on healthcare IT. They did recognize that the program was in a period of transition and that the volume of changes during this time may lead to these issues. Students completing the old curriculum felt that while there may be advantages to the new curriculum, pieces of the old were still needed. Many students in the old curriculum chose that curriculum because they were more interested in management and traditional HIM roles than the IT or tech side of the profession. These students expressed concern over the loss of some of the management portions of the curriculum due to the change. Overall, however, students in both curriculum sequences expressed satisfaction with the sequence they were completing as well as the feeling that the sequence was the best fit for them. Graduates also commented on the fact that IT was a growing area of emphasis in the HIM arena and that these skills would open new doors for employment in areas such as EHRs, healthcare IT, and data analytics. Graduates provided specific IT skills they 
had learned and described how they had applied these skills in their workplaces. Employers noted that they used varying levels of IT skills on the job, however, they stated that they felt future graduates would need a strong background in IT and data analytics. To support this they referenced the changes in the field and the increased emphasis on IT as well as the fact that IT courses and knowledge increase skills such as critical thinking, which are also needed by new graduates. However, employers in more traditional HIM roles had concerns about the loss of skills from the old curriculum, including management and coding skills. These employers tended to be somewhat wary of the new curriculum changes.

Program metrics point to the fact that the curriculum change was not initially perceived as a positive change but that these perceptions may have changed over time. When the curriculum change was first implemented, a number of students transferred out of the new curriculum or out of the HIM major. In the first cohort, 14 students started in the new curriculum and only 4 (28\%) of those finished in the new curriculum. Changes were made during the first year of the new curriculum implementation, including hiring an IT tutor for HIM students in their first 2 IT courses, rearranging HIM class schedules to accommodate IT courses, and adding recommended pre-requisites to be taken prior to the first required pre-requisite IT course. The second cohort of students in the new curriculum had $70 \%$ of the students on track to complete the IT track by May 2019.

\section{New Graduate Preparedness}

When asked about perceptions of preparedness, $100 \%$ of the students surveyed felt that they were prepared or highly prepared for their career in HIM. Students emphasized the fact that they felt that the applied focus of the HIM program was preparing them for jobs in the field. One student stated, "It’s preparing us for the real world." Students stated that in their professional 
practices they were praised for the knowledge they had. One student stated, "When I was on my Junior Professional Practice, my supervisor told me that she was very surprised about all the knowledge that I had about everything, like some of the stuff that I knew, she honestly didn’t even know.” HIM program graduates stated that overall they felt prepared with $82 \%$ of survey respondents stating that they felt they were prepared well for the HIM field. The graduates who felt they were not as well prepared cited specific areas in which they felt their skills were lacking. One such area was billing and revenue cycle. It was noted that a number of graduates are working in billing and revenue cycle jobs, a newer career track for HIM graduates. Other graduates emphasized the fact that while they felt the HIM program provided them with basic HIM skills and knowledge, they had to learn many things on the job. These graduates also pointed to the fact that the HIM field is very diverse and therefore, it is hard for an educational program to prepare students completely in all areas. Graduates in both curriculum sequences stated that they felt prepared for the field, with 3/4 (75\%) of the graduates in the new curriculum, and 17/18 (95\%) of graduates in the old curriculum stating that they felt they were prepared or highly prepared.

When employers were asked about the preparedness of ISU HIM students and graduates, $100 \%$ responded that the students and graduates were prepared or highly prepared. Many respondents commented on the fact that they felt that ISU HIM students were better prepared than students from other schools. Areas in which employers felt that ISU students or graduates were particularly well prepared included medical coding, business operations and processes, traditional HIM functions, and professionalism. Some employers did mention that they felt preparedness was also a function of student maturity or new graduate discipline. They mentioned as well that some students or new graduates were lacking skills in communication, 
both oral and written, as well as other basic workplace skills. While very few employers that were surveyed or interviewed had hosted professional practice students or hired new graduates that had completed the new curriculum, most were familiar with the curriculum changes. Many employers pointed to the need for new graduates to have basic IT, critical thinking, and database skills. The employers stated that they felt the recent curriculum changes would improve the preparation of students in the needed areas of IT, data analytics, critical thinking, and data governance.

RHIA exam pass rates were also analyzed to evaluate student preparedness. It was noted that no graduates who had completed the new curriculum had taken the exam. However, the exam pass rates did reflect other changes that were made to the curriculum in 2016, such as the greater emphasis on data analytics. It was noted that there were no substantial differences in the exam pass rates between the 2016, 2017, and 2018 cohorts (93\%, 82\%, and 86\%, respectively). These pass rates are all above the national average which was $64 \%-67 \%$ during this time frame (American Health Information Management Association, 2018). This indicates that ISU HIM students were well prepared for the national certification exam.

\section{Shifts in Entry-Level Skills and Knowledge of ISU Health Information Management Graduates}

While overall all groups supported the new curriculum and felt that it would better prepare students for the future of HIM, all groups expressed somewhat mixed feelings about the change in the curriculum. Many had concerns focused on the skills and knowledge that students would gain in the new curriculum and skills and knowledge that they would lose from the elimination of parts of the old curriculum. First, there was concern among the groups as to the level of IT education students needed in order to be successful in the field. There was also 
concern regarding the effect that the curriculum change would have on student interest in the major and HIM major enrollment. Finally, it was noted that there were very definite divides among individuals in these groups based on the individuals' jobs, career paths, and interests. While there was overall understanding that IT and data analytics are foci of the direction the HIM profession is heading, some individuals felt that the traditional skills, jobs, and careers were still meaningful and needed.

Students, graduates, and employers all expressed concern regarding the rigor of and need for computer programming or coding, the focus of the first two IT pre-requisite courses. Many students found these courses to be very difficult and extremely time consuming, to the point of taking time away from time spent on their early HIM courses. In addition, students questioned the value of these courses and the need for these skills in the HIM field. While some students stated that they could see the benefit of these courses for use in future IT coursework or in their future careers, others did not agree. Students also expressed concerns that these first two IT courses, IT 168 and IT 178, were so difficult that they could discourage students from pursuing an HIM major. While graduates overall supported the new curriculum and expressed the value of this knowledge in the field, some expressed concerns similar to those of the students. Some graduates stated that they did not feel that computer programming was needed in the HIM field. These classes were mentioned as being the part of the curriculum that was the least helpful to the graduates' careers. Graduates also agreed that the programming courses were difficult and time consuming and created an extremely rigorous course load. Employer responses also reflected these same concerns. While employers praised the addition of IT to the HIM curriculum, some respondents did not feel that HIM students needed to learn or gain skills in computer programming as these skills were not needed in the HIM field. 
In addition, many had concerns about how the addition of the IT sequence would affect student enrollment and the major in the future. Students in the old curriculum brought up the fact that they felt not all students would want such a heavy IT focus. Many of them chose the old curriculum due to the fact that they did not feel comfortable with the technology portion of the new curriculum or that they did not want that focus in their careers. They reiterated that these issues could also drive future students away from the HIM major. Some graduates agreed, stating that they felt that IT was not a good fit for all. They stated that there were jobs in which higher levels of IT skills were not needed and that some individuals would prefer those career paths. While employers felt that IT skills and knowledge would help prepare graduates for many new jobs and would broaden their career opportunities, some employers stated that, in certain traditional career paths, the IT knowledge would not be that helpful. Enrollment rates in the ISU HIM major seemed to reflect some of the groups' concerns. Between 2015 and 2018 the number of juniors enrolled in the major dropped from 30 to 8.

Among all groups it was noticed that there was a strong divide between those who were pursuing IT or more non-traditional career paths and those pursuing more traditional HIM career paths. There was a high level of support for the new curriculum among those in the first group. Students, graduates, and employers in this group focused on the fact that they felt that IT and data analytics was the future of HIM, education in these areas would broaden career opportunities for new graduates, and these skills were essential to success in the field. Students, graduates, and employers in the more traditional group, while supportive of the new curriculum, expressed concerns about loss of knowledge and skills that occurred through the elimination of parts of the old curriculum. Many students in the old curriculum expressed concerns about the loss of that curriculum track for students who are more interested in management roles. These 
students focused on the fact that they chose the old curriculum based on their personal career goals and felt that the old curriculum best met those goals. They further stated that even students interested in pursuing a healthcare IT career could benefit from further management training. Students stated ideally it would be beneficial if CAHIIM allowed for management and IT sequences within an HIM program. Graduates also expressed similar concerns, with some pointing to the fact that the old curriculum provided preparation for graduates going directly into management positions. Other graduates recommended that future students minor in business to obtain such skills and some graduates recommended adding courses to the HIM curriculum that focused on other business topics such finance and accounting. Employers in more traditional roles expressed concerns about future ISU HIM graduates' skills in traditional areas such as medical coding. Many stated that ISU was known as being the HIM program that produced the best coders and that they depended on ISU for medical coders. These employers clearly stated their concerns about finding quality coders after the curriculum change at ISU.

\section{Future Needs in Health Information Management}

When discussing the future of the HIM program at ISU, all groups and individuals expressed satisfaction with the program and the direction in which it is heading. Students expressed satisfaction with the small size of the program and the individualized attention from faculty. They encouraged maintenance of this feature. Students in the new curriculum expressed the desire, moving forward, for better integration of the IT portion of the curriculum with the HIM portion of the curriculum. Students in the old curriculum recommended integration of more of the old content into the new curriculum. Students also recognized that due to the curriculum change, the type of student who might be drawn to the HIM major could change resulting in a student body more focused on IT. With all this in mind, the students 
expressed the desire for the HIM program to maintain its status as a healthcare major instead of becoming a part of the School of IT.

Graduates focused many of their comments about the future of the HIM program on the fact that they feel that the new curriculum is preparing students for the future of the HIM profession and broadening graduates' career opportunities. Graduates who did not complete the new curriculum expressed a desire to obtain IT skills through continuing education as they feel that these skills will be needed in the future.

Employers expressed overwhelming satisfaction with the ISU HIM program and the direction that the program is heading. They based this support on changes they foresee in the HIM field and the skills they feel that new graduates should possess. However, many employers expressed concerns about the loss of some of the fundamental HIM skills and knowledge, most specifically, coding. When asked about future changes in the curriculum competencies that were currently being considered, there was concern that the baccalaureate curriculum competencies were being watered down. Employers recommended that ISU's HIM program maintain the rigor of the curriculum and focus on the local and regional healthcare employers’ needs. Many employers expressed concerns that further changes in the curriculum might result in ISU HIM graduates who were not prepared to meet these local and regional workforce needs.

\section{Conclusions}

The data collected provided deep insight into students, graduates, and employers perceptions of the recent curriculum change in ISU's HIM program as well as their perceptions of student preparedness. Overall, all groups were pleased with the changes and felt that new graduates were well prepared. However, there were some concerns within groups or across groups. The predominant themes that were identified through analysis of this data were 
perceptions of student satisfaction and student preparedness, perceptions of the new curriculum, concerns about loss of parts of the old curriculum, and future needs for the ISU HIM program and for HIM in general. These themes and analysis of the data surrounding these themes allowed for addressing the questions to be answered by this study. 


\section{CHAPTER V: IMPLICATIONS AND ACTION PLAN \\ Illinois State University Health Information Management Program}

The recent changes in the Health Information Management (HIM) profession as well as related changes in the Commission on Accreditation for Health Informatics and Information Management Education (CAHIIM) curriculum requirements have led to a significant curriculum change the Illinois State University (ISU) HIM program. In order to determine the effectiveness of this curriculum change, preparedness of ISU HIM graduates, and the effect of the change on the program overall, this evaluative study was completed. This study was designed to collect information regarding these issues and to provide data that could be used not only for program evaluation but also for program improvement.

The data gathered in this evaluative study provide much insight regarding perceptions of the ISU HIM program as well as the effect of the new curriculum on this program. The students, graduates, and employers who contributed to this study provided valuable information that can be used by the HIM program for improvements in the existing program as well as continued improvements moving forward. Ongoing changes in the CAHIIM required curriculum competencies provide challenges for HIM educational programs. Educational program changes usually require multiple levels of approval and take place over an extended time frame. The rapid changes in the HIM profession have resulted in repeated rapid changes in the required curriculum for such programs. The information obtained in this study provide information to be used for an action plan for improvements related to the most recent curriculum change as well as for forthcoming changes.

Involvement of stakeholders throughout this study and the use of the utilization-focused evaluation methodology provides for the use of the study findings for improvement of the ISU HIM program. As recommended by Patton (2012), the stakeholders have been included in the data 
analysis and are aware of the perceptions of the students, graduates, and employers, as well as the program metrics. With the theoretical concept of evaluation capacity building, or ECB, in mind, it should be noted that the stakeholders are invested in the results of this study and wish to use these results to implement programmatic change and improvement (Suarez-Balcazar \& Taylor-Ritzler, 2014). Faculty, staff, and administration are aware that the recent curriculum change was significant and that future changes are on the horizon. Use of this study's findings will be an integral part of enacting improvements in the HIM program now and in the future as the program faces additional required changes.

Many of the individuals who participated in this study expressed positive perceptions regarding the changes in ISU's HIM curriculum and the HIM graduates’ preparedness for the field. They recognized the changes in the field and the need for the revised curriculum, including the increased emphasis on data analytics, information governance, and information technology (IT) (AHIMA Data Analytics, 2017, AHIMA Information Governance Basics, 2017, \& Burning Glass, 2014). However, there were a number of individuals whose statements and perceptions indicated concern regarding the CAHIIM required curriculum changes and the ability for HIM educational programs to prepare students for local workforce needs.

\section{Information Technology Issues}

Those participating in this study raised a number of issues regarding the information technology (IT) components of the new curriculum. Their concerns and comments provide room for improvement in this area. Even prior to this study, improvements in this area were made. In the fall of 2017, an IT tutor was hired by the Department of Health Sciences specifically for HIM students needing assistance in IT 168 and 178. The tutoring was held in the HIM lab in order to make the students feel more comfortable in their environment and to help them become familiar with the HIM 
program and facilities. In addition, in late 2017, two recommended courses were added to the HIM curriculum. These courses, IT 164 and MAT 119, were added as recommendations for students to complete prior to starting the IT 168 course as they would help prepare students for the rigor of the initial IT programming course, IT 168. These courses are now recommended for all students who have no programming background and/or who have not completed a college algebra level course.

In addition to commenting on these changes that were made prior to this study, respondents provided many valuable recommendations that could be implemented. Some of the most commonly cited concerns regarding the IT sequence revolved around the required pre-requisite IT programming courses, IT 168 and IT 178. Questions were raised regarding the value of these courses in future IT courses and in the HIM field. In addition, students and graduates bemoaned the rigor of these courses and the concern they had that these courses took their time away from other HIM major courses. Regardless of the students' perceptions of these courses, they are required by the IT department as pre-requisites prior to the HIM major required IT courses. However, the HIM Program Director discussed this concern with IT students and faculty. When asked how these programming courses can benefit the students and why they are required for other IT courses that do not require programming, it was noted that these courses help students develop critical thinking, logic, and problem solving skills. These are all skills that will benefit students in future IT courses as well as in other areas of the HIM field. This information can be provided to reassure students that, while these courses are difficult and time consuming, they are valuable to their future in both IT classes and in the HIM field.

Another area of concern among students was that IT faculty seem to be unaccepting of HIM students in their classes or assume that HIM students have had the same background and experiences as the IT major students. This situation has arisen, in part, because the HIM students are the only 
non-IT majors in some of the IT courses. While the Chair of the School of IT has been quite supportive of the inclusion of HIM students in select IT courses, not all of the faculty are aware of or as supportive of this decision. The HIM Program Director will continue to work with the Chair of the School of IT to ensure ongoing faculty support of HIM students in their classes. One suggestion that has been made, and will be investigated further, is for the HIM program to work with the IT department to develop separate sections of the IT classes specifically for HIM students.

Students and graduates also raised concerns regarding the integration of IT and HIM classes and course content. This is an area that HIM faculty and IT faculty will need to collaborate on to insure that all faculty are aware of material covered in all courses and to enable cross-over and content connections. As the curriculum change is recent and the last mixed-curriculum cohort students are currently seniors, this is an important need for the 2019-2020 school year. These collaborative efforts should also result in a stronger healthcare IT focus within the major as well as additional HIM faculty support of students related to healthcare IT jobs and opportunities.

One of the most difficult issues involving the new curriculum is fitting the IT sequence into transfer students' schedules and ensuring time to degree. Many students highly recommended that students be advised to take IT 168 and IT 178 early in their college career, before starting their HIM major courses in the junior year. While this is the 4-year degree plan for native ISU students, this cannot be done for transfer students. In the last two years, scheduling difficulties and heavy course loads have affected transfer students' grades as well as time to degree. In the 2018 cohort 4/4 students had to attend an extra summer or semester to complete their degree requirements. While these students also completed minors in IT during that time, extra semester attendance is problematic for some students and is a negative metric for the program. HIM faculty will continue to work with the Department of Health Sciences Academic Advisor to improve upon this situation. If possible, 
students will be encouraged to take IT classes at their community colleges that they can transfer in for IT 168 and IT 178.

Continuing to develop close ties with the IT department and working with them to ensure HIM student success in their courses is essential to the new curriculum. As the faculty and staff improve upon these issues, students will experience fewer problems and frustrations with the new curriculum.

\section{Inclusion of Old Curriculum Content in New Curriculum}

While many expressed concerns about loss of some of the old curriculum content, much of this content has been incorporated into the new curriculum through integration into other courses. However, there are some areas that have not been incorporated. Economics and some higher-level management content were removed from the curriculum. Trends in Health Information Management, a course that included guest speakers from various non-hospital healthcare settings has been eliminated. Finally, and perhaps, most significantly, one medical coding class has been eliminated. There is obviously concern among many that these content areas are still required or desired by students, graduates, and employers. In fact, some graduates asked for more business content in the HIM program, citing a lack of skills and knowledge in the billing and revenue cycle management arena.

This is an area that HIM faculty will need to investigate further. Additional courses cannot be added due to the limit on the number of hours required for a major at ISU. The HIM curriculum currently has no allowance for electives as most students' schedules are full. Dividing the program into sequences, as some students suggested, is not an option according to CAHIIM required competencies. However, incorporating more of this content into existing courses is a consideration. Guest speakers who spoke in the Trends in Health Information Management class can be brought 
into other classes or to the Student Health Information Management Association meetings. Students who have extra time in their schedules can be encouraged to take management or business classes if that is their area of interest. On-going evaluation and monitoring of the curriculum and the effect of the change once it is fully implemented will also be important in addressing this area. The effects of the deletion of the coding class will continue to be monitored closely as this was a large area of concern among local employers.

\section{Student Recruitment}

While many individuals providing information for this study touched on this issue, very few, if any, actually mentioned recruitment. Many students, graduates, and employers expressed concerns about the number of students in the major decreasing due to the fact that not all students are interested in an IT heavy major. With the changes in the HIM profession and the resultant changes in the required CAHIIM curriculum competencies, the ISU HIM program must move forward and include IT as a significant portion of the HIM curriculum. Based on student and graduate comments, it is clear that the new curriculum will not attract the same types of students as the old curriculum. Many current and former HIM students were individuals who were interested in nursing but didn’t want to deal with the hands-on side of healthcare. These students were not always technologyfocused or interested in IT. It is felt that these types of students will, therefore, not be interested in an IT heavy HIM major. It is also clear, based on program metrics, that enrollment in the HIM major has decreased significantly since the curriculum change.

The HIM program must, therefore, work to recruit and attract a different type of student body. The profession’s national association, American Health Information Management Association (AHIMA), is working to get HIM classified as a STEM field. However, this process is not complete and may not be for several years. Therefore, the ISU HIM program must find ways to recruit STEM 
students for the new HIM curriculum. Forays into new recruitment strategies are underway and the HIM Program Director has been working with the Chair of the School of IT on campus-wide ITrelated major recruitment. The HIM faculty are also working closely with the Department of Health Sciences academic advisor to ensure recruitment of students with healthcare and IT interests.

In addition, further evaluation of this change as well as future curriculum changes should delve deeper into the changes' effects on students by gender, race, and ethnicity. Issues of equity, diversity, and inclusion should be considered both for student recruitment as well as student retention.

\section{On-going Evaluation of the Health Information Management Program}

The HIM field is in the midst of a time of great transition. There are significant changes in the field due to the advent of Electronic Health Records (EHRs). The need for IT skills to manage these EHRs and for data analytic skills to use the data that can be produced by EHRs has led to one of the most noteworthy changes in the HIM field to date. To provide appropriately educated, prepared, new HIM professionals for this changed filed, HIM educational programs were required to implement the most recent CAHIIM curriculum competencies by the fall of 2017. However, the changes in the field are so great that CAHIIM already has another set of curriculum competencies under review to be released before the end of 2018. ISU's HIM program is still implementing changes related to the last set of curriculum competencies, yet further changes are coming. This leads to the significance of the current study and to the need for ongoing program evaluation.

One of the tenets of the new proposed curriculum competencies is that the competencies have more flexibility and can be implemented to insure that an educational program is meeting their local needs. This study provides valuable information regarding the needs of the HIM workforce in ISU's local and regional area. Continued study in this vein will therefore be an integral part of the ISU 
HIM program's ability to meet CAHIIM curriculum competency requirements that serve the local area. Such study can also provide ongoing feedback as to the perceptions regarding the current and future curriculum changes. Further study may show, for example, that by reducing one medical coding class, ISU is no longer serving the local medical coding workforce needs. This could result in the need for further changes to the curriculum in order to improve the program for involved stakeholders, including students, graduates, and employers.

CAHIIM requires annual surveys of students, graduates, and employers. Questions on the surveys that ISU's HIM program uses for this purpose can be revised or added to in order to obtain deeper information about these groups' perceptions of the ISU HIM program and the curriculum. Such information is particularly important after any curriculum changes. This information, coupled with program metrics, and occasional interviews or focus groups, could easily provide data that could be used in an ongoing utilization-focused evaluation program designed to insure ongoing improvement of ISU's HIM program. When improvement changes are made based on such data, the program can feel confident that they are making improvements that are meaningful and will serve their stakeholders well (Judd \& Keith, 2018).

\section{Health Information Management Educational Community}

This evaluative study addresses many issues surrounding the latest CAHIIM curriculum competency requirements and the manner in which Illinois State University (ISU)'s Health Information Management (HIM) program implemented the required curriculum changes. While each program has the ability to implement the requirements in their own manner, it is assumed that there are similarities throughout the HIM educational community. One would also assume that HIM educational programs face similar challenges and that support, concerns, and complaints from program stakeholders are comparable. 


\section{Evaluative Program Guide}

This evaluative study provides an excellent guide for Health Information Management (HIM) program evaluation. While many HIM programs complete multiple program evaluation activities, frequently these activities are not used to implement meaningful programmatic improvements. By adopting a utilization-focused evaluation methodology and undertaking evaluation building capacity, HIM programs can easily add to their existing program evaluation activities and build a meaningful evaluation program.

A Utilization-Focused Evaluation (UFE) framework is useful in such evaluations due to the fact that it focuses on use of the findings to make positive changes in the program (Patton, 2012). In conjunction with this, use of the concept of Evaluation Capacity Building (ECB) is helpful in that it can insure that the faculty, department chair, dean, and other stakeholders understand the evaluative process and are ready to use the results for positive change (SuarezBalcazar \& Taylor-Ritzler, 2014). The combination of UFE and ECB results in a higher likelihood that the results of an evaluative study will be used. Implementation of such a program evaluation methodology can provide an educational program with valuable data that can be used to make meaningful programmatic changes.

The latest proposed CAHIIM curriculum competencies to be released in December 2018 are said to focus on flexible implementation in order to meet local needs. With this in mind, program evaluation is needed now more than ever. An HIM educational program cannot truly understand their local workforce needs without input from their stakeholders, including students, graduates, and employers.

The current study outlines the use of multiple data collection methods from multiple sources to provide useful and meaningful data. CAHIIM requires HIM programs to survey 
students, graduates, and employers to obtain information about their program. Revision of these surveys' questions or additions to these surveys can provide in depth information about the perceptions that these groups have about the program, any recent curriculum changes, or any forthcoming changes. In addition to surveys, HIM programs are also required to maintain a number of metrics. Objective measurements such as student retention, student completion rates, and RHIA examination pass rates can be used in conjunction with subjective data gathered through surveys to provide a more complete picture of the HIM program.

Depending on the focus of the evaluation, additional subjective data collection methods, such as focus groups and interviews can be used. For example, if local workforce needs are the focus of the evaluation, additional data should be gathered from employers through one of these methods. Collection of these types of data allow a program to delve deeply into their stakeholders' perceptions and get a true picture of the strengths and weaknesses of the program and curriculum.

Once data are collected, they can be analyzed through the methods outlined in this study. Quantitative data can be analyzed using basic descriptive statistics while qualitative data can be analyzed through the constant comparative method (Glaser, 1965). This method allows for analysis through comparisons and contrasts that eventually lead to the identification of broad categories and major themes in the data. These categories and themes can then be triangulated with the quantitative data to allow for data verification and identification of all pertinent themes discovered in the evaluation (Judd \& Keith, 2018).

\section{Use of Evaluation Results}

HIM professionals and educators are familiar with the concept of relying on data and are also accustomed to implementing quality improvements. Therefore, the evaluative study 
methodology should not be an unfamiliar concept and faculty should be comfortable using data from such activities.

Evaluations such as those outlined in this study can provide invaluable information to an individual HIM program as well as to the profession as a whole. The results of an evaluative study can point to areas needing improvement as well as to areas in which the program is doing well (Grayson, 2018). Some results may lead to the need to delve deeper to determine sources of problems and potential improvements. Using a UFE methodology helps to insure that key stakeholders understand the data and the need for programmatic improvements that may be identified through the data (Patton, 2012). This methodology provides additional support for implementation of changes for improvement.

Following changes and programmatic improvements, further evaluative monitoring should be completed to insure that the changes resulted in true improvement (Widrick, Mergen, \& Grant, 2002). This provides for on going improvement processes based on data and input from a variety of sources.

\section{National Implications}

As stated previously, the HIM profession is undergoing dramatic changes. This, in turn, has resulted in significant changes in the HIM educational program curriculum requirements. These CAHIIM required curriculum changes are being made quickly and require fast responses from educational programs. The 2014 Curriculum Competencies were required to be implemented in the fall of 2017. In April of 2018, changes in the baccalaureate competencies were released that were to be implemented in May of 2018. In June 2018, a draft of new curriculum competences was released, these to be approved by December 2018 and implemented in 2020-2021. 
At every American Health Information Management Association (AHIMA), Assembly on Education (AOE) conference, attendees voice concerns about the latest curriculum changes and the implementation of these changes. There are always concerns expressed in regards to how educational programs can meet these requirements as well as how they can assure appropriate student preparation. While many express these concerns, the general feeling is usually that CAHIIM does not place much emphasis on the educators' concerns and complaints. One method that could be used to gain CAHIIM attention is for these individuals to follow through with an evaluation of the implementation of the changes in their program, their alignment with CAHIIM curriculum requirements, and the effect these changes have on their student preparation.

If HIM educational programs from across the country provided such results to CAHIIM, it would result in a rich source of data for CAHIIM's use in developing curriculum requirements. Such evaluative data would include input from students, graduates, and employers. Workforce needs in areas across the country could be analyzed and trends could be identified. Student and graduate preparedness could be evaluated and alignment between preparedness and workforce needs could be assessed. Challenges in implementing required curriculum competencies could be identified and appropriate modifications could be made.

Perhaps most importantly, local trends could be identified. Flexible curriculum requirements could be met in ways that would best serve the educational programs' local workforce needs. HIM educational programs would have data backing up the reasoning behind curriculum implementation decisions. Programs could easily show how their implementation of the curriculum competencies meets their local workforce needs. Educational programs could ensure that their students were prepared for the jobs in their area. For example, if well-educated 
coders were in high demand in a particular area, the HIM program in that area would have the justification to offer additional coding classes to serve that need. This would prepare the program’s graduates for the local job market as well as serve the local healthcare community by meeting their workforce needs.

HIM Educational programs are required to collect a range of program evaluation data. In addition, these programs are staffed by faculty who are familiar with data analysis and quality improvement processes. With this in mind, the natural conclusion is that it should be easy for HIM educational programs to implement meaningful evaluation programs that provide data that can be used for programmatic improvement. Such efforts, if completed on a nationwide level, could result in individual programs with better-prepared students as well as implementation of national curriculum requirements that fit local workforce needs nationwide. 


\section{CHAPTER VI: CONCLUSION}

\section{Background}

In an effort to improve patient care and increase efficiencies in healthcare, in 2009, the United States government passed the Health Information Technology for Economic and Clinical Health Act (HITECH). This act encouraged the use of technology in healthcare and led to significant changes in one of the key components of healthcare, the patient record. This act led to the widespread adoption of Electronic Health Records (EHRs) throughout all levels of care in the healthcare field. Those who were responsible for the management of the patient record, Health Information Management (HIM) professionals, saw significant changes in their roles based on the new information technology (IT) focus. The change from paper to electronic records led to significant increases in the amount of IT and data analytics' knowledge and skills HIM professionals needed to possess. These changes in knowledge and skills needed for the field led to changes in the type of educational training needed for HIM professionals.

To that end, the Health Information educational accrediting body, the Commission on Accreditation for Health Informatics and Information Management Education (CAHIIM), published new required curriculum competencies in 2014 that were required to be put into place in all educational programs by the fall of 2017. These curriculum changes were significant and

included new topic areas as well as more extensive coverage of other areas. The newly required curriculum competencies required much greater emphasis on information technology, data analytics, and information governance. Due to the extent of the changes, many educational programs faced challenges implementing these changes, as was the case at Illinois State University in their HIM educational program. Courses had to be added and modified; the addition of courses meant rearranging and eliminating older courses so that students could still 
graduate within the four-year time frame and so that total credit hours were not exceeded. Faculty had to learn new skills in certain areas or find other options for some courses, such as those focused on higher level IT skills. For example, ISU's HIM program chose to have students take courses in the School of IT in order to obtain the level of IT skills needed for the field.

Despite these challenges, it was essential that HIM programs insure that they were preparing students appropriately for the new needs of the profession. The extent of the changes and the need to insure adequate student preparation led to the need to evaluate curriculum and programmatic revisions to insure that program goals were being met. This evaluative study was, therefore, designed to focus on an evaluation of the changes in one HIM program, specifically focusing on the ability of the changes to adequately prepare students for the current HIM field. This evaluative study was to be utilization-focused, meaning the results of the evaluation would be used by stakeholders for continuous program improvement. It was hoped that the findings would be used not only to benefit the program under review but also to provide insight for other HIM academic programs.

This evaluation was completed using an in-depth case study of the HIM academic program at ISU. After release of the new curriculum competencies by CAHIIM in 2014, the ISU HIM program completed a gap analysis. This analysis compared the existing curriculum to the new curriculum competencies required to be enacted by 2017. There were a number of areas that were identified in which curriculum had to be added in order to meet the new requirements. These were primarily in the IT and data analytics areas. Between 2014 and 2016, multiple changes were made to the curriculum by the HIM faculty. ISU started implementing these changes to the curriculum during the Fall of 2016 and fully transitioned to teaching only the new 
curriculum with students entering the junior year of the program in the Fall of 2018. These curricular changes included the following:

The addition of six information technology classes selected to cover the IT competencies of information assurance and security, systems development, and project management; these classes include: IT 168 - Structured Problem Solving Using the Computer, IT 178 - Computer Application Programming, IT 250 Fundamentals of Information Assurance and Security, IT 254 - Hardware and Software Concepts, IT 261 - Systems Development, and IT 262 - Information Technology Project Management.

The removal of three economics and management classes that were felt to overlap with HSC 346 - Healthcare Finance, and HSC 320 - Organization and Management of Health Information Services. The classes that were removed include ECO 105 - Principles of Economics, MQM 220 - Business Organization and Management, and MQM 323 - Human Resources Management.

- $\quad$ Extensive revisions to the Health Information Data Analysis and Introduction to Health Information Management classes to include further information regarding data analysis and data governance, as well as a much greater focus on the use of electronic health record systems.

- $\quad$ The integration of the Health Information Technology and Trends in Health Information Management classes into other existing HIM classes. Basic health information technology skills as well as non-traditional healthcare settings, the main topics of these two classes, were integrated throughout the HIM curriculum. 
Due to University policies regarding curriculum changes, these changes were implemented with the 2016 University Course Catalog. This meant that all incoming freshmen in the Fall of 2016 as well as some transfer students who started at ISU in the Fall of 2016 were required to complete the new curriculum. Other transfer students were given the option of completing the new or the old curriculum. This resulted in a transition process in which two cohorts of students, those graduating in 2018 and 2019, had a mix of students completing the old and new curricula.

Due to the fact that this curriculum change was so extensive, it was felt that a formal evaluation of the program curriculum change was needed to determine the impact of the CAHIIM curriculum change at ISU. This evaluation needed to include not only the impact of this change on student preparedness, but also on the program as a whole, including enrollment and retention, time to graduation, and Registered Health Information Administrator (RHIA) examination pass rates. This evaluation was designed to be quality improvement focused as well as utilization-focused; the goal being that the findings would be used to improve the curriculum and program.

\section{Methods and Theoretical Framework}

A variety of methods were, therefore, used to collect data and evaluate the program and the curriculum change. In order to delve deeply into the issues surrounding student preparedness and perceptions regarding the curriculum change, surveys, interviews, and focus groups were used to gather information from students, graduates, and employers. Various program metrics, such as enrollment rate, retention rate, new curriculum transfer rate, time to graduation, and RHIA examination pass rates were also included. It was felt that using data from various sources 
would allow for the most complete picture of the perceived and actual effects of the curriculum change on the ISU HIM program.

As one of the main goals of the evaluative study was for the findings to be used for improvement of the ISU HIM program, a utilization-focused evaluation framework was followed. This framework focuses on use of the evaluative findings for program improvement (Patton, 2012). In addition, this framework includes the close involvement of stakeholders throughout the evaluative process so that the stakeholders learn about the evaluative process and better understand this process. This results in a higher level of support for continuous, ongoing quality evaluative practices and leads to the use of the findings to improve systems and processes in the educational program (Preskill \& Boyle, 2008). This is known as evaluation capacity building (ECB), which is an integral part of the utilization-focused framework.

These concepts were appropriate for this study since the study findings were meant to be used to determine the effect of the curriculum change on the HIM program as well as to be used for programmatic improvements. The faculty had worked extensively prior to this evaluative study to insure that the new curriculum changes were implemented appropriately according to the CAHIIM requirements. Through these activities, the faculty and department chair had been building ECB and truly desired a meaningful evaluation of the program and curriculum changes that could be used for programmatic improvement and assurance that students' needs were being met. The stakeholders also understood the need for an on-going evaluative process that could be used moving forward as further curriculum changes were enacted in the future.

Based on research from Palomba and Banta (1999) and Patton (2012), this evaluative study was designed to evaluate how effective the HIM program was in preparing students for the field. Therefore, the focus was on the program, not on individual students. Various groups were 
surveyed, interviewed, or invited to participate in focus groups to provide in depth data regarding their experiences with the program and their perceptions of the program and of student preparedness. Senior students were surveyed and were invited to participate in focus groups specific to their curriculum under completion in order to provide information about their perceptions of the program as well as their feelings of preparedness. Graduates were surveyed for in-depth information about their experiences in the program as well as their perceptions of preparedness when entering the HIM field. Employers were surveyed and select employers were interviewed in order to gain insight into their perceptions of the ISU HIM program as well as their experiences with ISU HIM students and new graduates. Data gathered from each of these groups was analyzed using the constant comparative method and broad themes were identified. The groups' data was eventually analyzed together through the constant comparative method and overall themes were identified. HIM program metrics were initially analyzed using descriptive statistics then were combined with the qualitative data collected from the groups. The data from these various sources was compared and contrasted via triangulation to allow for data verification and identification of all pertinent themes. This process increased trustworthiness and allowed for confirmation of findings.

\section{Findings and Data Analysis}

Through the methodology outline above, several major themes were identified. These were: perceptions of student satisfaction and student preparedness, perceptions of the new curriculum, concerns about loss of parts of the old curriculum, and future needs for the ISU HIM program and for HIM education in general. These major themes aligned closely with the questions to be answered by this study and were used to address those questions and to identify the implications of the findings. 
Overall all groups felt that ISU's HIM program was quite effective in their implementation of the new curriculum and in preparing new graduates for the field. Students and graduates cited satisfaction with the program and their preparedness and employers responded that ISU's HIM program was very highly regarded. Most respondents stated that they agreed with the curriculum changes because they felt that those changes were needed to prepare students for the future of HIM. There were some concerns, however, regarding the addition of programming classes, as well as a feeling that not all students would want such a high emphasis on IT within the HIM program. There were also some concerns about loss of some of the traditional HIM skills that were still needed in the field. Program metrics provided backing for these concerns, in that a number of students switched from the new to old curriculum, if possible, and overall enrollment decreased.

It was noted that there was a strong divide between students, graduates, and employers who were pursuing or currently in less traditional, more IT related careers and those pursuing or in the more traditional career paths. There was a higher level of support for the new curriculum among those in the first group and a greater focus on the loss of traditional knowledge and skills among those in the second group. Students recommended two tracks or sequences within the HIM educational program, one focused on IT, and the other on more traditional HIM skills and management.

When looking towards the future needs of the ISU HIM program, many respondents stated that they were pleased with the direction in which the program was heading. However, again, some voiced concerns about the loss of some fundamental HIM skills. Another area of concern among respondents led to recommendations that ISU continue to maintain the rigor of their program and not allow it to be watered down by potential future curriculum changes. 
Finally, many respondents expressed concerns about local needs and maintenance of student preparedness for local needs moving forward.

\section{Implications}

The data gathered in this study provides great insight into the perceptions of the ISU HIM program as well as the effect of the new curriculum on this program. In addition, completion of this evaluative study provides a model for ISU's HIM program evaluation in the future as well as for HIM educational program evaluation in general.

For ISU’s HIM program, the findings of this study point to clear areas where improvement can be made as well as to areas to be considered. Based on the use of the utilization-focused framework as well as evaluation capacity building in this study, HIM faculty and staff are well prepared to use these evaluation findings and implement needed changes for programmatic improvement. In fact, based on student, graduate, and employer feedback prior to or during but outside of this study, some improvements have already been implemented.

It is clear that students struggle in the early IT programming classes. Some improvement initiatives have already been completed in this area such as the addition of recommended prerequisites and of an HIM specific IT tutor. Additional communications have taken place with the Chair of the School of IT regarding the value of these classes for HIM students as well as continued reminders to IT faculty that the HIM students come to these courses with different backgrounds than most IT majors.

Student and graduate respondents voiced the desire for greater integration between IT and HIM classes. This provides an opportunity for HIM faculty to work more closely with IT faculty to collaborate on content connections to improve student learning and preparedness. There was also concern voiced about the heavy workload for transfer students who are taking the early IT 
programming classes at the same time as their first HIM major courses. Again, this provides an opportunity for HIM faculty and staff to work on advising students about community college IT options they could complete before starting at ISU or providing additional support for students with this heavy workload during their first year at ISU.

A number of respondents expressed concern over the loss of course content, and therefore student and graduate skills, related to more traditional HIM functions and management. This is an area of consideration for HIM faculty. Further curriculum requirement changes are forthcoming which may have further effects in this area. Purportedly, these changes will be designed to be more flexible so that educational programs can insure that local needs are being met. Further evaluative study may be needed in this area to fully determine local needs moving forward and to assess this particular area of the curriculum. In the meantime, the faculty can consider incorporating more of this content into existing courses, utilizing guest speakers as appropriate, and encouraging interested students to pursue such coursework as electives.

Concerns among respondents regarding student interest in an IT heavy HIM major combined with HIM program metrics identifies student recruitment as being an important component of HIM program improvement. HIM program metrics clearly demonstrate that enrollment in the HIM major has decreased significantly since the curriculum change. While this study did not intend to provide statistical cause-and-effect evidence for this change, it is a notable decrease. HIM faculty and staff are aware that the new curriculum, with its increased focus on IT, will attract a different type of student than the old curriculum. Thus, HIM faculty and staff will need to focus on recruitment of STEM students for the new curriculum. Several forays into the needed changes in HIM student recruitment have been investigated and additional recruitment strategies will need to be implemented. 
The current evaluative study provides a clear model for future studies within the ISU HIM program as well as within HIM educational programs across the country. The HIM field is still in the midst of great and rapid change. Now that Electronic Health Records (EHRs) have been widely adopted, the focus is on improvement of these systems as well as use of the vast amounts of data available through these systems. In addition, patient privacy and security have become areas of greater concern with data breaches and hacks of EHR systems occurring at regular intervals. As the profession moves forward new challenges and new needs will continuously arise. In November 2018, the American Health Information Management Association (AHIMA) released their 2019 Strategic Plan, which points to further changes in the HIM field. In addition, CAHIIM is expected to release new curriculum competencies before the end of 2018. The change is occurring at a rapid pace, which challenges HIM academic programs to keep up. ISU’s HIM program has not even fully transitioned to the most recent CAHIIM curriculum change, yet new changes are coming.

As stated previously, the new proposed curriculum changes are supposed to be designed with more flexibility so that programs can implement them in a way that provides for student preparedness to meet the local workforce needs. As all these changes are implemented, and with the potential for flexibility to meet local needs, evaluation of such needs and the effectiveness of academic program changes will increase in importance. Evaluative studies can provide feedback as to the perceptions of involved stakeholders: students, graduates, and/or employers, regarding student preparedness and changes that are needed to meet local needs.

CAHIIM requires collection of some of this data. However, in most cases academic programs will need to add to this data and use this data to truly assess the effectiveness of their programs and their student preparedness. This study provides a model for how such evaluation 
can be completed in a meaningful way to identify areas of needed improvement and to ensure stakeholder involvement so that improvements can be implemented and ongoing quality evaluation can continue. Widrick, Mergen, \& Grant (2002) pointed to this through their recommendation to use the results of such studies to determine the needed areas of improvement and change, implement those changes, and monitor the results of those changes for true program improvement.

Such evaluative studies, if completed on a wide-spread basis, could also be used to inform CAHIIM and other decision makers as to the actual local workforce needs, current student preparedness, and areas of needed improvement or change. Such data could be used to justify curriculum decisions made under a flexible framework to insure that CAHIIM curriculum requirements continue to be met while also insuring local needs are being satisfied.

\section{Conclusion}

With rapid changes in the HIM field, followed quickly by CAHIIM curriculum requirement changes, HIM academic programs are challenged to insure that CAHIIM requirements are met and that students are adequately prepared for the HIM field they are entering. Evaluative studies provide an excellent method to be used to truly assess the effectiveness of the HIM academic program in meeting their goals of CAHIIM accreditation and insuring student preparedness. Anecdotal data and informal evaluation and assessment alone will not provide the depth of data needed for true evaluation of a program and for meaningful program improvement (Steake, Contreras, \& Arbesu, 2018).

This evaluative study resulted in valuable data regarding the HIM program at ISU, the effects on the program of the recent curriculum change, and student preparedness. In addition, this study provides a model for future use in ISU's HIM program as well as in other HIM 
academic programs. Through use of such studies and ongoing programmatic improvement, HIM programs can insure they are meeting their goals and that they are truly preparing students for the future of Health Information Management. 


\section{REFERENCES}

ACICS. (2010). History of accreditation. Retrieved from http://www.acics.org/accreditation/content.aspx?id=2258.

AHIMA. (2017). Data analytics. Retrieved from http://www.ahima.org/topics/ida.

AHIMA. (2017). Information governance basics. Retrieved from http://www.ahima.org/topics/infogovernance/igbasics.

AHIMA. (2017). Who we are. Retrieved from http://www.ahima.org.

American Health Information Management Association. (2018). Registered Health Information Administrator Report. Retrieved from https://www.ahimareports.com.

Apple, M. W. (2005). Education, markets, and an audit culture. Critical Quarterly, 47(1-2), 1129.

Armstrong, P. (2018). Bloom's taxonomy. Retrieved from https://cft.vanderbilt.edu/guides-subpages/blooms-taxonomy/.

Barry, J. M. (2004). The great influenza: The epic story of the deadliest plague in history. New York: Viking.

Bledstein, B. J. (1976). The culture of professionalism: the middle class and the development of higher education in America. New York: Norton.

Buchan, V., Rodenhiser, R., Hull, G., Smith, M, Rogers, J., Pike, C., \& Ray, JoAnn. (2004). Evaluating an assessment tool for undergraduate social work education: Analysis of the Baccalaureate Educational Assessment Package. Journal of Social Work Education, 40(2). 
Burning Glass (2014). Missed opportunities? The labor market in Health Informatics, 2014.

Retrieved from http://burning-glass.com/wp-content/uploads/BGHealth_Informatics_2014.pdf.

CAHIIM. (2012). Standards and interpretations for accreditation of baccalaureate degree programs in health information management. Retrieved from http://www.cahiim.org/documents/2012_HIM_Bacc_Stndrds.pdf.

Commission on Accreditation for Health Informatics and Information Management Education. (2017). Welcome to CAHIIM. Retrieved from http://www.cahiim.org.

Coffey, A. \& Atkinson, P. (1996). Making sense of qualitative data: Complementary research strategies. Thousand Oaks, CA: Sage.

Cohen, A. M., \& Kisker, C. B. (2010). The shaping of American higher education: Emergence and growth of the contemporary system. San Francisco, CA: Jossey-Bass Publishers.

El-Khawas, E. (2001). Accreditation in the USA: Origins, developments and future prospects. Retrieved from http://unesdoc.unesco.org/images/0012/001292/129295e.pdf.

Erlandson, D. A. (2018). Naturalistic Evaluation. In C. Secolsky \& D. B. Denison (Eds.), Handbook on measurement, assessment, and evaluation in higher education (pp. 473489). New York, NY: Routledge.

Flores, A. (2017). Accreditation is broken. Time to repair it. The Chronicle of Higher Education. Retrieved from http://www.chronicle.com/article/Accreditation-Is-Broken$\underline{\operatorname{Tim} / 240086 .}$

Gallagher, S. R. (2016). The Future of University Credentials: New Developments at the Intersection of Higher Education and Hiring. Cambridge, MA: Harvard Education Press. 
Glaser, B. G. (1965). The constant comparative method of qualitative analysis. Social Problems, 12(4), 436-445.

Glesne, C. (2006). Becoming qualitative researchers: An introduction ( $3^{\text {rd }}$ ed.). New York: Pearson Education, Inc.

Godfrey, K. E., \& Finkelstein, D. B. (2018) Responsive Evaluation. In C. Secolsky \& D. B. Denison (Eds.), Handbook on measurement, assessment, and evaluation in higher education (pp. 490-499). New York, NY: Routledge.

Grayson, T. E. (2018). Program evaluation, performance measures, and evaluability assessment in higher education. In C. Secolsky \& D. B. Denison (Eds.), Handbook on measurement, assessment, and evaluation in higher education (pp. 455-472). New York, NY:

Routledge.

Guthrie, L. A., \& Seybert, J. A. (2018). Benchmarking in community colleges. In C. Secolsky \& D. B. Denison (Eds.), Handbook on measurement, assessment, and evaluation in higher education (pp. 114-127). New York, NY: Routledge.

Harper, S. R., \& Hurtado, S. (2007). New Directions for Student Services: Nine themes in campus racial climates and implications for institutional transformation. Hoboken, NJ: Wiley Periodicals, Inc.

Harper, S. R., Patton, L. D., \& Wooden, O. S. (2009). Access and equity for African American students in higher education: A critical race historical analysis of policy efforts. The Journal of Higher Education, 80(4), 389-414.

Illinois State University. (2018). Review of the B.S. in Health Information Management Consultative Draft. Normal, IL 
Illinois State University. (2018). Review of the B.S. in Health Information Management Overview. Normal, IL

Institute for Teaching, Learning, and Academic Leadership. (n.d.). What is the difference between "assessment" and "evaluation"? University at Albany. Retrieved from http://www.itlal.org/index.php?q=node/93.

Judd, T., \& Keith, B. (2018). Implementing undergraduate student learning outcomes assessment at the program and institutional levels. In C. Secolsky \& D. B. Denison (Eds.), Handbook on measurement, assessment, and evaluation in higher education (pp. 69-86). New York, NY: Routledge.

Kelderman, E. (2013). Obama's accreditation proposals surprise higher-education leaders. The Chronicle of Higher Education. Retrieved from https://www.chronicle.com/article/Obamas-Accreditation/137311.

Labin, S. N., Duffy, J. L., Meyers, D. C., Wandersman, A., \& Lesesne, C. A. (2012). A research synthesis of the evaluation capacity building literature. American Journal of Evaluation, 00(0), 1-32.

Laden, B. V. (2004). Hispanic-Serving Institutions: What are they? Where are they? Community College Journal of Research and Practice, 28(3), 181-198.

Leathwood, C. (2005). Assessment policy and practice in higher education: Purpose, standards and equity. Assessment \& Evaluation in Higher Education, 30(3), p. 307-324.

Lincoln, Y. S., \& Guba, E. G. (1985). Naturalistic inquiry. Newbury Park, CA: Sage Publications, Inc.

Lorenz, C. (2012). If you're so smart, why are you under surveillance? Universities, neoliberalism, and new public management. Critical Inquiry, 38, 599-629. 
Maldonado, D. E. Z., Rhoads, R., \& Buenavista, T. L. (2005). The Student-Initiated Retention Project: Theoretical contributions and the role of self-empowerment. American Educational Research Journal, 42(4), 605-638.

McClellan, G. S., Fox, M. J. T., \& Lowe, S. C. (2005). New Directions for Student Services: Where we have been: A history of Native American higher education. Hoboken, NJ: Wiley Periodicals, Inc.

Miles, M. B., Huberman, A. M., \& Saldana, J. (2014). Qualitative data analysis: A methods sourcebook. Thousand Oaks, CA: Sage.

Obama, B. (2013). The president's plan for a strong middle class and a strong America. Washington, D.C.: The White House. Retrieved from https://obamawhitehouse.archives.gov/the-press-office/2013/02/12/president-s-planstrong-middle-class-and-strong-america.

Palkie, B. (2013, December). Perceived knowledge of health informatics competencies by Health Information Management professionals. AHIMA Body of Knowledge. Retrieved from http://bok.ahima.org/doc?oid=300534\#.WI0hEzKZPJw.

Palomba, C. A., \& Banta, T. W. (1999). Assessment Essentials: Planning, Implementing, and Improving Assessment in Higher Education. San Francisco, CA: Jossey-Bass Publishers.

Patton, M. Q. (2012). Essentials of utilization-focused evaluation. Thousand Oaks, California: Sage Publications.

Preskill, H. \& Boyle, S. (2008). A multidisciplinary model of evaluation capacity building. American Journal of Evaluation, 1-17. Doi: 10.1177/1098214008324182.

Pugh, W. J. (1995). A 'Curious Working of Cross Purposes' in the founding of the University of Chicago. History of Higher Education Quarterly, 15, 93-126. 
Reeves, R. V. (December 8, 2017). College and the end of upward mobility. The Chronicle of Higher Education. Retrieved from https:/www.chronicle.com/article/collegethe-end-ofupward/241916.

Rickards, W. H. (2018). Talking about data: The faculty discourse on practice, student learning, and evaluative processes. . In C. Secolsky \& D. B. Denison (Eds.), Handbook on measurement, assessment, and evaluation in higher education (pp. 100-113). New York, NY: Routledge.

Skrla, L. Scheurick, J. J., Garcia, J., Nolly, G. (2004). Equity audits: A practical leadership tool for developing equitable and excellent schools. Education Administration Quarterly, 40(1), P. 133-161.

St. John, E. P., Daun-Barnett, N., \& Moronski-Chapman, K. M. (2013). Public Policy and Higher Education. New York, NY: Routledge.

Stake, R. E., Contreras, G., \& Arbesu, I. (2018). Assessing the quality of a university, particularly its teaching. In C. Secolsky \& D. B. Denison (Eds.), Handbook on measurement, assessment, and evaluation in higher education (pp. 35-46). New York, NY: Routledge.

Strauss, A. L. \& Corgin, J.M. (1998). Basics of qualitative research: Techniques and procedures for developing grounded theory ( $2^{\text {nd }}$ ed.). Thousand Oaks: Sage.

Stufflebeam, D. L. (Spring 2001). New Directors for Evaluation: Evaluation Models. San Francisco, CA: Jossey-Bass.

Stufflebeam, D. L. \& Coryn, C. L. S. (2014). Evaluation Theory, Models, and Applications. (2 ${ }^{\text {nd }}$ Ed.). San Francisco, CA: Jossey-Bass Publishers. 
Suarez-Balcazar, Y. \& Taylor-Ritzler, T. (2014). Moving from science to practice in evaluation capacity building. American Journal of Evaluation, 35(1), 95-99.

Thelin, J. R. (2004). A history of American higher education. Baltimore, MD: The Johns Hopkins University Press.

Tyler, R. W. (1949). Basic Principles of Curriculum and Instruction. Chicago, IL: The University of Chicago Press.

U.S. Department of Health \& Human Services. (2017). HITECH Act Enforcement Interim Final Rule. Retrieved from https://www.hhs.gov/hipaa/for-professionals/specialtopics/HITECH-act-enforcement-interim-final-rule/index.html?language=es.

Veysey, L. (1965). The emergence of the American university. Chicago: University of Chicago Press.

Volkov, B. B. \& King, J. A. (2007). A checklist for building organizational evaluation capacity. Retrieved from http://www.dmeforpeace.org/sites/default/files/Volkov\%20and\%20King_Checklist\%20fo r\%20Building\%20Organizational\%20Evaluation\%20Capacity.pdf.

Widrick, S. M., Mergen, E., \& Grant, D. (2002). Measuring the dimensions of quality in higher education. Total Quality Management, 13(1), 123-131. 


\section{INFORMATION MANAGEMENT (HIM) AT THE}

\section{BACCALAUREATE DEGREE LEVEL}

\begin{tabular}{|l|c|c|}
\hline Entry-Level Competencies & $\begin{array}{c}\text { Required } \\
\text { Bloom's } \\
\text { Level }\end{array}$ & $\begin{array}{c}\text { Curricular Considerations - These are } \\
\text { topics programs may use to guide } \\
\text { students to achieve the competency at the } \\
\text { required Bloom's taxonomy level. }\end{array}$ \\
\hline
\end{tabular}

Domain I. Data Content, Structure \& Standards (Information Governance)

\section{Subdomain I.A. Classification Systems}

\begin{tabular}{|l|c|l|}
\hline $\begin{array}{l}\text { 1. Evaluate, implement and } \\
\text { manage electronic } \\
\text { applications/systems for clinical } \\
\text { classification and coding }\end{array}$ & 5 & $\begin{array}{l}\text { * Encoders, Computer Assisted Coding } \\
\text { (CAC), Systems Development Life Cycle }\end{array}$ \\
\hline $\begin{array}{l}\text { 2. Identify the functions and } \\
\text { relationships between healthcare } \\
\text { classification systems }\end{array}$ & 3 & $\begin{array}{l}\text { * Healthcare Classification Systems, } \\
\text { taxonomies, nomenclatures, terminologies } \\
\text { and clinical vocabularies (ICD, CPT, } \\
\text { SNOMED-CT, DSM, RxNorm: Standard } \\
\text { Clinical Drug Naming catalog) }\end{array}$ \\
\hline $\begin{array}{l}\text { 3. Map terminologies, } \\
\text { vocabularies and classification } \\
\text { systems }\end{array}$ & 4 & $\begin{array}{l}\text { * Mapping from a standard clinical } \\
\text { terminology to a HIPAA code set (LOINC } \\
\text { to CPT or SNOMED to ICD); Mapping } \\
\text { from one code set to another code set (one } \\
\text { revision of ICD to another) }\end{array}$ \\
\hline $\begin{array}{l}\text { 4. Evaluate the accuracy of } \\
\text { diagnostic and procedural coding }\end{array}$ & 5 & $\begin{array}{l}\text { * Principles and applications of } \\
\text { Classification Systems and auditing }\end{array}$ \\
\hline
\end{tabular}

Subdomain I.B. Health Record Content and Documentation

1. Verify that documentation in the health record supports the

4

* Health record components for all record types 


\begin{tabular}{|c|c|c|}
\hline $\begin{array}{l}\text { diagnosis and reflects the patient's } \\
\text { progress, clinical findings, and } \\
\text { discharge status }\end{array}$ & & \\
\hline $\begin{array}{l}\text { 2. Compile organization-wide } \\
\text { health record documentation } \\
\text { guidelines }\end{array}$ & 6 & $\begin{array}{l}\text { * Standards and regulations for the Joint } \\
\text { Commission, Commission on Accreditation } \\
\text { of Rehabilitation Facilities (CARF), \& } \\
\text { Centers for Medicare and Medicaid Services } \\
\text { CMS); Health record documentation policies } \\
\text { and procedures }\end{array}$ \\
\hline $\begin{array}{l}\text { 3. Interpret health information } \\
\text { standards }\end{array}$ & 5 & \\
\hline \multicolumn{3}{|l|}{$\begin{array}{l}\text { Subdomain I.C. Data } \\
\text { Governance }\end{array}$} \\
\hline $\begin{array}{l}\text { 1. Format data to satisfy } \\
\text { integration needs }\end{array}$ & 4 & $\begin{array}{l}\text { * Interoperability principles; Capture, } \\
\text { structure, and use of health information }\end{array}$ \\
\hline $\begin{array}{l}\text { 2. Construct and maintain the } \\
\text { standardization of data dictionaries } \\
\text { to meet the needs of the enterprise }\end{array}$ & 6 & $\begin{array}{l}\text { * Data sources and data dictionary } \\
\text { composition }\end{array}$ \\
\hline $\begin{array}{l}\text { 3. Demonstrate compliance with } \\
\text { internal and external data } \\
\text { dictionary requirements }\end{array}$ & 3 & $\begin{array}{l}\text { * Accreditation standards for The Joint } \\
\text { Commission, National Committee for } \\
\text { Quality Assurance (NCQA), CARF, } \\
\text { Community Health Accreditation Program } \\
\text { (CHAP), Utilization Review Accreditation } \\
\text { Commission (URAC), HL7, American } \\
\text { Society for Testing and Materials (ASTM), } \\
\text { Healthplan Employer Data Information Sets } \\
\text { (HEDIS), Outcome and Assessment } \\
\text { Information Set (OASIS), and Uniform } \\
\text { Hospital Discharge Data Set (UHDDS) }\end{array}$ \\
\hline $\begin{array}{l}\text { 4. Advocate information } \\
\text { operability and information } \\
\text { exchange }\end{array}$ & 5 & $\begin{array}{l}\text { * Interoperability Standards and Health } \\
\text { Information Exchanges (HIEs) }\end{array}$ \\
\hline \multicolumn{3}{|l|}{$\begin{array}{l}\text { Subdomain I.D. Data } \\
\text { Management }\end{array}$} \\
\hline $\begin{array}{l}\text { 1. Analyze information needs of } \\
\text { customers across the healthcare } \\
\text { continuum }\end{array}$ & 4 & \\
\hline
\end{tabular}




\begin{tabular}{|c|c|c|}
\hline $\begin{array}{l}\text { 2. Evaluate health information } \\
\text { systems and data storage design }\end{array}$ & 5 & $\begin{array}{l}\text { * Storage media, disaster recovery, and } \\
\text { cloud computing }\end{array}$ \\
\hline $\begin{array}{l}\text { 3. Manage clinical } \\
\text { indices/databases/registries }\end{array}$ & 5 & $\begin{array}{l}\text { * Policies for secondary data sources, } \\
\text { registries, and indices }\end{array}$ \\
\hline $\begin{array}{l}\text { 4. Apply knowledge of database } \\
\text { architecture and design to meet } \\
\text { organizational needs }\end{array}$ & 3 & $\begin{array}{l}\text { * Data dictionary, data modeling, and data } \\
\text { warehousing; Database architecture and } \\
\text { design }\end{array}$ \\
\hline $\begin{array}{l}\text { 5. Evaluate data from varying } \\
\text { sources to create meaningful } \\
\text { presentations }\end{array}$ & 5 & \\
\hline \multicolumn{3}{|c|}{ Subdomain I.E. Secondary Data Sources } \\
\hline $\begin{array}{l}\text { 1. Validate data from secondary } \\
\text { sources to include in the patient's } \\
\text { record, including personal health } \\
\text { records }\end{array}$ & 3 & $\begin{array}{l}\text { * Data stewardship \& Information } \\
\text { Governance Standards; Patient-Centered } \\
\text { Health Information technology and portals }\end{array}$ \\
\hline \multicolumn{3}{|c|}{ Domain II. Information Protection: Access, Disclosure, Archival, Privacy \& Security } \\
\hline \multicolumn{3}{|l|}{ Subdomain II.A. Health Law } \\
\hline $\begin{array}{l}\text { 1. Identify laws and regulations } \\
\text { applicable to health care }\end{array}$ & 3 & $\begin{array}{l}\text { * Health information laws and regulations } \\
\text { including HIPAA, The Joint Commission, } \\
\text { State laws, and Centers for Medicare and } \\
\text { Medicaid Services (CMS) }\end{array}$ \\
\hline $\begin{array}{l}\text { 2. Analyze legal concepts and } \\
\text { principles to the practice of HIM }\end{array}$ & 4 & \\
\hline \multicolumn{3}{|c|}{ Subdomain II.B. Data Privacy, Confidentiality \& Security } \\
\hline $\begin{array}{l}\text { 1. Analyze privacy, security and } \\
\text { confidentiality policies and } \\
\text { procedures for internal and } \\
\text { external use and exchange of } \\
\text { health information }\end{array}$ & 4 & $\begin{array}{l}\text { * Patient verification and identity } \\
\text { management policies; Privacy, } \\
\text { confidentiality, security principles, policies } \\
\text { and procedures, and federal/state laws; E- } \\
\text { Discovery }\end{array}$ \\
\hline $\begin{array}{l}\text { 2. Recommend elements included } \\
\text { in the design of audit trails and } \\
\text { data quality monitoring programs }\end{array}$ & 5 & $\begin{array}{l}\text { * Data security (audits, controls, data } \\
\text { recovery, e-security, disaster recovery } \\
\text { planning, and business continuity planning) }\end{array}$ \\
\hline $\begin{array}{l}\text { 3. Collaborate in the design and } \\
\text { implementation of risk assessment, } \\
\text { contingency planning, and data } \\
\text { recovery procedures }\end{array}$ & 4 & $\begin{array}{l}\text { * Health information archival and retrieval } \\
\text { systems; Data security protection methods } \\
\text { (authentication, encryption, decryption, and } \\
\text { firewalls) }\end{array}$ \\
\hline
\end{tabular}




\begin{tabular}{|c|c|c|}
\hline $\begin{array}{l}\text { 4. Analyze the security and } \\
\text { privacy implications of mobile } \\
\text { health technologies }\end{array}$ & 4 & \\
\hline $\begin{array}{l}\text { 5. Develop educational programs } \\
\text { for employees in privacy, security, } \\
\text { and confidentiality }\end{array}$ & 6 & $\begin{array}{l}\text { * Privacy \& security laws/regulations, adult } \\
\text { education strategies, and training methods }\end{array}$ \\
\hline \multicolumn{3}{|c|}{ Subdomain II.C. Release of Information } \\
\hline $\begin{array}{l}\text { 1. Create policies and procedures } \\
\text { to manage access and disclosure of } \\
\text { personal health information }\end{array}$ & 6 & $\begin{array}{l}\text { * Principles for releasing PHI; Elements of } \\
\text { an authorization }\end{array}$ \\
\hline $\begin{array}{l}\text { 2. Protect electronic health } \\
\text { information through } \\
\text { confidentiality and security } \\
\text { measures, policies and procedures }\end{array}$ & 3 & * Audit techniques and principles \\
\hline \multicolumn{3}{|c|}{$\begin{array}{l}\text { Domain III. Informatics, Analytics and Data } \\
\text { Use }\end{array}$} \\
\hline \multicolumn{3}{|c|}{$\begin{array}{l}\text { Subdomain III.A. Health Information } \\
\text { Technologies }\end{array}$} \\
\hline $\begin{array}{l}\text { 1. Utilize technology for data } \\
\text { collection, storage, analysis, and } \\
\text { reporting of information }\end{array}$ & 3 & $\begin{array}{l}\text { * Health information archival and retrieval } \\
\text { systems; Computer concepts (hardware } \\
\text { components, network systems architecture } \\
\text { operating systems and languages, software } \\
\text { packages and tools, and cloud computing } \\
\text { applications) }\end{array}$ \\
\hline $\begin{array}{l}\text { 2. Assess systems capabilities to } \\
\text { meet regulatory requirements }\end{array}$ & 5 & $\begin{array}{l}\text { * Electronic signatures, data correction, and } \\
\text { audit logs }\end{array}$ \\
\hline $\begin{array}{l}\text { 3. Recommend device selection } \\
\text { based on workflow, ergonomic } \\
\text { and human factors }\end{array}$ & 5 & * Human factors and user interface design \\
\hline $\begin{array}{l}\text { 4. Take part in the development of } \\
\text { networks, including intranet and } \\
\text { Internet applications }\end{array}$ & 4 & $\begin{array}{l}\text { * Communication technologies (Network- } \\
\text { LANS, WANS, WLANS, and VPNs); } \\
\text { Internet technologies (Intranet, web-based } \\
\text { systems, standards SGML, and XML) }\end{array}$ \\
\hline $\begin{array}{l}\text { 5. Evaluate system architecture, } \\
\text { database design, data warehousing }\end{array}$ & 5 & $\begin{array}{l}\text { * System testing; Interface management; } \\
\text { Data relationships }\end{array}$ \\
\hline $\begin{array}{l}\text { 6. Create the electronic structure } \\
\text { of health data to meet a variety of } \\
\text { end user needs }\end{array}$ & 6 & $\begin{array}{l}\text { * Data information and file structures (data } \\
\text { administration, data definitions, data } \\
\text { dictionary, data modeling, data structures, } \\
\text { data warehousing, and database } \\
\text { management systems) }\end{array}$ \\
\hline
\end{tabular}




\begin{tabular}{|c|c|c|}
\hline $\begin{array}{l}\text { 1. Take part in the development of } \\
\text { information management plans } \\
\text { that support the organization's } \\
\text { current and future strategy and } \\
\text { goals }\end{array}$ & 4 & $\begin{array}{l}\text { * Corporate strategic plan, operation } \\
\text { improvement planning, and information } \\
\text { management plans; Disaster and recovery } \\
\text { planning }\end{array}$ \\
\hline $\begin{array}{l}\text { 2. Take part in the planning, } \\
\text { design, selection, implementation, } \\
\text { integration, testing, evaluation, } \\
\text { and support of health information } \\
\text { technologies }\end{array}$ & 4 & $\begin{array}{l}\text { * Systems development life cycle (systems } \\
\text { analysis, design, implementation, } \\
\text { evaluation, maintenance, EHRs, HIEs, and } \\
\text { RECs) }\end{array}$ \\
\hline \multicolumn{3}{|c|}{$\begin{array}{l}\text { Subdomain III.C. Analytics and Decision } \\
\text { Support }\end{array}$} \\
\hline $\begin{array}{l}\text { 1. Apply analytical results to } \\
\text { facilitate decision-making }\end{array}$ & 3 & * Data display, power point, and dashboards \\
\hline $\begin{array}{l}\text { 2. Apply data extraction } \\
\text { methodologies }\end{array}$ & 3 & $\begin{array}{l}\text { * Healthcare statistical formulas (LOS, } \\
\text { death, birth, and infection rates); Data } \\
\text { capture tools and technologies (forms, } \\
\text { computer screens, templates, other health } \\
\text { record documentation tools; clinical, } \\
\text { financial, and administrative) }\end{array}$ \\
\hline $\begin{array}{l}\text { 3. Recommend organizational } \\
\text { action based on knowledge } \\
\text { obtained from data exploration and } \\
\text { mining }\end{array}$ & 5 & \\
\hline $\begin{array}{l}\text { 4. Analyze clinical data to identify } \\
\text { trends that demonstrate quality, } \\
\text { safety, and effectiveness of } \\
\text { healthcare }\end{array}$ & 4 & $\begin{array}{l}\text { * Descriptive statistics (mean, standard } \\
\text { deviation, ranges, and percentiles); } \\
\text { Inferential statistics (T-tests, ANOVA, } \\
\text { regression analysis, reliability, and validity); } \\
\text { Epidemiological applications }\end{array}$ \\
\hline $\begin{array}{l}\text { 5. Apply knowledge of database } \\
\text { querying and data exploration and } \\
\text { mining techniques to facilitate } \\
\text { information retrieval }\end{array}$ & 3 & \\
\hline $\begin{array}{l}\text { 6. Evaluate administrative reports } \\
\text { using appropriate software }\end{array}$ & 5 & \\
\hline \multicolumn{3}{|c|}{ Subdomain III.D. Health Care Statistics } \\
\hline 1. Interpret inferential statistics & 5 & $\begin{array}{l}\text { * Inferential statistics (T-tests, ANOVA, } \\
\text { regression analysis, reliability, and validity); } \\
\text { Computerized statistical packages (SPSS \& } \\
\text { SAS) }\end{array}$ \\
\hline $\begin{array}{l}\text { 2. Analyze statistical data for } \\
\text { decision making }\end{array}$ & 4 & $\begin{array}{l}\text { * Data reporting of statistical healthcare data } \\
\text { and presentation techniques }\end{array}$ \\
\hline
\end{tabular}




\begin{tabular}{|l|l|l|}
\hline $\begin{array}{l}\text { Subdomain III.E. Research } \\
\text { Methods }\end{array}$ & 3 & $\begin{array}{l}\text { * Research design/methods (quantitative, } \\
\text { qualitative, evaluative, mixed, and } \\
\text { outcomes); Literature review and evaluation; } \\
\text { Knowledge-based research techniques } \\
\text { (Medline, CMS libraries, AHRQ, and other } \\
\text { websites) }\end{array}$ \\
\hline $\begin{array}{l}\text { 1. Apply principles of research and } \\
\text { clinical literature evaluation to } \\
\text { improve outcomes }\end{array}$ & 3 & $\begin{array}{l}\text { * National guidelines regarding human- } \\
\text { subjects research (IRB process); Research } \\
\text { protocol data management }\end{array}$ \\
\hline $\begin{array}{l}\text { 2. Plan adherence to Institutional } \\
\text { Review Board (IRB) processes } \\
\text { and policies }\end{array}$ & &
\end{tabular}

\section{Subdomain III.F. Consumer Informatics}

\begin{tabular}{|l|c|l|}
\hline $\begin{array}{l}\text { 1. Educate consumers on patient- } \\
\text { centered health information } \\
\text { technologies }\end{array}$ & 3 & $\begin{array}{l}\text { * Patient centered medical homes; Patient } \\
\text { portals, patient safety, and patient education; } \\
\text { Personal Health Record (PHR) }\end{array}$ \\
\hline
\end{tabular}

\section{Subdomain III.G. Health Information Exchange}

1. Collaborate in the development of operational policies and procedures for health information exchange

2. Conduct system testing to ensure data integrity and quality of health information exchange

3. Differentiate between various models for health information exchange

* Research design/methods (quantitative, qualitative, evaluative, mixed, and Knowledge-based research techniques (Medline, CMS libraries, AHRQ, and other websites)

* National guidelines regarding humanprotocol data management

Subdomain III.H. Information Integrity and Data Quality

\begin{tabular}{|l|c|l|}
\hline $\begin{array}{l}\text { 1. Discover threats to data } \\
\text { integrity and validity }\end{array}$ & 3 & $\begin{array}{l}\text { * Intrusion detection systems, audit design, } \\
\text { and principles }\end{array}$ \\
\hline $\begin{array}{l}\text { 2. Implement policies and } \\
\text { procedures to ensure data integrity } \\
\text { internal and external }\end{array}$ & 3 & $\begin{array}{l}\text { * Authentication, encryption, and password } \\
\text { management }\end{array}$ \\
\hline 3. Apply quality management tools & 3 & $\begin{array}{l}\text { * Control charts, pareto charts, fishbone } \\
\text { diagrams and other statistical process } \\
\text { control techniques }\end{array}$ \\
\hline $\begin{array}{l}\text { 4. Perform quality assessment } \\
\text { including quality management, } \\
\text { data quality, and identification of } \\
\text { best practices for health } \\
\text { information systems }\end{array}$ & 4 & $\begin{array}{l}\text { * Data quality assessment and integrity; } \\
\text { Disease management process (case } \\
\text { management, critical paths, and care } \\
\text { coordination); Outcomes measurement } \\
\text { (patient as patient, customer satisfaction, } \\
\text { and disease specific); Patient and }\end{array}$ \\
\hline
\end{tabular}




\begin{tabular}{|l|l|l|} 
& & organization safety initiatives \\
\hline $\begin{array}{l}\text { 5. Model policy initiatives that } \\
\text { influence data integrity }\end{array}$ & 3 & \\
\hline $\begin{array}{l}\text { Domain IV. Revenue } \\
\text { Management }\end{array}$ & \\
\hline
\end{tabular}

Subdomain IV. A. Revenue Cycle and Reimbursement

\begin{tabular}{|l|l|l|}
\hline & & $\begin{array}{l}\text { * Clinical data management; Case mix } \\
\text { management; Reimbursement management; } \\
\text { Payment Systems (Prospective Payment } \\
\text { System (PPS), DRGs, Resource-Based } \\
\text { Relative Value Scale (RBRVS), Resource } \\
\text { Utilization Groups (RUG), Value-Based } \\
\text { Purchasing (VBP), MSDRGs, commercial, } \\
\text { managed care, and federal insurance plans); } \\
\text { 1. Manage the use of clinical data } \\
\text { reimbursement systems } \\
\text { inpating and reimbursement at hospital } \\
\text { and other delivery settings }\end{array}$ \\
\hline $\begin{array}{l}\text { 2. Take part in selection and } \\
\text { development of applications and } \\
\text { processes for chargemaster and } \\
\text { claims management }\end{array}$ & 5 & $*$ Chargemaster management \\
\hline $\begin{array}{l}\text { 3. Apply principles of healthcare } \\
\text { finance for revenue management }\end{array}$ & 3 & * Cost reporting, budget variances, and \\
\hline
\end{tabular}


4. Implement processes for revenue cycle management and reporting
* Corrective Coding Initiative (CCI)Electronic Billing X12N; Compliance strategies and reporting; Audit process (compliance and reimbursement); Revenue cycle process; Utilization and resource management

Domain V. Compliance

Subdomain V.A. Regulatory

\begin{tabular}{|c|c|c|}
\hline $\begin{array}{l}\text { 1. Appraise current laws and } \\
\text { standards related to health } \\
\text { information initiatives }\end{array}$ & 5 & $\begin{array}{l}\text { * Compliance strategies and reporting; } \\
\text { Regulatory and licensure requirements; } \\
\text { Elements of compliance programs; Patient } \\
\text { safety }\end{array}$ \\
\hline $\begin{array}{l}\text { 2. Determine processes for } \\
\text { compliance with current laws and } \\
\text { standards related to health } \\
\text { information initiatives and revenue } \\
\text { cycle }\end{array}$ & 5 & $\begin{array}{l}\text { * Policies and procedures; Non-retaliation } \\
\text { policies; Auditing and monitoring }\end{array}$ \\
\hline \multicolumn{3}{|l|}{ Subdomain V.B. Coding } \\
\hline $\begin{array}{l}\text { 1. Construct and maintain } \\
\text { processes, policies, and procedures } \\
\text { to ensure the accuracy of coded } \\
\text { data based on established } \\
\text { guidelines }\end{array}$ & 6 & $\begin{array}{l}\text { *UHDDS and Federal compliance } \\
\text { guidelines; Official coding guidelines from } \\
\text { CMS, AMA, National Committee on Vital } \\
\text { and Health Statistics (NCHVS), National } \\
\text { Correct Coding Initiative (NCCI), and AHA }\end{array}$ \\
\hline 2. Manage coding audits & 5 & * Audit principles and reporting \\
\hline $\begin{array}{l}\text { 3. Identify severity of illness and } \\
\text { its impact on healthcare payment } \\
\text { systems }\end{array}$ & 3 & $\begin{array}{l}\text { * Case mix; Computer Assisted Coding } \\
\text { (CAC) systems }\end{array}$ \\
\hline
\end{tabular}

\section{Subdomain V.C. Fraud} Surveillance

1. Determine policies and procedures to monitor abuse or fraudulent trends

\section{Subdomain V.D. Clinical Documentation Improvement}

1. Implement provider querying techniques to resolve coding discrepancies
* Query process (written, verbal, \& template

3 queries; timeliness \& interpretation; and query retention) 


\begin{tabular}{|l|l|l|}
$\begin{array}{l}\text { 2. Create methods to manage } \\
\text { Present on Admission (POA), }\end{array}$ & & $*$ Clinical Documentation Improvement \\
$\begin{array}{l}\text { Hospital Acquired Conditions } \\
\text { (HACs), and other CDI }\end{array}$ & 6 & $\begin{array}{l}\text { (CDI) metrics and reporting process } \\
\text { (concurrent, retrospective, and post-bill } \\
\text { review) }\end{array}$ \\
\hline
\end{tabular}

\section{Domain VI. Leadership}

\section{Subdomain VI.A. Leadership \\ Roles}

\begin{tabular}{|c|c|c|}
\hline $\begin{array}{l}\text { 1. Take part in effective } \\
\text { negotiating and use influencing } \\
\text { skills }\end{array}$ & 4 & \\
\hline $\begin{array}{l}\text { 2. Discover personal leadership } \\
\text { style using contemporary } \\
\text { leadership theory and principles }\end{array}$ & 3 & \\
\hline $\begin{array}{l}\text { 3. Take part in effective } \\
\text { communication through project } \\
\text { reports, business reports and } \\
\text { professional communications }\end{array}$ & 4 & \\
\hline $\begin{array}{l}\text { 4. Apply personnel management } \\
\text { skills }\end{array}$ & 3 & $\begin{array}{l}\text { * Communication and interpersonal skills; } \\
\text { Leadership and governance }\end{array}$ \\
\hline $\begin{array}{l}\text { 5. Take part in enterprise-wide } \\
\text { committees }\end{array}$ & 4 & $\begin{array}{l}\text { * Facilitation, networking, and consensus } \\
\text { building }\end{array}$ \\
\hline 6. Build effective teams & 6 & * Team/consensus building \\
\hline
\end{tabular}

Subdomain VI.B. Change Management

\begin{tabular}{|l|c|l|}
\hline $\begin{array}{l}\text { 1. Interpret concepts of change } \\
\text { management theories, techniques } \\
\text { and leadership }\end{array}$ & 5 & $\begin{array}{l}* \text { Change management; Risk exposure; } \\
\text { Organizational design and mergers }\end{array}$ \\
\hline Subdomain VI.C. Work Design and Process Improvement \\
\hline $\begin{array}{l}\text { 1. Analyze workflow processes } \\
\text { and responsibilities to meet } \\
\text { organizational needs }\end{array}$ & 4 & $\begin{array}{l}* \text { Workflow reengineering and workflow } \\
\text { design techniques }\end{array}$ \\
\hline $\begin{array}{l}\text { 2. Construct performance } \\
\text { management measures }\end{array}$ & 6 & $\begin{array}{l}* \text { Benchmarking techniques (productivity } \\
\text { standards, report cards, and dashboards) }\end{array}$ \\
\hline 3. Demonstrate workflow concepts & 3 & $\begin{array}{l}* \text { Use cases; Top down diagrams; Swimlane } \\
\text { diagrams }\end{array}$ \\
\hline $\begin{array}{l}\text { Subdomain VI.D. Human Resources } \\
\text { Management }\end{array}$ & \multicolumn{2}{l}{} \\
\hline
\end{tabular}




\begin{tabular}{|c|c|c|}
\hline $\begin{array}{l}\text { 1. Manage human resources to } \\
\text { facilitate staff recruitment, } \\
\text { retention, and supervision }\end{array}$ & 5 & $\begin{array}{l}* \text { Principles of human resources } \\
\text { management (recruitment, supervision, } \\
\text { retention, counseling, and disciplinary } \\
\text { action) }\end{array}$ \\
\hline $\begin{array}{l}\text { 2. Ensure compliance with } \\
\text { employment laws }\end{array}$ & 5 & $\begin{array}{l}\text { * Employment laws and labor laws } \\
\text { (federal/state); Equal Employment } \\
\text { Opportunity Commission (EEOC) }\end{array}$ \\
\hline $\begin{array}{l}\text { 3. Create and implement staff } \\
\text { orientation and training programs }\end{array}$ & 6 & \\
\hline $\begin{array}{l}\text { 4. Benchmark staff performance } \\
\text { data incorporating labor analytics }\end{array}$ & 4 & \\
\hline $\begin{array}{l}\text { 5. Evaluate staffing levels and } \\
\text { productivity, and provide feedback } \\
\text { to staff regarding performance }\end{array}$ & 5 & $\begin{array}{l}\text { * Performance standards; Professional } \\
\text { development in self and others }\end{array}$ \\
\hline \multicolumn{3}{|l|}{$\begin{array}{l}\text { Subdomain VI.E. Training and } \\
\text { Development }\end{array}$} \\
\hline $\begin{array}{l}\text { 1. Evaluate initial and on-going } \\
\text { training programs }\end{array}$ & 5 & \\
\hline \multicolumn{3}{|c|}{ Subdomain VI.F. Strategic and Organizational Management } \\
\hline $\begin{array}{l}\text { 1. Identify departmental and } \\
\text { organizational survey readiness for } \\
\text { accreditation, licensing, and/or } \\
\text { certification processes }\end{array}$ & 3 & $\begin{array}{l}\text { * Accreditation standards (The Joint } \\
\text { Commission, National Committee for } \\
\text { Quality Assurance (NCQA), Commission on } \\
\text { Accreditation of Rehabilitation Facilities } \\
\text { (CARF), Community Health Accreditation } \\
\text { Partners (CHAP), Utilization Review } \\
\text { Accreditation Commission (URAC), } \\
\text { Provider credentialing requirements, and } \\
\text { CMS Conditions of Participation) }\end{array}$ \\
\hline $\begin{array}{l}\text { 2. Implement a departmental } \\
\text { strategic plan }\end{array}$ & 3 & $\begin{array}{l}\text { * Strategic planning, critical thinking, and } \\
\text { benchmarking }\end{array}$ \\
\hline $\begin{array}{l}\text { 3. Apply general principles of } \\
\text { management in the administration } \\
\text { of health information services }\end{array}$ & 3 & * Organizational structures and theory \\
\hline $\begin{array}{l}\text { 4. Evaluate how healthcare policy- } \\
\text { making both directly and } \\
\text { indirectly impacts the national and } \\
\text { global healthcare delivery systems }\end{array}$ & 5 & * State, local, and federal policies \\
\hline $\begin{array}{l}\text { 5. Identify the different types of } \\
\text { organizations, services, and } \\
\text { personnel and their } \\
\text { interrelationships across the health } \\
\text { care delivery system }\end{array}$ & 3 & $\begin{array}{l}\text { * Payers/providers in all delivery settings; } \\
\text { Accountable Care Organizations (ACOs) } \\
\text { and Managed Care Organizations (MCOs); } \\
\text { Medical devices and biotech }\end{array}$ \\
\hline
\end{tabular}




\begin{tabular}{|l|c|l|}
\hline $\begin{array}{l}\text { 6. Collaborate in the development } \\
\text { and implementation of information } \\
\text { governance initiatives }\end{array}$ & 4 & \\
\hline $\begin{array}{l}\text { 7. Facilitate the use of enterprise- } \\
\text { wide information assets to support } \\
\text { organizational strategies and } \\
\text { objectives }\end{array}$ & 4 & $\begin{array}{l}\text { * Information management planning; } \\
\text { Enterprise information management; Master } \\
\text { data/information management }\end{array}$ \\
\hline
\end{tabular}

\section{Subdomain VI.G. Financial Management}

\begin{tabular}{|c|c|c|}
\hline $\begin{array}{l}\text { 1. Evaluate capital, operating } \\
\text { and/or project budgets using basic } \\
\text { accounting principles }\end{array}$ & 5 & $\begin{array}{l}\text { * Budget process (capital \& operating; } \\
\text { staffing \& budgeting) }\end{array}$ \\
\hline $\begin{array}{l}\text { 2. Perform cost-benefit analysis } \\
\text { for resource planning and } \\
\text { allocation }\end{array}$ & 4 & $\begin{array}{l}\text { * Accounting principles; Cost/benefit } \\
\text { analysis (outsourcing \& acquisition) }\end{array}$ \\
\hline $\begin{array}{l}\text { 3. Evaluate the stages of the } \\
\text { procurement process }\end{array}$ & 5 & $\begin{array}{l}\text { * Content of and answers to a Request for } \\
\text { Proposal (RFP), Request For Information } \\
\text { (RFI), and Request for Quotation (RFQ) }\end{array}$ \\
\hline \multicolumn{3}{|l|}{ Subdomain VI.H. Ethics } \\
\hline $\begin{array}{l}\text { 1. Comply with ethical standards } \\
\text { of practice }\end{array}$ & 5 & $\begin{array}{l}\text { * Professional ethics issues; Ethical decision } \\
\text { making process; AHIMA Code of Ethics; } \\
\text { Patient rights; Patient safety }\end{array}$ \\
\hline $\begin{array}{l}\text { 2. Evaluate the culture of a } \\
\text { department }\end{array}$ & 5 & \\
\hline $\begin{array}{l}\text { 3. Assess how cultural issues } \\
\text { affect health, healthcare quality, } \\
\text { cost, and HIM }\end{array}$ & 5 & $\begin{array}{l}\text { * Healthcare professionals and cultural } \\
\text { diversity; Cultural competence and self- } \\
\text { awareness; Assumptions, biases, and } \\
\text { stereotypes }\end{array}$ \\
\hline \multirow{2}{*}{$\begin{array}{l}\text { 4. Create programs and policies } \\
\text { that support a culture of diversity }\end{array}$} & \multirow[b]{2}{*}{6} & $\begin{array}{l}\text { *Diversity awareness training programs: } \\
\text { age, race, sexual orientation, education, } \\
\text { work experience, geographic location, and } \\
\text { disability }\end{array}$ \\
\hline & & $\begin{array}{l}\text { * Regulations such as Americans with } \\
\text { Disabilities Act (ADA) and Equal } \\
\text { Employment Opportunity Commission } \\
\text { (EEOC) }\end{array}$ \\
\hline \multicolumn{3}{|l|}{$\begin{array}{l}\text { Subdomain VI.I. Project } \\
\text { Management }\end{array}$} \\
\hline $\begin{array}{l}\text { 1. Take part in system selection } \\
\text { processes }\end{array}$ & 4 & * RFI and RFP \\
\hline
\end{tabular}




\begin{tabular}{|l|c|l|}
$\begin{array}{l}\text { 2. Recommend clinical, } \\
\text { administrative, and specialty } \\
\text { service applications }\end{array}$ & 5 & $*$ RFP vendor selection \\
\hline $\begin{array}{l}\text { 3. Apply project management } \\
\text { techniques to ensure efficient } \\
\text { workflow and appropriate } \\
\text { outcomes }\end{array}$ & 3 & $\begin{array}{l}* \text { GANTT Charts, benchmarking, and risk } \\
\text { analysis tools }\end{array}$ \\
\hline $\begin{array}{l}\text { 4. Facilitate project management } \\
\text { by integrating work efforts }\end{array}$ & 4 & $\begin{array}{l}\text { * Project management principles; Issue } \\
\text { tracking, and facilitation techniques }\end{array}$ \\
\hline $\begin{array}{l}\text { Subdomain VI.J. Vendor/Contract } \\
\text { Management }\end{array}$ & 5 & $\begin{array}{l}* \text { Contract management; System acquisition } \\
\text { and evaluation }\end{array}$ \\
\hline $\begin{array}{l}\text { 1. Evaluate vendor contracts } \\
\text { 2. Develop negotiation skills in the } \\
\text { process of system selection }\end{array}$ & 6 & \\
\hline Subdomain VI.K. Enterprise Information Management \\
\hline $\begin{array}{l}\text { 1. Manage information as a key } \\
\text { strategic resource and mission tool }\end{array}$ & 5 & $\begin{array}{l}\text { * Information Management Plan; } \\
\text { Information as an asset }\end{array}$ \\
\hline \begin{tabular}{l} 
Supporting Body of Knowledge (Pre-requisite or Evidence of Knowledge) \\
\hline 1. Pathophysiology and Pharmacology
\end{tabular} \\
\hline 2. Anatomy and Physiology \\
\hline 4. Medical Terminology
\end{tabular}

Source: CAHIIM, 2017 


\section{APPENDIX B: CONSENT FORMS}

\section{Recruitment Letter (or Email) for Employer Interviews}

Dear

I am a doctoral student at Illinois State University conducting dissertation research with Dr. Phyllis McCluskey-Titus in the College of Education. I am conducting a research study evaluating the recent curriculum change in the Health Information Management program at ISU. This curriculum change was made to meet the revised Commission on Accreditation for Health Informatics and Information Management (CAHIIM) curricular requirements.

I am inviting you to participate, which will involve an audio-taped interview with me that will take place at a location convenient to you. I expect the interview to last approximately 45-60 minutes. The questions will be related to your thoughts and perceptions of the curriculum change and student preparedness for the HIM field.

Your participation is voluntary. You are free to quit at any time. There are minimal social risks to this research study. These could include being nervous or uncomfortable answering questions about the HIM curriculum. These could also include concerns about prejudices related to participation or non-participation. Please be assured that no information that you reveal in the interview regarding your perceptions of the curriculum changes will be identified with your name or identity. And of course, you have the right to refuse to answer any questions in the interview.

If you would like to be a part of this research study, please respond to this email. I will contact you within 1-2 days to set up a convenient time for the interview.

Thank you very much for considering this request. Your opinions would be invaluable to the success of this research study.

Sincerely,

Jennifer Peterson 


\section{Recruitment Letter (or Email) for Student Focus Groups}

Dear

I am a doctoral student at Illinois State University conducting dissertation research with Dr. Phyllis McCluskey-Titus in the College of Education. I am conducting a research study evaluating the recent curriculum change in the Health Information Management program at ISU. This curriculum change was made to meet the revised Commission on Accreditation for Health Informatics and Information Management (CAHIIM) curricular requirements.

I am inviting you to participate, which will involve one focus group meeting facilitated by me that will take place at a location convenient to you and will last about 1 hour. The discussion will be related to your thoughts and perceptions of the curriculum change and student preparedness for the HIM field.

Your participation is voluntary. You are free to quit at any time. There are minimal social risks to this research study. These could include being nervous or uncomfortable answering questions about the HIM curriculum. These could also include concerns about prejudices related to participation or non-participation. Please be assured that no information that you reveal in the focus group regarding your perceptions of the curriculum changes will be identified with your name or identity. And of course, you have the right to refuse to answer any questions in the focus group.

If you would like to be a part of this research study, please respond to this email. I will contact you within 1-2 days to let you know the time, date, and location of the focus group meeting.

Thank you very much for considering this request. Your opinions would be invaluable to the success of this research study.

Sincerely,

Jennifer Peterson 


\section{Consent Form for Student Surveys}

Dear

I am a graduate student under the direction of Dr. Phyllis McCluskey-Titus in the College of Education at Illinois State University. I am conducting a research study to evaluate the recent curriculum changes in the Health Information Management (HIM) program at ISU and student, graduate, and employer perceptions of those changes. I am inviting you to participate, which will involve completing a brief survey. This survey should take no more than 10-15 minutes of your time

Your participation in this study is voluntary. If you choose not to participate or to withdraw from the study at any time, there will be no penalty of any kind. Your decision to participate or not to participate will not affect your grade or student status in any way. The results of the study will be used for a dissertation study as well as in future written publications and oral presentations, but your name will never be used. The survey is administered anonymously and will not be traced back to you or to any server you might use. I will take all precautions to maintain your confidentiality. The data collected in this survey will be stored securely by me.

There are minimal social risks to this research study. These could include being nervous or uncomfortable answering questions about the HIM curriculum. These could also include concerns about breach of confidentiality. As stated above all precautions will be taken to maintain your confidentiality. These could also include concerns about prejudices related to participation or non-participation. Please be assured that no information that you reveal in the survey regarding your perceptions of the curriculum changes will be identified with your name or identity. And of course, you have the right to refuse to answer any questions on the survey. There will be no extra credit, penalties, or prejudices associated with participation or nonparticipation in this study. I am reasonably unlikely to ever know if you participated before or after final grades are posted.

There will be no direct benefit to you. However, the results could provide additional information to the Health Sciences Department and the HIM program that could be used to improve the HIM program.

If you have any questions concerning the research study, please call me at (309) 438-7236 or Dr. Phyllis McCluskey-Titus at (309) 438-5989.

Sincerely,

Jennifer Peterson

Clicking “Next” indicates consent to participate.

If you have any questions about your rights as a subject/participant in this research, or if you feel you have been placed at risk, you can contact the Research Ethics \& Compliance Office at Illinois State University at (309) 438-5527. 


\section{Consent Form for Student Focus Groups}

Dear

I am a graduate student under the direction of Dr. Phyllis McCluskey-Titus in the College of Education at Illinois State University. I am conducting a research study to evaluate the recent curriculum changes in the Health Information Management (HIM) program at ISU and student, graduate, and employer perceptions of those changes. I am inviting you to participate, which will involve one focus group meeting facilitated by me that will take place at a location convenient to you and will last about 1 hour. The focus group will be audio taped, with your permission.

Your participation in this study is voluntary. If you choose not to participate or to withdraw from the study at any time, there will be no penalty of any kind. Your decision to participate or not to participate will not affect your relationship with ISU in any way. The results of the study will be used for a dissertation study as well as in future written publications and oral presentations, but your name will never be used. I will take all precautions to maintain your confidentiality. Pseudonyms will be used during the interview and in the final report. The data collected in this focus group will be stored securely by me and consent forms will be stored separately from the interview notes themselves. All students who participate in the focus group will be asked not to share information discussed in the group. However, it cannot be guaranteed that this information may not be shared by another student.

There are minimal social risks to this research study. These could include being nervous or uncomfortable answering questions about the HIM curriculum. These could also include concerns about breach of confidentiality. As stated above, all precautions will be taken to maintain your confidentiality. These could also include concerns about prejudices related to participation or non-participation. Please be assured that no information that you reveal in the focus group regarding your perceptions of the curriculum changes will be identified with your name or identity. And of course, you have the right to refuse to answer any questions during the focus group. There will be no penalties or prejudices associated with participation or nonparticipation in this study. I am reasonably unlikely to ever know if you participated before or after final grades are posted.

There will be no direct benefit to you. However, the results could provide additional information to the Health Sciences Department and the HIM program that could be used to improve the HIM program.

If you have any questions concerning the research study, please call me at (309) 438-7236 or Dr. Phyllis McCluskey-Titus at (309) 438-5989.

Sincerely,

Jennifer Peterson

I give consent to participate in the above study. 
Signature

I give consent for the focus group to be audiotaped.
Date

Date

Signature

If you have any questions about your rights as a subject/participant in this research, or if you feel
you have been placed at risk, you can contact the Research Ethics \& Compliance Office at Illinois State University at (309) 438-5527. 


\section{Consent Form for Graduate and Employer Surveys}

Dear

I am a graduate student under the direction of Dr. Phyllis McCluskey-Titus in the College of Education at Illinois State University. I am conducting a research study to evaluate the recent curriculum changes in the Health Information Management (HIM) program at ISU and student, graduate, and employer perceptions of those changes. I am inviting you to participate, which will involve completing a brief survey. This survey should take no more than 10-15 minutes of your time

Your participation in this study is voluntary. If you choose not to participate or to withdraw from the study at any time, there will be no penalty of any kind. The results of the study will be used for a dissertation study as well as in future written publications and oral presentations, but your name will never be used. The survey is administered anonymously and will not be traced back to you or to any server you might use. I will take all precautions to maintain your confidentiality. The data collected in this survey will be stored securely by me.

There are minimal social risks to this research study. These could include being nervous or uncomfortable answering questions about the HIM curriculum. These could also include concerns about breach of confidentiality. As state above, all precautions will be taken to maintain your confidentiality. These could also include concerns about prejudices related to participation or non-participation. Please be assured that no information that you reveal in the survey regarding your perceptions of the curriculum changes will be identified with your name or identity. And of course, you have the right to refuse to answer any questions on the survey. There will be no penalties or prejudices associated with participation or non-participation in this study.

There will be no direct benefit to you. However, the results could provide additional information to the Health Sciences Department and the HIM program that could be used to improve the HIM program.

If you have any questions concerning the research study, please call me at (309) 438-7236 or Dr. Phyllis McCluskey-Titus at (309) 438-5989.

Sincerely,

Jennifer Peterson

Clicking “Next” indicates consent to participate.

If you have any questions about your rights as a subject/participant in this research, or if you feel you have been placed at risk, you can contact the Research Ethics \& Compliance Office at Illinois State University at (309) 438-5527. 


\section{Consent Form for Employer Interviews}

Dear

I am a graduate student under the direction of Dr. Phyllis McCluskey-Titus in the College of Education at Illinois State University. I am conducting a research study to evaluate the recent curriculum changes in the Health Information Management (HIM) program at ISU and student, graduate, and employer perceptions of those changes. I am inviting you to participate, which will involve one interview with me that will take place at a location convenient to you and will last about 30-45 minutes. The interview will be audio taped, with your permission.

Your participation in this study is voluntary. If you choose not to participate or to withdraw from the study at any time, there will be no penalty of any kind. Your decision to participate or not to participate will not affect your relationship with ISU in any way. The results of the study will be used for a dissertation study as well as in future written publications and oral presentations, but your name will never be used. I will take all precautions to maintain your confidentiality. Pseudonyms will be used during the interview and in the final report. The data collected in this interview will be stored securely by me and consent forms will be stored separately from the interview notes themselves.

There are minimal social risks to this research study. These could include being nervous or uncomfortable answering questions about the HIM curriculum. These could also include concerns about breach of confidentiality. As stated above all precautions will be taken to maintain your confidentiality. These could also include concerns about prejudices related to participation or non-participation. Please be assured that no information that you reveal in the interview regarding your perceptions of the curriculum changes will be identified with your name or identity. To minimize risk, interviews will be conducted in settings that provide the maximum amount of privacy and confidentiality to you. And of course, you have the right to refuse to answer any questions during the interview. There will be no penalties or prejudices associated with participation or non-participation in this study.

There will be no direct benefit to you. However, the results could provide additional information to the Health Sciences Department and the HIM program that could be used to improve the HIM program.

If you have any questions concerning the research study, please call me at (309) 438-7236 or Dr. Phyllis McCluskey-Titus at (309) 438-5989.

Sincerely,

Jennifer Peterson

I give consent to participate in the above study. 
Signature

Date

I give consent for my interview to be audiotaped.

Signature

Date

If you have any questions about your rights as a subject/participant in this research, or if you feel you have been placed at risk, you can contact the Research Ethics \& Compliance Office at Illinois State University at (309) 438-5527. 
APPENDIX C: INTERVIEW QUESTIONS, FOCUS GROUP GUIDE, AND SURVEYS

\section{Student Survey}

1. Did you complete the new (IT) curriculum or the old (management) curriculum? If old, skip Question 2.

2. How prepared do you feel the IT courses have prepared you for your career in HIM? (Highly prepared, prepared, unsure, unprepared, highly unprepared)

3. What area(s) of HIM are you planning to pursue?

4. Are you satisfied with the curricula that you are completing in the HIM program?

5. What courses in the curriculum do you feel will be most helpful to your career?

6. What courses in the curriculum do you feel will be least helpful to your career?

7. Overall, how do you feel the HIM curriculum prepared you for your career? (Highly prepared, prepared, unknown, unprepared, highly unprepared)

8. Do you have other comments or suggestions regarding the HIM curriculum at ISU? 


\section{Student Focus Groups Guide}

1. Did you choose your curriculum sequence? If yes, why?

2. How do you feel about the courses that you are taking in your curriculum sequence?

3. What challenges have you faced with this sequence, academic or otherwise (course difficulty, scheduling, time to graduation, etc.)?

4. What area(s) of HIM are you interested in pursuing?

5. How do you feel this sequence is preparing you for the area(s) of HIM that you want to pursue?

6. How do you see yourself using the skills you have learned in this sequence in your career?

7. Do you feel that you will be lacking in any skills?

8. What improvements would you recommend for the ISU HIM program?

9. What advice would you give to students considering the HIM program at ISU and going into the HIM field? 


\section{Graduate Survey (to be given at six months or one year after graduation)}

1. Did you complete the new (IT) curriculum or the old (management) curriculum? If old, skip Question 2.

2. Did you feel the IT courses prepared you for your career in HIM?

(Highly prepared, prepared, unsure, unprepared, highly unprepared)

3. Did you feel the Data Analysis course (HSC 300) prepared you for your career in HIM? (Highly prepared, prepared, unsure, unprepared, highly unprepared)

4. What is your current job? Where is this job?

5. How did you feel that the HIM curriculum at ISU prepared you for your current job?

6. What do you see as the strengths of the new curriculum?

7. What do you see as the weakness of the new curriculum?

8. What part of the curriculum did you feel was the most helpful in your career?

9. What part of the curriculum did you feel was the least helpful in your career?

10. Overall, how do you feel the HIM curriculum prepared you for your career?

(Highly prepared, prepared, unknown, unprepared, highly unprepared)

11. What advice would you give to students considering the HIM program at ISU and going into the HIM field?

12. Do you have other comments or suggestions regarding the HIM curriculum at ISU? 


\section{Employer Survey}

1. What do you see as the most essential skills for your employees to possess prior to employment?

2. What do you see as the most essential skills for your employees to learn on the job?

3. How important are IT skills for employees that you hire?

(Very important, important, somewhat important, not important)

4. What IT skills are most important?

5. How important are data analysis skills for employees that you hire?

(Very important, important, somewhat important, not important)

6. What data analysis skills are most important?

7. Have you had ISU students complete their senior professional practice in your department? (yes, no)

8. Do you have ISU graduates as current employees in your department? (yes, no)

9. Have any of the senior professional practice students or employees completed the new curriculum in ISU's HIM program? (yes, no, unknown) (If no, skip to question 9.)

10. Do you feel that the new IT/data analysis curricula has better prepared these students/employees for the HIM field? (yes, no)

11. Are you pleased with the professional preparation of these students/employees? (yes, no)

12. Overall, how do you feel the ISU HIM curriculum has prepared students for their HIM career?

(Highly prepared, prepared, unknown, unprepared, highly unprepared)

13. Please comment on specifics regarding these students'/employees' preparation.

14. Do you have other comments or suggestions regarding the HIM curriculum at ISU? 


\section{Employer Interviews}

1. What is your current position?

2. How often do you use IT skills in your position? What kinds of IT skills?

3. How have you learned the IT skills you use?

4. How often do you use data analysis skills in your position? What kinds of data analysis skills?

5. How have you learned the data analysis skills you use?

6. Have you had ISU HIM students as Professional Practice Students? If so, approximately how many? How recently?

7. Have you hired ISU HIM graduates? If so, approximately, how many? How recently?

8. How prepared do you feel ISU students/graduates are for the HIM field?

9. What areas do you feel they are well-prepared in?

10. What areas do you feel they are not well-prepared in?

11. Have you had ISU students as professional practice students or hired ISU graduates who have completed the new curriculum?

12. How prepared do you feel these ISU students/graduates are for the HIM field?

13. In what areas do you feel they are well-prepared?

14. In what areas do you feel they are not well-prepared?

15. How do you feel that the new curriculum is providing students with appropriate IT skills for the HIM field?

16. How do you feel that the new curriculum is providing students with appropriate data analytic skills for the HIM field? 
17. Are there any other thoughts you would like to share regarding ISU students'/graduates' preparation for the HIM field? 